\title{
INTERFACIAL STRUCTURE AND DOUBLE LAYER CAPACITANCE OF IONIC LIQUIDS
}

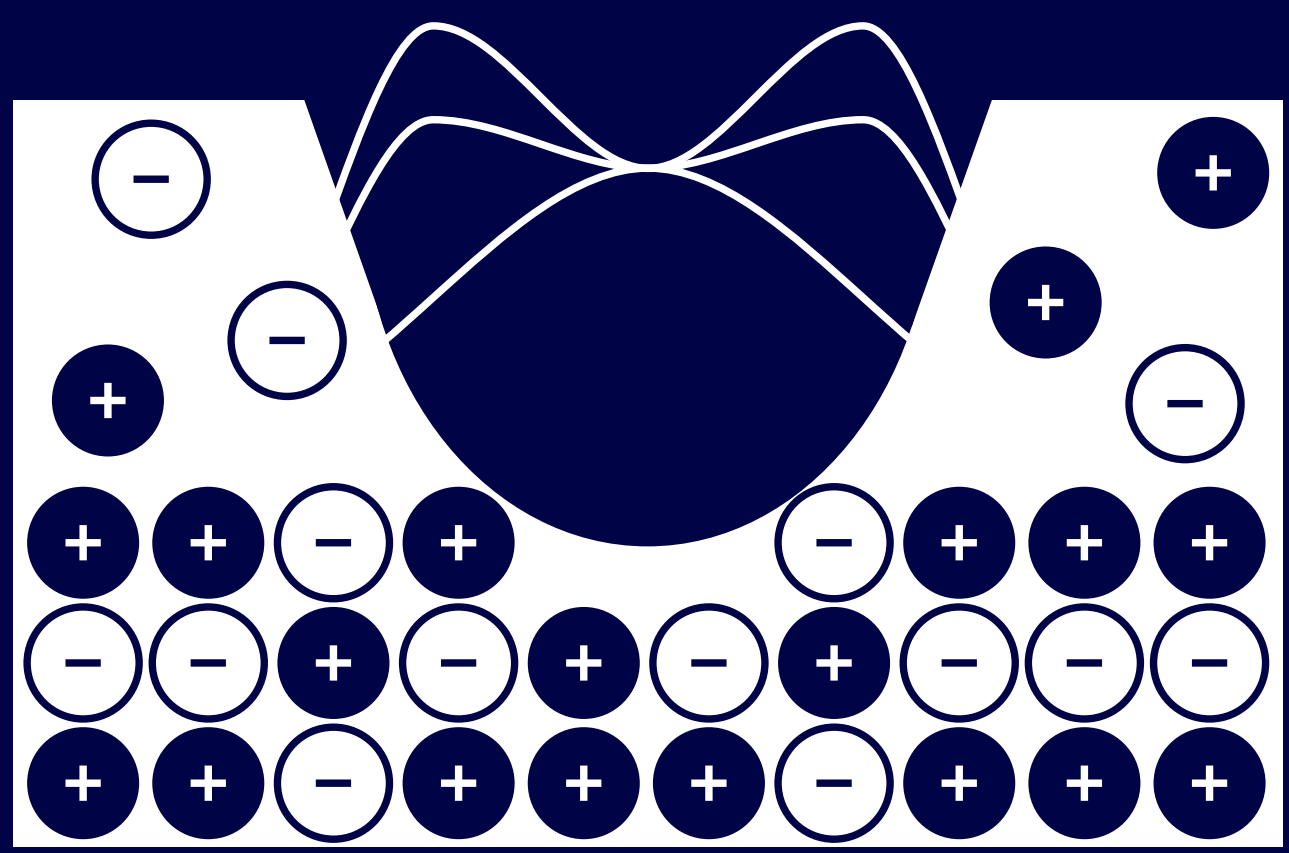

Monchai Jitvisate 


\section{INTERFACIAL STRUCTURE AND DOUBLE LAYER CAPACITANCE OF IONIC LIQUIDS}

Monchai Jitvisate 


\section{Graduation committee:}

\section{Chairman and Secretary}

Prof. dr. ir. J. W. M. Hilgenkamp University of Twente, The Netherlands

\section{Supervisor and co-supervisor}

Prof. dr. S. G. Lemay

Dr. J. R. T. Seddon

\section{Committee members}

Prof. dr. F. G. Mugele

Dr. ir. W. Olthuis

Prof. dr. C. Holm

Prof. dr. R. Bennewitz

Prof. dr. M. Mezger
University of Twente, The Netherlands University of Twente, The Netherlands
University of Twente, The Netherlands University of Twente, The Netherlands University of Stuttgart, Germany Saarland University, Germany Johannes Gutenberg University Mainz, Germany

The research described in this thesis was carried out at the Nanoionics (NI) group of the University of Twente, The Netherlands. The author acknowledges financial support from the Development and Promotion of Science and Technology Talents Project (DPST) of the Royal Thai Government.

Copyright (c) Monchai Jitvisate 2018

All rights reserved. No part of this publication may be reproduced or transmitted, in any form or by any means, without the prior permission of the author.

Title: Interfacial structure and double layer capacitance of ionic liquids Author: Monchai Jitvisate

ISBN: 978-90-365-4505-1

DOI: $10.3990 / 1.9789036545051$

Author's email: mjitvisate@gmail.com

Cover design: Monchai Jitvisate 


\title{
INTERFACIAL STRUCTURE AND DOUBLE LAYER CAPACITANCE OF IONIC LIQUIDS
}

\author{
DISSERTATION \\ to obtain \\ the degree of doctor at the University of Twente, \\ on the authority of the rector magnificus, \\ Prof. dr. T. T. M. Palstra, \\ on account of the decision of the graduation committee, \\ to be publicly defended \\ on Thursday $22^{\text {nd }}$ March 2018 at 14:45 \\ by \\ Monchai Jitvisate \\ born on $18^{\text {th }}$ November 1988 \\ in Nakhon Sawan, Thailand
}


This thesis has been approved by:

Prof. dr. S. G. Lemay (supervisor)

Dr. J. R. T. Seddon (co-supervisor) 
For all Thais. 

"The first principle is that you must not fool yourself and you are the easiest person to fool."

- Richard Feynman 



\section{Contents}

1 Introduction 1

1.1 Ionic liquids as electrolytes $\ldots \ldots \ldots \ldots 2$

1.2 Electrical double layer $(\mathrm{EDL}) \ldots \ldots \ldots . \ldots . \ldots 4$

1.2.1 Classical models for EDL . . . . . . . . . . 5

1.2.2 EDL in ionic liquids: The mean-field theory . . . . . 7

1.3 Experimental study of EDL in ionic liquids . . . . . . . . 10

1.3.1 EDL capacitance . . . . . . . . . . . . . . 10

1.3.2 Near-wall molecular structure of ILs . . . . . . . . . 14

1.4 Thesis outline . . . . . . . . . . . . . . . . 17

2 Experimental Techniques $\quad 29$

2.1 Electrochemical measurements . . . . . . . . . . . . 30

2.2 Atomic force microscopy $(\mathrm{AFM}) \ldots \ldots . \ldots . \ldots 32$

3 Direct Measurement of the Differential Capacitance of SolventFree and Dilute Ionic Liquids $\quad 43$

3.1 Introduction . . . . . . . . . . . . . . . . . 44

3.2 Experimental methods . . . . . . . . . . . . . . . . . . . . . 45

3.3 Results and discussion . . . . . . . . . . . . . . 46

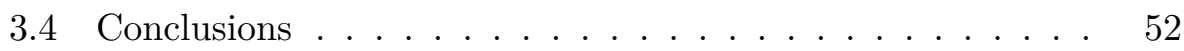

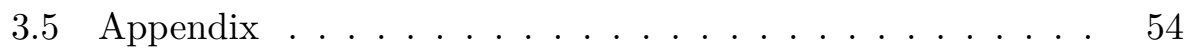

3.5.1 Data analysis . . . . . . . . . . . . 54

3.5 .2 Supporting tables and figures . . . . . . . . . 54

4 Local Structure and Flow Properties of Ionic Liquids on Charged and Inert Substrates 65

4.1 Introduction . . . . . . . . . . . . . . . . 66

4.2 Experimental methods . . . . . . . . . . . . . . 67

4.3 Results and discussion . . . . . . . . . . . . . . 68

4.3.1 Force-distance spectroscopy . . . . . . . . . . 68

4.3.2 Small-amplitude modulation . . . . . . . . . . . 71

4.4 Conclusions . . . . . . . . . . . . . . . . . . . 77 
5 Near-Wall Molecular Ordering of Dilute Ionic Liquids $\mathbf{8 3}$

5.1 Introduction . . . . . . . . . . . . . . . . 84

5.2 Experimental methods . . . . . . . . . . . . . . . . . . 85

5.3 Results and discussion . . . . . . . . . . . . . 87

5.4 Conclusions . . . . . . . . . . . . . . . . . . . . 91

5.5 Appendix ........................ 92

5.5.1 Force-distance curves measured in different ionic liquids at varied ion compositions . . . . . . . . . . 92

5.5.2 Molecular dimensions of ionic liquids . . . . . . . . . 93

6 Ion Dissociation in Ionic Liquid Mixtures 99

6.1 Introduction . . . . . . . . . . . . . . . . . . 100

6.2 Experimental methods . . . . . . . . . . . . . . . . . . 101

6.3 Results and discussion . . . . . . . . . . . . . . . . 102

6.4 Conclusions . . . . . . . . . . . . . . . . . 107

6.5 Appendix . . . . . . . . . . . . . . . . . . . 109

6.5.1 Force-distance curve of $[\mathrm{Emim}]^{+}\left[\mathrm{BF}_{4}\right]^{-}$on silicon dioxide surface . . . . . . . . . . . . . 109

6.5.2 Effect of temperature on the dielectric constant of ethylene glycol . . . . . . . . . . . . . . . . 109

7 Conclusions and Future Work $\quad 115$

7.1 Conclusions . . . . . . . . . . . . . . . . . . 115

7.2 Future work . . . . . . . . . . . . . . . 117

$\begin{array}{ll}\text { Summary } & 120\end{array}$

$\begin{array}{ll}\text { Samenvatting } & 124\end{array}$

$\begin{array}{ll}\text { Acknowledgements } & 128\end{array}$ 




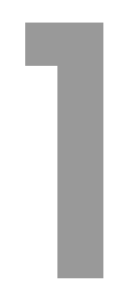

\section{Introduction}

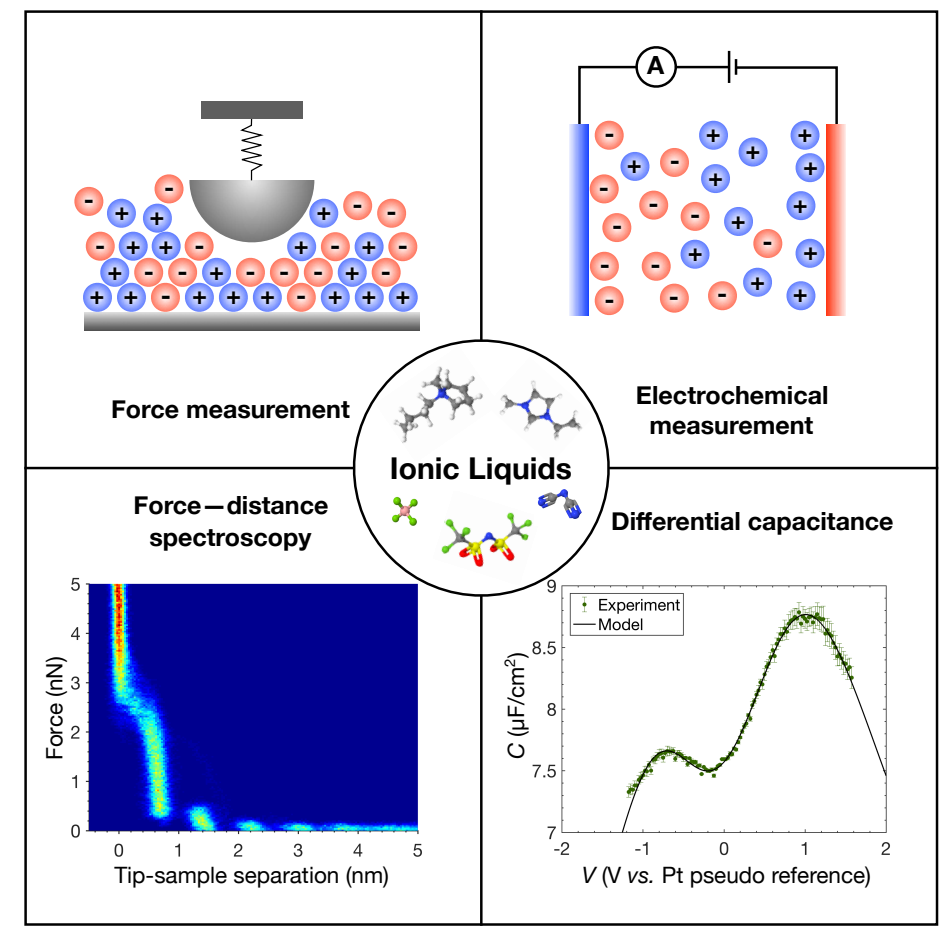

This chapter gives a general description of ionic liquids and a brief introduction to the importance of studying ionic liquids at interfaces. A short summary of electrical double layer theories is presented as well as a brief review on the experimental studies of ionic liquids' interfacial behaviors. 


\subsection{Ionic liquids as electrolytes}

Electrolytes are abundant in nature and can be found everywhere, from inside the cells of organisms to the oceans. Humans know electrolytes as salts and have used them in everyday life for thousands of years. Salts impact all lives because all living things evolve to depend on them. Some electrolytes, for example, sodium chloride $(\mathrm{NaCl})$ or commonly known as table salt, had brought civilization to mankind and had been regarded for its value in historical time. In modern days, electrolytes play a key role in technologies, for example, most electronic devices, such as smart phones, are powered by the batteries that directly rely on the electrolytes inside them.

From a scientific aspect, electrolytes have been intensively studied both in physics and chemistry for centuries. Common electrolytes, e.g., $\mathrm{NaCl}$, $\mathrm{KCl}, \mathrm{LiCl}, \mathrm{CaCl}_{2}$, etc., are in solid state (usually have crystalline structure) at ambient conditions. Their molecules are composed of oppositely charged ions that are held together by ionic bonds, which are fundamentally the Coulomb interactions. These ions can dissociate into positive ions (so called cations) and negative ions (so called anions) when dissolved in polar solvents, such as water. As a result, dissolved ions are able to move in the media, leading to many key properties, such as, electrical conductivity and osmotic pressure, which have many implications on several natural phenomena. Pure salts can also "melt" into liquid phase when given sufficient amount of heat, rather than dissolving in polar solvents. This process typically happens at very high temperature (e.g., $\mathrm{NaCl}$ has a melting point of $800^{\circ} \mathrm{C}$ ) because electrostatic interactions are strong in such systems. ${ }^{1}$ These liquid electrolytes at high temperature are particularly known as molten salts, and their properties are interesting and beneficial for many high temperature applications and technologies. ${ }^{1-3}$ However, they are less relevant to life because of their extremely high temperature.

There is another class of electrolytes which can be in liquid state at room temperature (usually refers to the temperature range below $100^{\circ} \mathrm{C}$ ), and it is not necessarily to be dissolved in solvents nor to be given a huge amount of heat. This class of electrolytes is known as ionic liquids (ILs) or room 

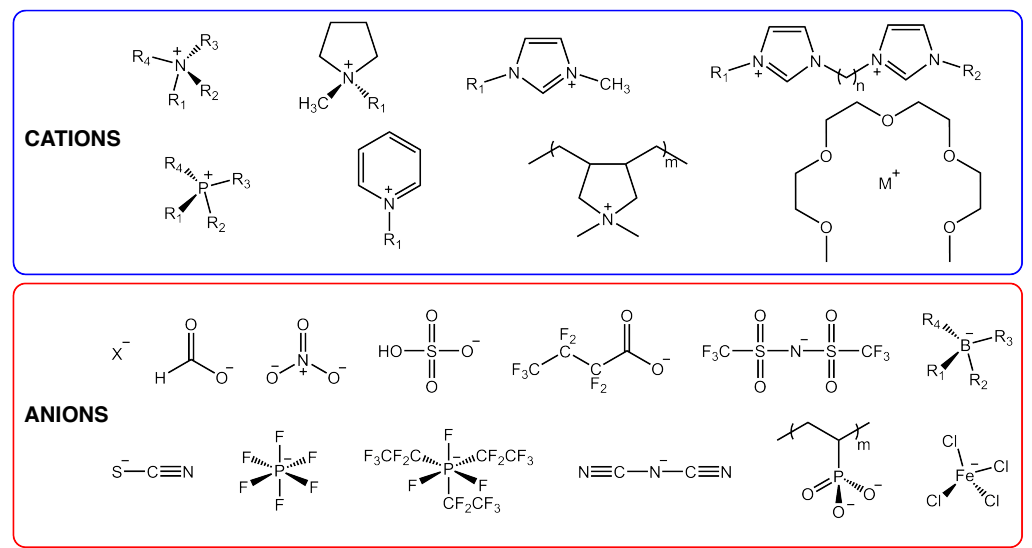

Figure 1.1: Examples of some IL cations and anions that are popular in literature. Adapted and reprinted with permission from R. Hayes et al., Chem. Rev., 2015, 115, 6357-6424, Copyright (c) 2015 American Chemical Society.

temperature ionic liquids (RTILs). ${ }^{4-8 \dagger}$ Unlike traditional electrolytes that are composed mainly of monatomic or diatomic inorganic ions, most ILs are polyatomic organic ions that have substantially large size (5-10 times larger ionic radii than ions like $\mathrm{Li}^{+}$or $\mathrm{K}^{+}$). IL ions usually have anisotropic and asymmetric structure with non-uniform molecular charge density. ${ }^{9-14}$ These geometric constraints are the main causes that restrict ILs' crystallization at low temperature that occurs in traditional salts, leading to their wide liquidus range. ${ }^{15}$ These characters, therefore, lead to a collection of unique properties, such as, high ionic strength, extremely low vapor pressure, wide electrochemical window (ECW), and high thermal and chemical stabilities, which are of technological interest. ${ }^{4,7,9,16,17}$

There is a large number of known IL cations and anions (some well known examples are shown in Figure 1.1), from which different ions can be mixed with each other and form several combinations of ILs, making them to be regarded as a "designer" electrolytes. ${ }^{5-7,9,18}$ Applications follow as a consequence of ILs' promising properties. They have much potential in various disciplines to be used as, for example, lubricants in micro and nano devices, ${ }^{19-24}$ electrolytes for electrochemical energy storage devices, ${ }^{25-32}$ media for electrochemical reactions or electrodepositions, ${ }^{33-36}$ solvents for

\footnotetext{
${ }^{\dagger}$ These two terms are used interchangeably in this thesis.
} 
surface catalysis and synthesis, ${ }^{6,7}$ media for nano particle synthesis and self assembly, ${ }^{37,38}$ etc. Among these examples, using ILs in the energy-related applications, such as batteries and supercapacitors, is a mainstream goal. The major reason is because the amount of energy stored in such devices depends on the electrochemical stability of the materials, which is very high in ILs as they have significantly wide ECW (up to 5-6 V but typically about $2-3 \mathrm{~V}$, while water has an ECW about $1.2 \mathrm{~V}) .{ }^{9,39}$ Another advantage is their low vapor pressure and high thermal stability, which will allow more flexible use and increase the life time of the devices as compared to normal solvents.

The arrangements and properties at surfaces are of key importance for many applications, and have thus been a main research in the past decade. ${ }^{5,9}$ The study of the interfacial behaviors of ILs (and other electrolytes or charged particles) is done within the framework of an electrical double layer (EDL) theory, ${ }^{40,41}$ which describe the responses of charge particles to an electric field at the interfaces. The classical picture is based on the Poisson-Boltzmann theory and dilute electrolytes are well understood in the limit of the Debye-Hückel approximation. ${ }^{42}$ However, ILs do not seem to fall into such case due to their complexity. Can we use this classical theory to understand ILs? What should we improve to have a better understanding of this material? What is the true interfacial character of ILs? These questions are challenging scientists to explore the fundamental nature of ILs and the answers to these questions are still open, which will lead to a better understanding of these materials, as well as improvements in applications.

\section{$1.2 \quad$ Electrical double layer (EDL)}

An EDL is a key factor for understanding interfacial behaviors of materials. Many models were proposed, some of them are simple and some of them are quite complicated, depending on the complexity of the systems. It is worthwhile to take a brief looking back to the knowledge that we have from the past, which will provide a background for understanding recent advanced theories. 


\subsubsection{Classical models for EDL}

The concepts of the EDL were developed about a century ago. The earliest model was proposed in 1853 by Helmholtz. ${ }^{43}$ In this model the counter-ions in electrolytes form a plane of opposite charge next to the original charged surface (the electrode). This two charged planes resemble a parallel-plate capacitor, and the model predicts constant capacitance per unit area for a given EDL thickness, written as

$$
C_{\mathrm{H}}=\frac{\epsilon_{0} \epsilon}{d}
$$

where $\epsilon_{0}$ is the permittivity of free space, $\epsilon$ is the dielectric constant of the medium, and $d$ is the distance of molecular order between the charged planes. However, Helmholtz's model fails to explain real experimental data, which show variation of capacitance with electrode potential and electrolyte concentration, suggesting that either $\epsilon$ or $d$ depends on these quantities and more complex model is required. ${ }^{41}$

Around 1910-1913, Gouy and Chapman introduced the idea of "diffuse layer" of ions to improve the EDL model. ${ }^{44,45}$ In the Gouy-Chapman (GC) model, the ions form a distance-dependent distribution that smear within the "Gouy length", $\lambda_{\mathrm{G}}$, from the surface due to thermal excitation rather than a "compact layer" as in Helmholtz's model. The Gouy length for 1:1 elctrolytes can be expressed as

$$
\lambda_{\mathrm{G}}=\frac{\lambda_{\mathrm{D}}}{\cosh (u / 2)}
$$

In this expression, $u=e V / k_{\mathrm{B}} T$ is a nondimensionalized potential, where $e$ is the elementary charge, $V$ is the potential drop across the EDL, $k_{\mathrm{B}}$ is the Boltzmann's constant, and $T$ is the absolute temperature. Here, $\lambda_{\mathrm{D}}=\left(8 \pi L_{\mathrm{B}} c_{0}\right)^{-1 / 2}$, is the "Debye length" 42 expressed through the Bjerrum length, $L_{\mathrm{B}}=e^{2} / 4 \pi \epsilon_{0} \epsilon k_{\mathrm{B}} T$ (the separation at which the Coulomb interaction between two elementary charges is equal to the thermal energy $k_{\mathrm{B}} T$ in the medium of dielectric constant $\epsilon$ ), and $c_{0}$ is the bulk electrolyte concentration. Therefore, the capacitance of Gouy-Chapman model can 


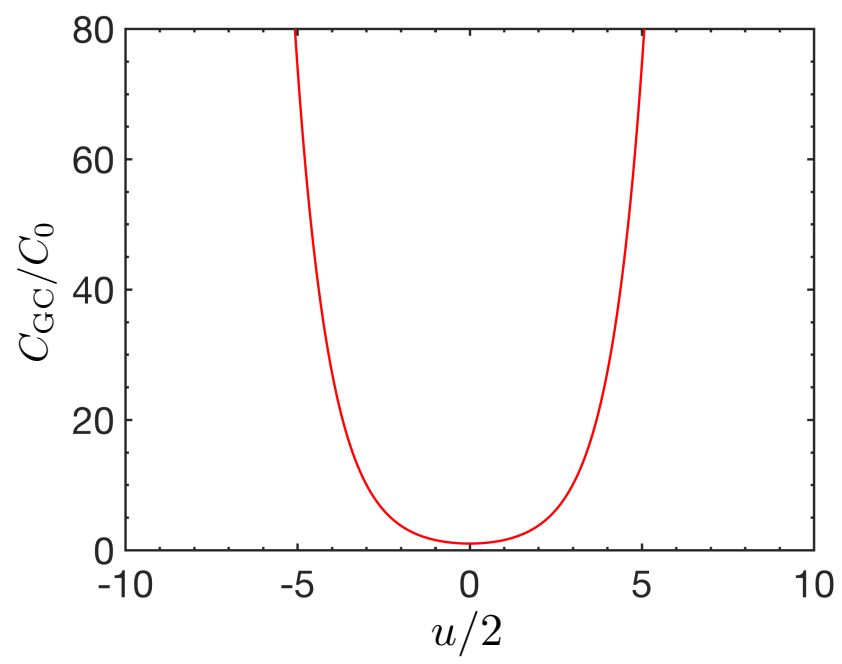

Figure 1.2: U-shape capacitance curve as predicted by the GC model of eq 1.3.

be written as

$$
C_{\mathrm{GC}}=\frac{\epsilon_{0} \epsilon}{\lambda_{\mathrm{G}}}=C_{0} \cosh (u / 2)
$$

where $C_{0}=\epsilon_{0} \epsilon / \lambda_{\mathrm{D}}$ is called the Debye capacitance. The value of GC capacitance depends on electrode potential, having a "U-like" shape that grows infinitely with increasing electrode polarization as shown in Figure 1.2. The potential at minimum capacitance value is regarded as the potential of zero charge (PZC), which is the potential at which the magnitude of the charge on the electrode and electrolyte sides is equal.

This model can explain the measured capacitance but only within a small potential range (not too far from the PZC) and in very low concentration electrolytes. The breaking down of the GC model at high potential is mainly because it allows the Gouy length, $\lambda_{G}$, to decrease unlimitedly, which means the approximation that ions do not have a finite size in this model breaks down.

It was Stern who attempted to solve the discrepancies between the measured capacitance and the theoretically predicted value at high potential and concentration. He modified the GC model by introducing a "cut-off" by adding a compact layer capacitance - the picture adopted from Helmholtz's 
model. In the Gouy-Chapman-Stern (GCS) model, ${ }^{46}$ the EDL is thought to have both compact layer (now called Stern layer) and diffuse layer. The differential capacitance is then the combination of two components and can be depicted as

$$
\frac{1}{C_{\mathrm{GCS}}}=\frac{1}{C_{\mathrm{H}}}+\frac{1}{C_{\mathrm{GC}}}
$$

Following the GCS model, it is the diffuse layer capacitance that determines the capacitance at low electrode polarization and electrolyte concentration, while the constant compact layer capacitance contributes more to the measured capacitance at large potential and concentrated ion concentration. This model has become a classical picture for describing the EDL in conventional electrolytes. Note that the model does not cover the effect of specific adsorption, either from ions or solvent molecules, which is usually measured in real experiments. ${ }^{41}$

\subsubsection{EDL in ionic liquids: The mean-field theory}

The capacitance of ILs at electrodes was measured and found to have little in common with GC theory, which brought attention to the development of a new theoretical model. Note that one of the weaknesses of the GC model is the neglect of the finite size of ions, which is one of the important characters that makes ILs distinct from conventional salt solutions. In 2007, Kornyshev proposed a lattice gas model for spherical ionic liquids on flat electrodes, based on the mean-field theory, suggesting that the differential capacitance of ILs should look different from CG theory. ${ }^{47}$ In this lattice gas model approach, spherical $N_{+}$cations and $N_{-}$anions, with the total fixed number $\bar{N}=N_{+}+N_{-}$, are randomly distributed over $N$ available lattice sites (except under an influence of the external electric field). The system's free energy can be written as

$$
\begin{aligned}
F=e V\left(N_{+}-N_{-}\right)+a_{+} N_{+}^{2}+ & a_{-} N_{-}^{2}+b N_{+} N_{-} \\
& -k_{\mathrm{B}} T \ln \frac{N !}{\left(N-N_{+}-N_{-}\right) N_{+} ! N_{-} !}
\end{aligned}
$$


The first term of eq 1.5 represents electrostatic interaction. The second, third, and forth terms are accounted for the short-range ion correlations (cation-cation, anion-anion, and cation-anion, respectively). The last term is an entropic term accounting for the size of the ions. The first attempt to obtain an analytical expression for the differential capacitance was done by considering the ions to behave as an ideal gas, that is, there is no interaction between them and $a_{+}, a_{-}$, and $b$ are then equal to zero. The ion distributions can be calculated by minimizing the free energy with respect to the number of ions. These distributions are then inserted into the Poisson equation, which can be solved, thus establishing the relationship between the surface charge, $\sigma$, and electrode potential, $V$. The differential capacitance can be obtained following the definition $C=(\mathrm{d} \sigma / \mathrm{d} V)$, which yield the result for this lattice gas model as

$$
C=C_{0} \frac{\cosh (u / 2)}{1+2 \gamma \sinh ^{2}(u / 2)} \sqrt{\frac{2 \gamma \sinh ^{2}(u / 2)}{\ln \left[1+2 \gamma \sinh ^{2}(u / 2)\right]}}
$$

The parameter $\gamma$ that appears in eq 1.6 is a key of the model, representing the compacity, defined as the ratio of of the ion concentration in bulk region, $c_{0}$, to the maximum possible local concentration, $c_{\max }$,

$$
\gamma=\frac{\bar{N}}{N}=\frac{2 c_{0}}{c_{\max }}
$$

The compacity, $\gamma$, has values between 1 and 0 , where the limit of $\gamma \rightarrow 1$ corresponds to the ultra dense system and $\gamma \rightarrow 0$ is the limit of dilute or classical electrolyte (the model reduces to GC model). A cartoon representation is shown in Figure 1.3 to describe the physical meaning of $\gamma$.

The differential capacitance obtained from eq 1.6 is plotted as in Figure 1.4. The capacitance curves show clear differences from the GC theory by having either a bell-shape (for $\gamma>1 / 3$ ) or a camel-shape (for $\gamma<1 / 3$ ) rather than the traditional U-like shape. The differential capacitance falls down at high electrode potential, as a result of the effect called lattice saturation or crowding. The physical meaning of this phenomenon can be explained in the way that the ions are lined up on the electrode and occupy almost all available sites at high electrode potential, retarding charge 


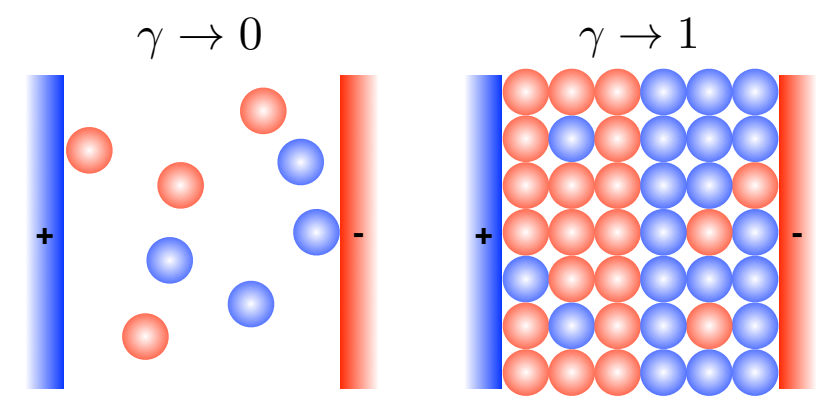

Figure 1.3: A cartoon showing ILs between two planar electrodes describing the meaning of compacity parameter, $\gamma$, with the red and the blue spheres depicting anions and cations, respectively. The space area represents the voids in the system.

storage at the interface. This effect is mainly caused by the finite volume of the ions that is introduced into the model.

The mean-field model can be phenomenologically modified to account for an asymmetry of ion sizes by assuming that $c_{\max }$ is different for cations and anions having different sizes, and therefore, distinct ion compacity. This results in the compacity to be parameterized as

$$
\gamma(u)=\gamma_{-}+\frac{\left(\gamma_{+}-\gamma_{-}\right)}{1+\exp (u)}
$$

where $\gamma_{+}$and $\gamma_{-}$are the compacity of cations and anions, respectively. This introduces asymmetry into the model, resulting in higher capacitance peak for ions having higher compacity.

A decade later, the original model of Kornyshev was extended by Goodwin et al. to account for short-range ion correlations, which means $a_{+}, a_{-}$, and $b$ in eq 1.5 are not zero. ${ }^{48,49}$ The motivation behind the improvement is because the original model can only explain the experimental findings in a qualitative way. Fitting experimental data to the model cannot be done successfully. In the extended model, a scaling parameter, $\alpha$, arises from the existence of ion correlations, which allows the model to be more flexible to fit with experimental data. The resultant differential capacitance can be 


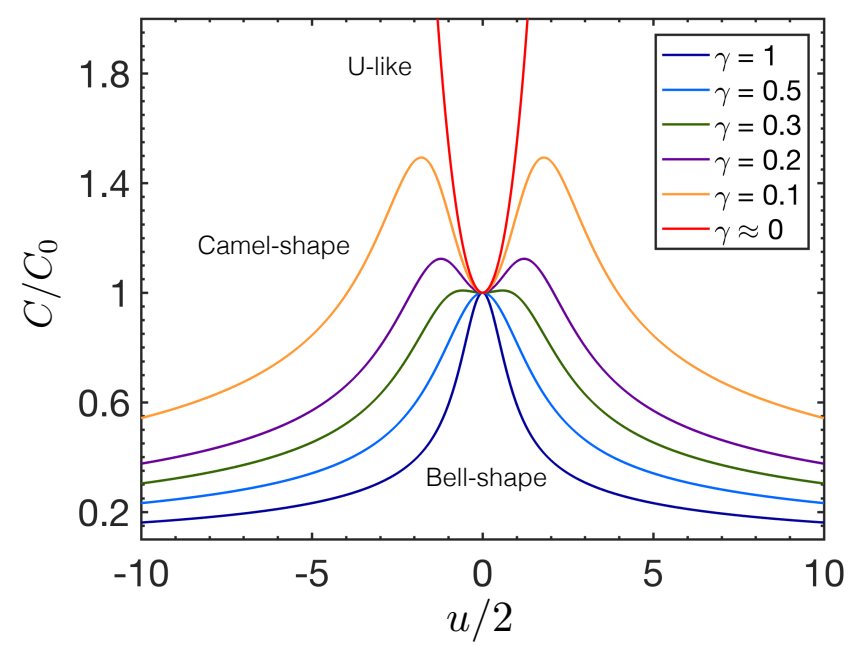

Figure 1.4: Potential-dependent capacitance curves as predicted by the meanfield theory, eq 1.6, for different values of $\gamma$. The graphs show the crossover from pure IL to dilute regime, where the crossover from "bell" to "camel" takes place at $\gamma=\frac{1}{3}$.

written as

$$
C=\tilde{C}_{0} \frac{\cosh (\alpha u / 2)}{1+2 \gamma \sinh ^{2}(\alpha u / 2)} \sqrt{\frac{2 \gamma \sinh ^{2}(\alpha u / 2)}{\ln \left[1+2 \gamma \sinh ^{2}(\alpha u / 2)\right]}}
$$

where $\tilde{C}_{0}=C_{0} / \sqrt{\alpha}$ is a scaled Debye capacitance. The compacity of the asymmetric case can also be modified similarly as $\gamma(u)=\gamma_{-}+\left(\gamma_{+}-\right.$ $\left.\gamma_{-}\right) /(1+\exp (\alpha u))$. Further reading for complete derivation can be found in literature. ${ }^{48,49}$

\subsection{Experimental study of EDL in ionic liquids}

\subsubsection{EDL capacitance}

An EDL is mainly composed of ions that are responding to an electric field generated from charged surfaces. Experimental studies of this charge stored in the EDL can be made in different ways, but one of those is to measure a differential capacitance, which is a potential-dependent capacitance of a 
non-linear capacitor, such as in the EDL or semiconductor diode. ${ }^{41}$ The expression for the differential capacitance follows from the physical definition, which is the rate of change of stored surface charge to the surface potential, that is

$$
C_{\text {diff }}=\frac{\mathrm{d} \sigma}{\mathrm{d} V}
$$

where $\sigma$ represent the surface charge and $V$ denotes surface potential. ${ }^{41}$

Measuring the differential capacitance will directly relate the experimental results to the theoretical models for EDL that describe the interfacial behaviors and electrical responses of ions. The differential capacitance is a quantity defined at equilibrium, which makes it more challenging to measure in ILs compared with conventional electrolytes. This is mainly because of uncommon properties of the ILs, such as their low diffusion coefficient. ${ }^{50-52}$ Several works have reported experimental data for IL differential capacitance and these existing data are difficult to compare due to large variety of ILs and electrode materials used in the measurements. ${ }^{53-71}$. However, measuring the differential capacitance of ILs has proven to be of great practical challenge $\mathrm{e}^{9,53-64,68}$ Cyclic voltammetry $(\mathrm{CV})$ and electrochemical impedance spectroscopy (EIS) are the two most popular techniques used for IL capacitance measurements in literature. However, experimental observations from these techniques are controversial, inconsistent, and often unable to confirm of refute the existing models. ${ }^{9,53-64,68-71}$ The discrepancy is likely to be originated from the assumptions made for each techniques, which are true for conventional or aqueous electrolytes but likely to be inapplicable for ILs.

In the $\mathrm{CV}$ technique, the electrode potential is swept between positive and negative ECW limits and the current is measured as a function of electrode potential. The measured current is the total current, $i_{\text {tot }}$, contributed from the charging current, $i_{\mathrm{C}}$, and faradaic current, $i_{\mathrm{F}}$. The charging current has a simple definition as the rate of the charge flow through a given area, thus $i_{\mathrm{C}}=\mathrm{d} q / \mathrm{d} t$, while the faradaic current depends on the redox reactions at the liquid/electrode interface. ${ }^{41}$ To extract the capacitance from CV, 
we can derive the expression by starting from these current as

$$
i_{\mathrm{tot}}=\frac{\mathrm{d} q}{\mathrm{~d} t}+i_{\mathrm{F}}=C \frac{\mathrm{d} V}{\mathrm{~d} t}+V \frac{\mathrm{d} C}{\mathrm{~d} t}+i_{\mathrm{F}}
$$

where $C$ is an EDL capacitance and $V$ is the electrode voltage. In a traditional electrolyte where the ion responses to an electric field is assumed to be quick, the term $\mathrm{d} C / \mathrm{d} t$ is just simply dropped out from eq $1.11 .^{41,63,64}$ Therefore, the EDL capacitance is just a slope of a linear equation where the independent variable is the "scan rate" $(\mathrm{d} V / \mathrm{d} t)$. However, the assumption of "quick response" does not seem to be true for ILs as the hysteresis effects caused by ion reorientation can play an important role to the measured current as found in the x-ray reflectivity experiment. ${ }^{72}$ As a result, analysing the CV data with such an assumption for ILs may give incorrect results. The experimental data in the literature rarely show similarity of the measured differential capacitance to the mean-field model for ILs or the classical GC model. Additionally, the results do not obviously correspond to the EIS data (Figure 1.5). ${ }^{63,64}$

EIS is somewhat different from $\mathrm{CV}$ in the sense that instead of a linear potential sweep alone, there is a small amplitude alternating voltage imposed on it and the impedance of the system is measured. Data analysis requires knowledge of an equivalent circuit model to represent the actual system. As a result, the accuracy is strongly dependent on the model design. In a classical electrolyte, the EDL is modelled as a capacitor or a constant phase element (for a non-ideal system), while the bulk solution is equivalent to a resistor. ${ }^{41}$ To collect the data, in principle, the full spectrum of frequency should be recorded for each potential and the data are analysed from this information. However, this approach will take substantially long measurement time and can easily lead to undesired effects such as electrode hysteresis and liquid degradation. ${ }^{63,64,66,67,73-77}$ Many works adopted an alternative single-frequency method, where the "appropriate" frequency is determined first and is then used for all scanned potentials. The latter method is quite tricky because it is not obvious that the selected frequency is truly appropriate. Different works report data collected with different frequencies, which are found to have a variation in results. ${ }^{53-55,57-59,61,62}$ 

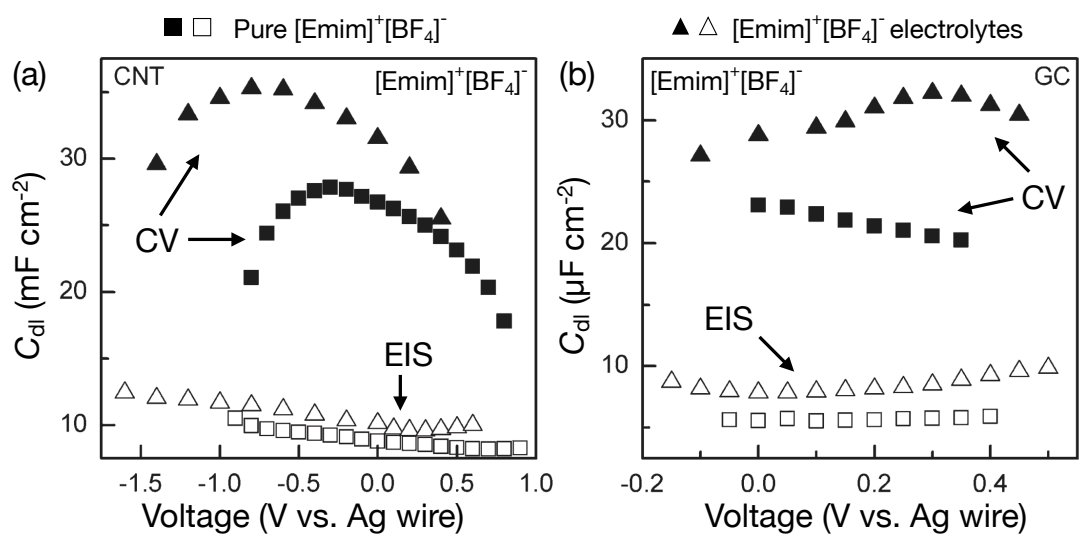

Figure 1.5: Comparison of the differential capacitance measured with CV (closed symbols) and EIS (open symbols) at (a) carbon nanotube electrode and (b) glassy carbon electrode. The results show clear discrepancy between two techniques used in the measurement, and do not follow the know theories. Adapted and reprinted with permission from J. Zheng et al., J. Phys. Chem. C, 2011, 115 (15), 75277537, Copyright (c) 2011 American Chemical Society.

Some data measured with EIS show a capacitance that agrees qualitatively with the predicted model, either appearing as bell- or camel-shape with the decreasing capacitance at large electrode polarization due to lattice saturation. ${ }^{61,62}$ Some of the data can even capture more information on the different time scales of the capacitance. ${ }^{68}$ However, there are still discrepancies between the results obtained from the same technique, leading to difficulties to confirm the suitability of the technique for capacitance measurement in ILs.

The diversity of the existing data together with their discrepancy lead to an unclear conclusion about the true nature of the differential capacitance of ILs, which also holds back theoretical advancement. As this is an important topic and clearer data are needed to push the field forward, we use a different technique to $\mathrm{CV}$ or EIS to independently measure the differential capacitance of both solvent-free and dilute ILs. The detailed explanation can be read further in Chapter 3 . 


\subsubsection{Near-wall molecular structure of ILs}

The mean-field theory is beneficial for explaining the macroscopic picture of an EDL, especially the measured capacitance. However, ILs have more complexities than traditional dilute electrolytes, such as ion correlations, effects of molecular structure of ions, and the geometry and chemical composition of the electrode, that cannot be completely described by the meanfield model. In such cases, computer simulations are an essential tool for the study, to extend the limitations of the analytical mean-field approach. Studying ILs can be done for both interfacial and bulk liquid and the popular methods found in literature are the Monte Carlo and molecular dynamics (MD) simulations. ${ }^{9,78}$

The results from simulations reveal that the EDL in ILs has an oscillatory structure, in which the cation-rich layers alternate with anion-rich layers at small and moderate electrode potential. ${ }^{79-83}$ This effect is known as overscreening, which also exists in molten salts. ${ }^{84}$ This overscreening is the main behavior that distinguishes the real EDL structure in ILs from the prediction from mean-field model. At high electrode potential, the overscreening is replaced by the lattice saturation effect, which can be observed from the mean-field model (the decreasing of the differential capacitance at high electrode potential). ${ }^{47}$

Oscillatory or discrete structures on the surface are measured in ILs using force measurement techniques, such as surface force apparatus (SFA) and atomic force microscopy (AFM), for which examples are shown in Figure $1.6^{19,20,69,85-92}$ The oscillatory zone found between the surface separation is about $1-10 \mathrm{~nm}$ thick, with the "step size" or "layer thickness" similar to an ion pair. X-ray reflexivity also confirms that surface layering can occur on an isolated interface, where the confinement effect is excluded. ${ }^{93-95}$ The orderly alternating cation-anion layering has not been proven by force-distance measurements as we only know from the technique that the "pop-out" layers are neutral but whether each single layer is ion-rich or completely neutral is indistinguishable. ${ }^{9}$

The origin of the oscillatory structural forces in ILs is the same as in molecular liquids, where the packing constraints induce oscillation of molec- 
(a)

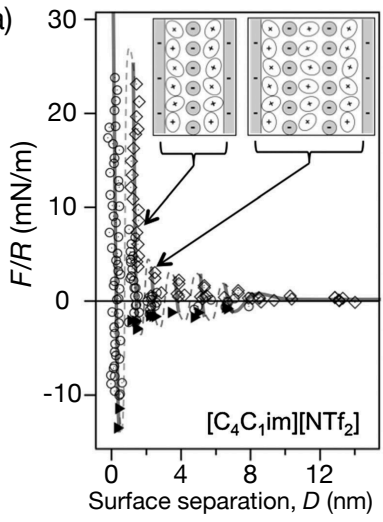

(b)

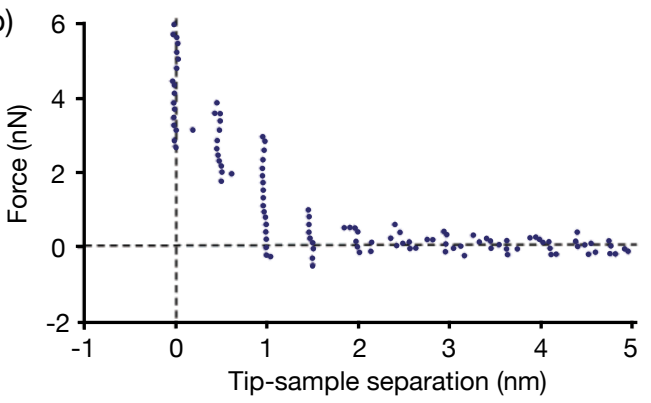

Figure 1.6: Nano-confined force measurements show discrete layers of ILs with the size of each layers corresponds to the molecular size of the ions. Adapted and reprinted with permission from S. Perkin, Phys. Chem. Chem. Phys., 2012, 14, 5052-5062, Copyright (c) 2012 Royal Society of Chemistry, and R. Atkin et al., J. Phys. Chem. C, 2007, 111 (13), 5162-5168, Copyright (C) 2007 American Chemical Society.

ular density in confined geometry. ${ }^{40}$ Surface material, surface charge, and surface roughness can have an influence on the layer formation, where higher surface charge and smoother surfaces tend to pronounce ion ordering. ${ }^{9,96}$ Small increases in temperature do not significantly affect the ion structure. Increasing temperature from $14^{\circ} \mathrm{C}$ to about $30{ }^{\circ} \mathrm{C}$ can only decrease the magnitude of force required to "push through" each layers, but does not change the number of layers, layer thickness or location of each layer on the force curves. ${ }^{92}$

Measuring the friction on discrete IL layers is also possible by measuring the lateral force as a function of normal load. It was found that the friction has discrete values depending on liquid film thickness and normal load, which will have direct implications for lubrication applications. ${ }^{97,98}$ Topological imaging of the ILs layers can also be done using an AFM, which reveals the the patterns of molecular orientations at different surface properties. $^{99-101}$

Discrete layers at interfaces are well accepted for ILs. Nevertheless, recent force measurements show the existence of a long-range repulsive monotonic force next to charged walls. ${ }^{102-107}$ The length scale of this force was ob- 
(a)

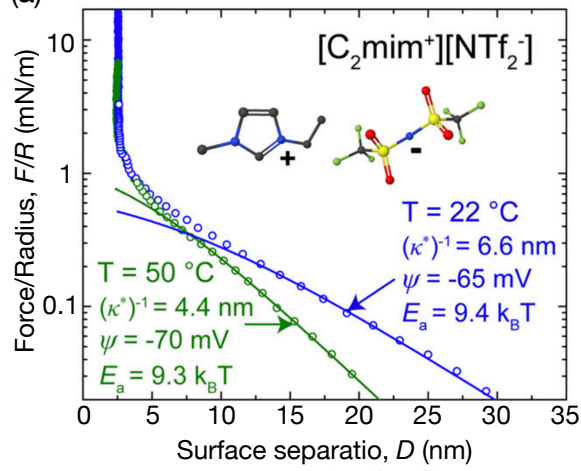

(b)

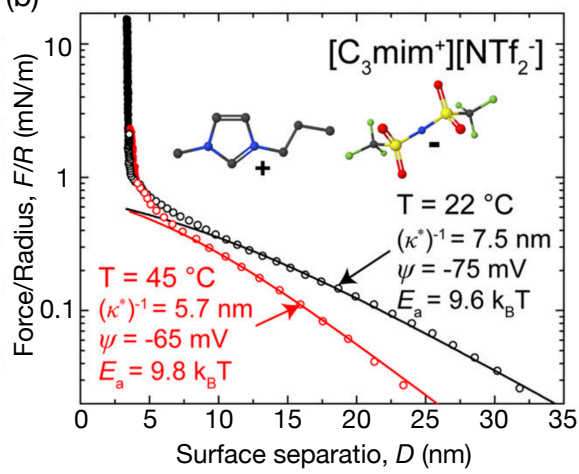

Figure 1.7: Long-range forces measured in pure ILs (a) $[\mathrm{Emim}]^{+}\left[\mathrm{NTf}_{2}\right]^{-}$and (b) $[\mathrm{Pmim}]^{+}\left[\mathrm{NTf}_{2}\right]^{-}$show shorter screening lengths at higher temperature. Adapted and reprinted with permission from M. A. Gebbie et al., Proc. Natl. Acad. Sci. U. S. A., 2015, 112 (24), 7432-7437, Copyright (c) 2015 National Academy of Sciences.

served to extend up to $\sim 30 \mathrm{~nm}$ into the bulk, larger than the oscillatory decay length of the near-surface structure. The exponential decay length of the long-range force in ILs is found to decrease with raising temperature (Figure 1.7), and is interpreted as caused by an increasing number of effective charge carriers in the liquid. ${ }^{103,104}$ This interpretation leads to a conclusion that ILs behave as dilute electrolytes, where the ions are mostly associated to form "neutral" couples with only a small number of them in a dissociated state and the neutral aggregations are dissociated by thermal excitation at elevated temperatures, well fitted with classical EDL theory. However, choices of surface and ILs used in the measurement seem to be important for the long-range force to be measurable, ${ }^{104,107}$ which makes it system dependent. As a result, independent measurements using different techniques other than force measurements is required to strengthen both the existing data and interpretation. ${ }^{9}$ The observation of long-range force in ILs contradicted with a theoretical study, where the free ion fraction in ILs was found to be approximately $67 \%$, much greater than what observed from the force measurement. ${ }^{108}$ This leads to an intense discussion about the true nature of dense electrolytes and ILs, which is still an open-end 
question. $^{86,104,109}$

\subsection{Thesis outline}

This thesis reports experimental studies on EDL of ionic liquids at different surface and bulk liquid conditions. Force measurement and electrochemical techniques were used as main tools.

Chapter 2 reports and discusses on the relevant experimental techniques used throughout this thesis. The discussion is stressed on the practical aspects and important points that should be considered in the experiments.

Chapter 3 focuses on the differential capacitance measurement in solvent-free and dilute ionic liquids using chronoamperometry (CA) technique, including the comparison of experimental data with theoretical prediction.

Chapter 4 studies the effects of surface charge to the local ordering and flow property of ionic liquids on the surfaces having different surface charge density. The interfacial molecular structures were probed using force-distance (FD) and small-amplitude force-distance (SAFD) spectroscopies.

Chapter 5 investigates the changes of near-wall molecular ordering of ionic liquids with varied bulk concentration using FD spectroscopy.

Chapter 6 studies the dissociation of ILs in ethylene glycol by using colloidal probe microscopy to measure the EDL force at different temperatures.

Chapter $\mathbf{7}$ provides the conclusions of the works done within the framework of this thesis and suggests an opportunity for future experiments. 


\section{References}

[1] Graves, A. and Inman, D. (1970) The Electrical Double Layer in Molten Salts: Part 2. The Double-layer Capacitance. J. Electroanal. Chem., 25(3), 357-372.

[2] Mamantov, G. and Marassi, R. (2012) Molten Salt Chemistry: An Introduction and Selected Applications, Vol. 202, Springer Science \&amp; Business Media, .

[3] Gaune-Escard, M. (2012) Molten Salts: From Fundamentals to Applications, Vol. 52, Springer Science \&amp; Business Media, .

[4] Ohno, H. (2005) Electrochemical Aspects of Ionic Liquids, John Wiley \& Sons, .

[5] Plechkova, N. V. and Seddon, K. R. (2008) Applications of Ionic Liquids in the Chemical Industry. Chem. Soc. Rev., 37(1), 123-150.

[6] Hallett, J. P. and Welton, T. (2011) Room-temperature Ionic Liquids: Solvents for Synthesis and Catalysis. 2. Chem. Rev., 111(5), 3508-3576.

[7] Welton, T. (1999) Room-Temperature Ionic Liquids. Solvents for Synthesis and Catalysis. Chem. Rev., 99(8), 2071-2084.

[8] Wasserscheid, P. and Welton, T. (2008) Ionic Liquids in Synthesis, John Wiley \&amp; Sons, .

[9] Fedorov, M. V. and Kornyshev, A. A. (2014) Ionic Liquids at Electrified Interfaces. Chem. Rev., 114(5), 2978-3036.

[10] Hunt, P. A., Kirchner, B., and Welton, T. (2006) Characterising the Electronic Structure of Ionic Liquids: An Examination of the 1-butyl-3methylimidazolium chloride Ion Pair. Chem.-Eur. J., 12(26), 6762-6775.

[11] Koßmann, S., Thar, J., Kirchner, B., Hunt, P. A., and Welton, T. (2006) Cooperativity in Ionic Liquids. J. Chem. Phys., 124(17), 174506.

[12] Lehmann, S. B., Roatsch, M., Schöppke, M., and Kirchner, B. (2010) On the Physical Origin of the Cation-Anion Intermediate Bond in Ionic Liquids Part I. Placing a (weak) Hydrogen Bond between Two Charges. Phys. Chem. Chem. Phys., 12(27), 7473-7486.

[13] Kurig, H., Vestli, M., Tõnurist, K., Jänes, A., and Lust, E. (2012) Influence of Room Temperature Ionic Liquid Anion Chemical Composition and Electrical Charge Delocalization on the Supercapacitor Properties. J. Electrochem. Soc., 159(7), A944-A951.

[14] Rigby, J. and Izgorodina, E. I. (2013) Assessment of Atomic Partial Charge Schemes for Polarisation and Charge Transfer Effects in Ionic Liquids. Phys. Chem. Chem. Phys., 15(5), 1632-1646.

[15] Krossing, I., Slattery, J. M., Daguenet, C., Dyson, P. J., Oleinikova, A., and 
Weingärtner, H. (2006) Why Are Ionic Liquids Liquid? A Simple Explanation Based on Lattice and Solvation Energies. J. Am. Chem. Soc., 128(41), 13427-13434.

[16] Armand, M., Endres, F., MacFarlane, D. R., Ohno, H., and Scrosati, B. (2009) Ionic-Liquid Materials for the Electrochemical Challenges of the Future. Nat. Mater., 8(8), 621-629.

[17] Kim, T. Y., Lee, H. W., Stoller, M., Dreyer, D. R., Bielawski, C. W., Ruoff, R. S., and Suh, K. S. (2010) High-performance Supercapacitors Based on Poly (Ionic Liquid)-Modified Graphene Electrodes. ACS Nano, 5(1), 436442.

[18] Niedermeyer, H., Hallett, J. P., Villar-Garcia, I. J., Hunt, P. A., and Welton, T. (2012) Mixtures of Ionic Liquids. Chem. Soc. Rev., 41(23), 7780-7802.

[19] Perkin, S., Albrecht, T., and Klein, J. (2010) Layering and Shear Properties of an Ionic Liquid, 1-ethyl-3-methylimidazolium Ethylsulfate, Confined to Nano-films between Mica Surfaces. Physical chemistry chemical physics, 12(6), 1243-1247.

[20] Perkin, S. (2012) Ionic Liquids in Confined Geometries. Phys. Chem. Chem. Phys., 14(15), 5052-5062.

[21] Elbourne, A., Sweeney, J., Webber, G. B., Wanless, E. J., Warr, G. G., Rutland, M. W., and Atkin, R. (2013) Adsorbed and Near-surface Structure of Ionic Liquids Determines Nanoscale Friction. Chem. Commun., 49(60), 6797-6799.

[22] Zhou, F., Liang, Y., and Liu, W. (2009) Ionic Liquid Lubricants: Designed Chemistry for Engineering Applications. Chem. Soc. Rev., 38(9), 25902599.

[23] Palacio, M. and Bhushan, B. (2010) A Review of Ionic Liquids for Green Molecular Lubrication in Nanotechnology. Tribol. Lett., 40(2), 247-268.

[24] Werzer, O., Cranston, E. D., Warr, G. G., Atkin, R., and Rutland, M. W. (2012) Ionic Liquid Nanotribology: Mica-Silica Interactions in Ethylammonium Nitrate. Phys. Chem. Chem. Phys., 14(15), 5147-5152.

[25] Lin, R., Taberna, P.-L., Fantini, S., Presser, V., Pérez, C. R., Malbosc, F., Rupesinghe, N. L., Teo, K. B., Gogotsi, Y., and Simon, P. (2011) Capacitive Energy Storage from- 50 to $100 \mathrm{C}$ Using an Ionic Liquid Electrolyte. J. Phys. Chem. Lett., 2(19), 2396-2401.

[26] Palm, R., Kurig, H., Tõnurist, K., Jänes, A., and Lust, E. (2012) Is the Mixture of 1-ethyl-3-methylimidazolium tetrafluoroborate and 1-butyl-3methylimidazolium tetrafluoroborate Applicable as Electrolyte in Electrical Double Layer Capacitors?. Electrochem. Commun., 22, 203-206. 
[27] Mastragostino, M. and Soavi, F. (2007) Strategies for High-Performance Supercapacitors for HEV. J. Power Sources, 174(1), 89-93.

[28] Simon, P. and Gogotsi, Y. (2008) Materials for Electrochemical Capacitors. Nat. Mater., 7(11), 845-854.

[29] Borgel, V., Markevich, E., Aurbach, D., Semrau, G., and Schmidt, M. (2009) On the Application of Ionic Liquids for Rechargeable Li Batteries: High Voltage Systems. J. Power Sources, 189(1), 331-336.

[30] Xiang, J., Wu, F., Chen, R., Li, L., and Yu, H. (2013) High Voltage and Safe Electrolytes based on Ionic Liquid and Sulfone for Lithium-Ion Batteries. J. Power Sources, 233, 115-120.

[31] Li, B., Wang, L., Kang, B., Wang, P., and Qiu, Y. (2006) Review of Recent Progress in Solid-State Dye-Sensitized Solar Cells. Sol. Energ. Mater. Sol., 90(5), 549-573.

[32] Hagfeldt, A., Boschloo, G., Sun, L., Kloo, L., and Pettersson, H. (2010) Dye-Sensitized Solar Cells. Chem. Rev., 110(11), 6595-6663.

[33] Galinski, M., Lewandowski, A., and Stepniak, I. (2006) Ionic Liquids as Electrolytes. Electrochim. Acta., 51(26), 5567-5580.

[34] MacFarlane, D. R., Forsyth, M., Howlett, P. C., Pringle, J. M., Sun, J., Annat, G., Neil, W., and Izgorodina, E. I. (2007) Ionic Liquids in Electrochemical Devices and Processes: Managing Interfacial Electrochemistry. Acc. Chem. Res., 40(11), 1165-1173.

[35] Yoshida, J.-i., Kataoka, K., Horcajada, R., and Nagaki, A. (2008) Modern Strategies in Electroorganic Synthesis. Chem. Rev., 108(7), 2265-2299.

[36] Hapiot, P. and Lagrost, C. (2008) Electrochemical Reactivity in Roomtemperature Ionic Liquids. Chem. Rev., 108(7), 2238-2264.

[37] He, Y., Li, Z., Simone, P., and Lodge, T. P. (2006) Self-assembly of Block Copolymer Micelles in an Ionic Liquid. J. Am. Chem. Soc., 128(8), 27452750.

[38] Zhou, Y. and Antonietti, M. (2003) Synthesis of Very Small TiO2 Nanocrystals in a Room-temperature Ionic Liquid and their Self-assembly Toward Mesoporous Spherical Aggregates. J. Am. Chem. Soc., 125(49), 1496014961.

[39] Lewandowski, A. and Świderska Mocek, A. (2009) Ionic Liquids as Electrolytes for Li-ion Batteries - an Overview of Electrochemical Studies. J. Power Sources, 194(2), 601-609.

[40] Israelachvili, J. N. (2011) Intermolecular and Surface Forces, Academic press, .

[41] Bard, A. J. and Faulkner, L. R. (2001) Electrochemical Methods: Funda- 
mentals and Applications, John Wiley \& Son, 2 edition.

[42] Debye, P. J. W. and Hückel, E. A. A. (1923) J. Phys. Z., 24(185).

[43] von Helmholtz, H. (1853) Ann. Phys. Chem., 89, 353-377.

[44] Gouy, L. G. (1909) C. R. Hebd. Acad. Sci., 149(654).

[45] Gouy, L. G. (1910) J. Phys. Théor. Appl., 9(457).

[46] Stern, O. (1924) Z. Electrochem., 30(508).

[47] Kornyshev, A. A. (2007) Double-Layer in Ionic Liquids: Paradigm Change?. J. Phys. Chem. B, 111, 5545.

[48] Goodwin, Z. A., Feng, G., and Kornyshev, A. A. (2017) Mean-Field Theory of Electrical Double Layer In Ionic Liquids with Account of Short-Range Correlations. Electrochim. Acta., 225, 190-197.

[49] Goodwin, Z. A. and Kornyshev, A. A. (2017) Underscreening, Overscreening and Double-Layer Capacitance. Electrochem. Commun., 82, 129-133.

[50] Tsuzuki, S., Tokuda, H., Hayamizu, K., and Watanabe, M. (2005) Magnitude and Directionality of Interaction in Ion Pairs of Iionic Liquids: Relationship with Ionic Conductivity. J. Phys. Chem. B, 109(34), 16474-16481.

[51] Tsuzuki, S., Shinoda, W., Saito, H., Mikami, M., Tokuda, H., and Watanabe, M. (2009) Molecular Dynamics Simulations of Ionic Liquids: Cation and Anion Dependence of Self-diffusion Coefficients of Ions. J. Phys. Chem. $B, \mathbf{1 1 3}(31), 10641-10649$.

[52] Eiden, P., Bulut, S., Köchner, T., Friedrich, C., Schubert, T., and Krossing, I. (2010) In Silico Predictions of the Temperature-dependent Viscosities and Electrical Conductivities of Functionalized and Nonfunctionalized Ionic Liquids. J. Phys. Chem. B, 115(2), 300-309.

[53] Alam, M. T., Islam, M. M., Okajima, T., and Ohsaka, T. (2007) Measurements of Differential Capacitance at Mercury/Room-temperature Ionic Liquids Interfaces. J. Phys. Chem. C, 111(49), 18326-18333.

[54] Alam, M. T., Islam, M. M., Okajima, T., and Ohsaka, T. (2007) Measurements of Differential Capacitance in Room Temperature Ionic Liquid at Mercury, Glassy Carbon and Gold Electrode Interfaces. Electrochem. Commun., 9(9), 2370-2374.

[55] Alam, M. T., Islam, M. M., Okajima, T., and Ohsaka, T. (2008) Ionic Liquid Structure Dependent Electrical Double Layer at the Mercury Interface. $J$. Phys. Chem. C, 112(7), 2601-2606.

[56] Alam, M. T., Islam, M. M., Okajima, T., and Ohsaka, T. (2008) Capacitance Measurements in a Series of Room-temperature Ionic Liquids at Glassy Carbon and Gold Electrode Interfaces. J. Phys. Chem. C, 112(42), $16600-16608$. 
[57] Alam, M. T., Islam, M. M., Okajima, T., and Ohsaka, T. (2009) Electrical Double Layer in Mixtures of Room-temperature Ionic Liquids. J. Phys. Chem. C, 113(16), 6596-6601.

[58] Alam, M. T., Masud, J., Islam, M. M., Okajima, T., and Ohsaka, T. (2011) Differential Capacitance at Au (111) in 1-alkyl-3-methylimidazolium tetrafluoroborate based Room-temperature Ionic Liquids. J. Phys. Chem. C, 115(40), 19797-19804.

[59] Islam, M. M., Alam, M. T., and Ohsaka, T. (2008) Electrical Double-layer Structure in Ionic Liquids: A Corroboration of the Theoretical Model by Experimental Results. J. Phys. Chem. C, 112(42), 16568-16574.

[60] Islam, M. M., Alam, M. T., Okajima, T., and Ohsaka, T. (2009) Electrical Double Layer Structure in Ionic Liquids: An Understanding of the Unusual Capacitance-potential Curve at a Nonmetallic Electrode. J. Phys. Chem. $C, \mathbf{1 1 3}(9), 3386-3389$.

[61] Lockett, V., Sedev, R., Ralston, J., Horne, M., and Rodopoulos, T. (2008) Differential Capacitance of the Electrical Double Layer in Imidazoliumbased Ionic Liquids: Influence of Potential, Cation size, and Temperature. J. Phys. Chem. C, 112(19), 7486-7495.

[62] Lockett, V., Horne, M., Sedev, R., Rodopoulos, T., and Ralston, J. (2010) Differential Capacitance of the Double Layer at the Electrode/Ionic Liquids Interface. Phys. Chem. Chem. Phys., 12(39), 12499-12512.

[63] Zheng, J., Goonetilleke, P., Pettit, C., and Roy, D. (2010) Probing the Electrochemical Double Layer of an Ionic Liquid using Voltammetry and Impedance Spectroscopy: A Comparative Study of Carbon Nanotube and Glassy Carbon Electrodes in [EMIM]+[EtSO 4]-. Talanta, 81(3), 1045-1055.

[64] Zheng, J., Moganty, S. S., Goonetilleke, P. C., Baltus, R. E., and Roy, D. (2011) A Comparative Study of the Electrochemical Characteristics of $[$ Emim+][BF4-] and [Bmim+][BF4-] Ionic Liquids at the Surfaces of Carbon Nanotube and Glassy Carbon Electrodes. J. Phys. Chem. C, 115(15), 75277537.

[65] Gnahm, M., Pajkossy, T., and Kolb, D. (2010) The Interface between Au (111) and an Ionic Liquid. Electrochim. Acta., 55(21), 6212-6217.

[66] Drüschler, M., Huber, B., and Roling, B. (2011) On Capacitive Processes at the Interface between 1-Ethyl-3-methylimidazolium tris (pentafluoroethyl) trifluorophosphate and Au (111). J. Phys. Chem. C, 115(14), 6802-6808.

[67] Pajkossy, T. and Kolb, D. M. (2011) The Interfacial Capacitance of Au (100) in an Ionic Liquid, 1-butyl-3-methyl-imidazolium hexafluorophosphate. Electrochem. Commun., 13(3), 284-286. 
[68] Roling, B., Drüschler, M., and Huber, B. (2012) Slow and Fast Capacitive Process Taking Place at the Ionic Liquid/Electrode Interface. Faraday Discuss., 154, 303-311.

[69] Atkin, R., Borisenko, N., Drüschler, M., El Abedin, S. Z., Endres, F., Hayes, R., Huber, B., and Roling, B. (2011) An in situ STM/AFM and Impedance Spectroscopy Study of the Extremely Pure 1-butyl-1-methylpyrrolidinium tris (pentafluoroethyl) trifluorophosphate/Au (111) Interface: Potential Dependent Solvation Layers and the Herringbone Reconstruction. Phys. Chem. Chem. Phys., 13(15), 6849-6857.

[70] Atkin, R., Borisenko, N., Drüschler, M., Endres, F., Hayes, R., Huber, B., and Roling, B. (2014) Structure and Dynamics of the Interfacial Layer between Ionic Liquids and Electrode Materials. J. Mol. Liq., 192, 44-54.

[71] Li, M.-G., Chen, L., Zhong, Y.-X., Chen, Z.-B., Yan, J.-W., and Mao, B.-W. (2016) The Electrochemical Interface of Ag (111) in 1-ethyl-3methylimidazolium bis (trifluoromethylsulfonyl) imide Ionic Liquid-A Combined in-situ Scanning Probe Microscopy and Impedance Study. Electrochim. Acta., 197, 282-289.

[72] Uysal, A., Zhou, H., Feng, G., Lee, S. S., Li, S., Fenter, P., Cummings, P. T., Fulvio, P. F., Dai, S., and McDonough, J. K. (2013) Structural Origins of Potential Dependent Hysteresis at the Electrified Graphene/Ionic Liquid Interface. J. Phys. Chem. C, 118(1), 569-574.

[73] Roling, B. and Drüschler, M. (2012) Comments on "Intrinsic Limitations of Impedance Measurements in Determining Electric Double Layer Capacitances" by H. Wang and L. Pilon [Electrochim. Acta 63 (2012) 55]. Electrochim. Acta., 76, 526-528.

[74] Wang, H. and Pilon, L. (2012) Intrinsic Limitations of Impedance Measurements in Determining Electric Double Layer Capacitances. Electrochim. Acta., 63, 55-63.

[75] Wang, H. and Pilon, L. (2012) Reply to Comments on "Intrinsic Limitations of Impedance Measurements in Determining Electric Double Layer Capacitances" by H. Wang, L. Pilon [Electrochimica Acta 63 (2012) 55]. Electrochim. Acta., 76, 529-531.

[76] Drüschler, M. and Roling, B. (2011) Commentary on 'The Interface between $\mathrm{Au}$ (111) and an Ionic Liquid'. Electrochim. Acta., 56(20), 7243-7245.

[77] Pajkossy, T. (2011) Response to the Commentary of Marcel Drüschler and Bernhard Roling on 'The interface between $\mathrm{Au}$ (111) and an ionic liquid'. Electrochim. Acta., 56(20), 7246-7247.

[78] Hayes, R., Warr, G. G., and Atkin, R. (2015) Structure and Nanostructure 
in Ionic Liquids. Chem. Rev., 115(13), 6357-6426.

[79] Lynden-Bell, R. (2003) Gas-Liquid Interfaces of Room Temperature Ionic Liquids. Mol. Phys., 101(16), 2625-2633.

[80] Lynden-Bell, R., Kohanoff, J., and Del Popolo, M. (2005) Simulation of Interfaces between Room Temperature Ionic Liquids and Other Liquids. Faraday Discuss., 129, 57-67.

[81] Lynden-Bell, R. M., Del Pópolo, M. G., Youngs, T. G., Kohanoff, J., Hanke, C. G., Harper, J. B., and Pinilla, C. C. (2007) Simulations of Ionic Liquids, Solutions, and Surfaces. Acc. Chem. Res., 40(11), 1138-1145.

[82] Pinilla, C., Del Popolo, M., Kohanoff, J., and Lynden-Bell, R. M. (2007) Polarization Relaxation in an Ionic Liquid Confined between Electrified Walls. J. Phys. Chem. B, 111(18), 4877-4884.

[83] Fedorov, M. V. and Kornyshev, A. A. (2008) Towards Understanding the Structure and Capacitance of Electrical Double Layer in Ionic Liquids. Electrochim. Acta., 53(23), 6835-6840.

[84] Tosi, M. and Kornyshev, A. (1991) Condensed Matter Physics Aspects of Electrochemistry.

[85] Perkin, S., Crowhurst, L., Niedermeyer, H., Welton, T., Smith, A. M., and Gosvami, N. N. (2011) Self-assembly in the Electrical Double Layer of Ionic Liquids. Chem. Commun., 47(23), 6572-6574.

[86] Perkin, S., Salanne, M., Madden, P., and Lynden-Bell, R. (2013) Is a Stern and Diffuse Layer Model Appropriate to Ionic Liquids at Surfaces?. Proc. Natl. Acad. Sci. U. S. A., 110(44), E4121-E4121.

[87] Smith, A. M., Lovelock, K. R., and Perkin, S. (2013) Monolayer and Bilayer Structures in Ionic Liquids and their Mixtures Confined to Nano-Films. Faraday Discuss., 167, 279-292.

[88] Smith, A. M., Lovelock, K. R., Gosvami, N. N., Licence, P., Dolan, A., Welton, T., and Perkin, S. (2013) Monolayer to Bilayer Structural Transition in Confined Pyrrolidinium-Based Ionic Liquids. J. Phys. Chem. Lett., 4(3), 378-382.

[89] Atkin, R. and Warr, G. G. (2007) Structure in Confined Room-Temperature Ionic Liquids. J. Phys. Chem. C, 111(13), 5162-5168.

[90] Atkin, R., El Abedin, S. Z., Hayes, R., Gasparotto, L. H., Borisenko, N., and Endres, F. (2009) AFM and STM Studies on the Surface Interaction of [BMP] TFSA and [EMIm] TFSA Ionic Liquids with Au (111). J. Phys. Chem. C, 113(30), 13266-13272.

[91] Seddon, J. R. (2014) Conservative and Dissipative Interactions of Ionic Liquids in Nanoconfinement. J. Phys. Chem. C, 118(38), 22197-22201. 
[92] Wakeham, D., Hayes, R., Warr, G. G., and Atkin, R. (2009) Influence of Temperature and Molecular Structure on Ionic Liquid Solvation Layers. $J$. Phys. Chem. B, 113(17), 5961-5966.

[93] Mezger, M., Schröder, H., Reichert, H., Schramm, S., Okasinski, J. S., Schöder, S., Honkimäki, V., Deutsch, M., Ocko, B. M., Ralston, J., et al. (2008) Molecular Layering of Fluorinated Ionic Liquids at a Charged Sapphire (0001) Surface. Science, 322(5900), 424-428.

[94] Mezger, M., Ocko, B. M., Reichert, H., and Deutsch, M. (2013) Surface Layering and Melting in an Ionic Liquid Studied by Resonant Soft X-ray Reflectivity. Proc. Natl. Acad. Sci. U. S. A., 110(10), 3733-3737.

[95] Wakeham, D., Nelson, A., Warr, G. G., and Atkin, R. (2011) Probing the Protic Ionic Liquid Surface Using X-ray Reflectivity. Phys. Chem. Chem. Phys., 13(46), 20828-20835.

[96] Hayes, R., Warr, G. G., and Atkin, R. (2010) At the Interface: Solvation and Designing Ionic Liquids. Phys. Chem. Chem. Phys., 12(8), 1709-1723.

[97] Smith, A. M., Lovelock, K. R., Gosvami, N. N., Welton, T., and Perkin, S. (2013) Quantized Friction Across Ionic Liquid Thin Films. Phys. Chem. Chem. Phys., 15(37), 15317-15320.

[98] Hoth, J., Hausen, F., Müser, M. H., and Bennewitz, R. (2014) Force Microscopy of Layering and Friction in an Ionic Liquid. J. Phys.: Condens. Matter, 26(28), 284110.

[99] McDonald, S., Elbourne, A., Warr, G. G., and Atkin, R. (2016) Metal Ion Adsorption at the Ionic Liquid-Mica Interface. Nanoscale, 8(2), 906-914.

[100] Elbourne, A., Cronshaw, S., Voïtchovsky, K., Warr, G. G., and Atkin, R. (2015) Near Surface Properties of Mixtures of Propylammonium Nitrate with n-alkanols 1. Nanostructure. Phys. Chem. Chem. Phys., 17(40), 2662126628.

[101] Elbourne, A., McDonald, S., Voïchovsky, K., Endres, F., Warr, G. G., and Atkin, R. (2015) Nanostructure of the Ionic Liquid-Graphite Stern Layer. ACS nano, 9(7), 7608-7620.

[102] Gebbie, M. A., Valtiner, M., Banquy, X., Fox, E. T., Henderson, W. A., and Israelachvili, J. N. (2013) Ionic Liquids Behave as Dilute Electrolyte Solutions. Proc. Natl. Acad. Sci. U. S. A., 110(24), 9674-9679.

[103] Gebbie, M. A., Dobbs, H. A., Valtiner, M., and Israelachvili, J. N. (2015) Long-range Electrostatic Screening in Ionic Liquids. Proc. Natl. Acad. Sci. U. S. A., 112(24), 7432-7437.

[104] Gebbie, M. A., Smith, A. M., Dobbs, H. A., Warr, G. G., Banquy, X., Valtiner, M., Rutland, M. W., Israelachvili, J. N., Perkin, S., and Atkin, 
R. (2017) Long Range Electrostatic Forces in Ionic Liquids. Chem. Comm., 53(7), 1214-1224.

[105] Smith, A. M., Lee, A. A., and Perkin, S. (2016) The Electrostatic Screening Length in Concentrated Electrolytes Increases with Concentration. J. Phys. Chem. Lett., 7(12), 2157-2163.

[106] Smith, A. M., Perkin, S., et al. (2017) Switching the Structural Force in Ionic Liquid-Solvent Mixtures by Varying Composition. Phys. Rev. Lett., 118(9), 096002.

[107] Hjalmarsson, N., Atkin, R., and Rutland, M. W. (2017) Switchable Longrange Double Layer Force Observed in a Protic Ionic Liquid. Chem. Commun., 53(3), 647-650.

[108] Lee, A. A., Vella, D., Perkin, S., and Goriely, A. (2014) Are RoomTemperature Ionic Liquids Dilute Electrolytes?. J. Phys. Chem. Lett., 6(1), 159-163.

[109] Gebbie, M. A., Valtiner, M., Banquy, X., Henderson, W. A., and Israelachvili, J. N. (2013) Reply to Perkin et al.: Experimental Observations Demonstrate that Ionic Liquids Form Both Bound (Stern) and Diffuse Electric Double Layers. Proc. Natl. Acad. Sci. U. S. A., 110(44), E4122. 




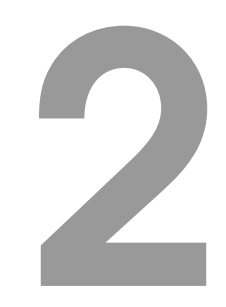

\section{Experimental Techniques}

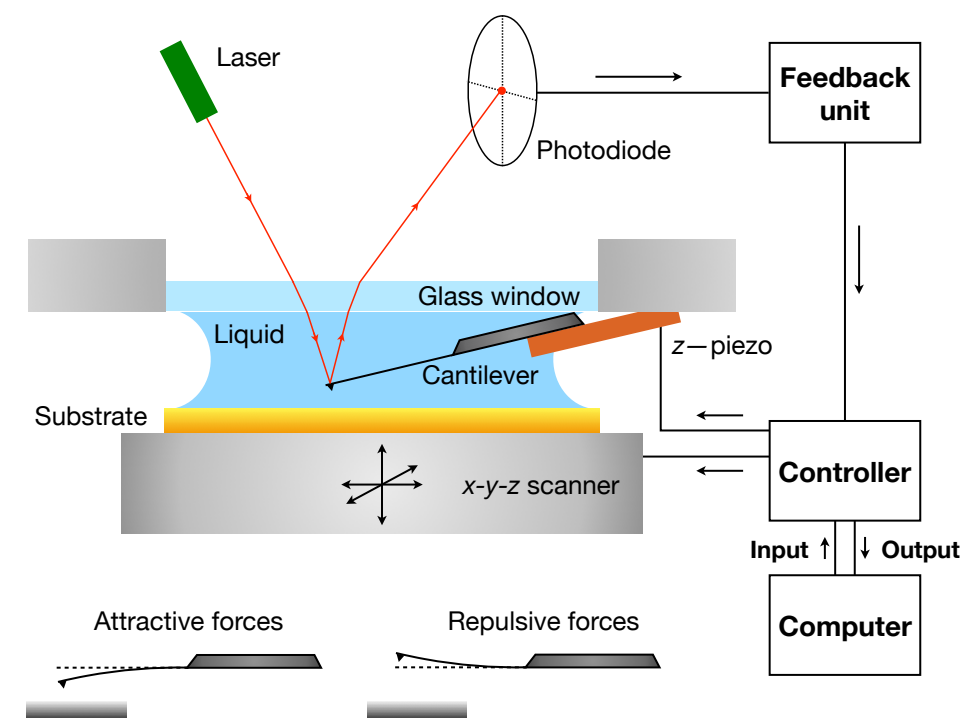

This chapter is dedicated to the experimental techniques used in this thesis, which are electrochemical techniques and atomic force microscopy (AFM). These techniques are well established but there are some details that must be considered when working in ILs. Therefore, this chapter is intended to add technical aspects of those techniques rather than a basic introduction, which can be found in standard textbooks. Most of the discussions in this chapter will focus on what was found practically during the measurements, which could benefit experimental studies in the future. 


\section{$2.1 \quad$ Electrochemical measurements}

Electrochemical techniques are used to measure electrochemical responses of materials. There are two techniques used in this thesis, which are cyclic voltammetry (CV) and chronoamperometry (CA). CV is mainly used for determining the electrochemical window (ECW) of the ILs and CA is used in the differential capacitance experiments in chapter 3. An important part in practical measurements for both techniques is an electrochemical cell, which comprises of electrodes, potentiostat, and sample liquid container.

Electrodes are made of conducting materials, which form an interface with test solutions. There are three types of electrodes in a 3-electrode system. The first electrode is a working electrode (WE), which is an electrode where the desired potential is applied and the reactions of interest take place. The second electrode is a reference electrode, which is an electrode of known potential and close to ideal nonpolarizability, acting as a reference point for measuring the potential at the WE. The third electrode is a counter electrode ( $\mathrm{CE}$ ) or sometimes called auxiliary electrode, which passes all the current needed to maintain the desired potential at the WE. ${ }^{1}$

The RE is the most complex of the three electrodes. There are several standard RE for aqueous systems available commercially, such as silversilver chloride or calomel electrodes. However, there is no standard RE for ILs because there are several choices of existing ILs. It was advised that an ideal reference electrode for ILs should be based on ILs as the solvent mixed with redox species, but little attention has been paid to the development in this medium. ${ }^{2,3}$ Instead, a pseudo RE, in which a piece of inert metal is directly immersed in an electrolyte, are frequently used for differential capacitance experiment in ILs, where redox reactions are avoided. ${ }^{4-9}$ In such cases, building a real RE may lead to a risk of contamination from the redox species, which can easily ruin the experiment. The requirement for a pseudo RE is that the potential, although unknown, is stable over the course of experiments. ${ }^{3}$ Platinum and silver are the two most popular pseudo REs used for measuring the capacitance in ILs. ${ }^{3-9}$ We found in our experiments that platinum pseudo RE performed quite stably, as the open circuit potential was measured to have similar values for different 

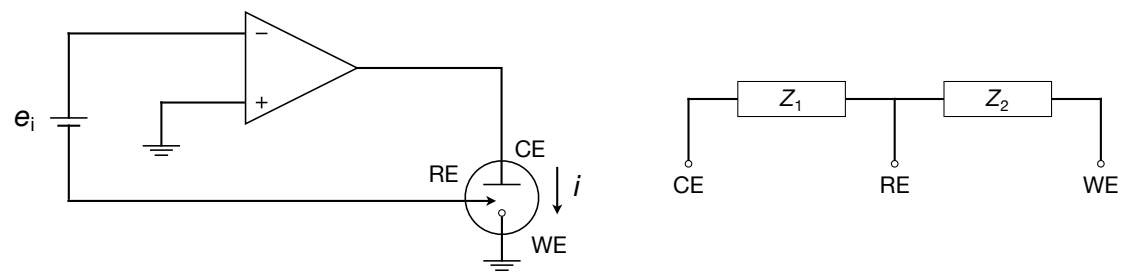

Figure 2.1: A simple potentiostat (left) and the view of an electrochemical cell as an impedance network (right), where the impedances, $Z$, represent the bulk electrolyte resistance and interfacial double layer capacitances at electrode/electrolyte interfaces.

experiments in a given IL and the cyclic voltammograms were found to be at fixed potential ranges over several cycles and long measuring time, without shifting. However, this is only true within the ECW since the decomposed molecules that formed at the ECW can adsorb on the electrode, leading to an unstable potential.

The potentiostat is an electronic component, used for controlling the potential and measuring the current. ${ }^{1}$ A schematic diagram of a potentiostat is shown in Figure 2.1 with the impedance representation of an electrochemical cell. The current through the cell is controlled by the operational amplifier so that the RE is always at $-e_{\mathrm{i}}$ vs. ground. Since the WE is grounded, the WE potential is $e_{\mathrm{i}} \mathrm{vs}$. RE, regardless of fluctuations of the impedance between all electrodes. To maintain this condition, the operational amplifier will adjust its output, resulting in the current passing through the CE.

The ECW is the potential range that shows electrochemical stability of the solutions. ILs have typically large ECW as discussed in chapter $1 .^{1,3,10,11}$ However, their ECW can be narrower than usual due to trace contaminants such as water. ${ }^{11}$ The ECW can be characterized by performing a CV measurement, where the potential ramp is applied to the electrode and the current is measured as a function of electrode potential. 


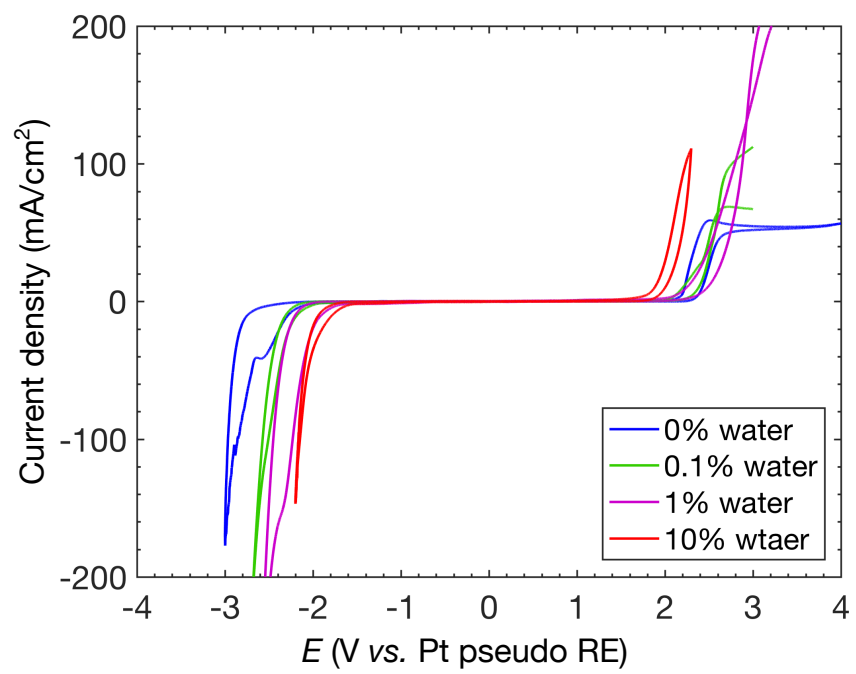

Figure 2.2: Cyclic voltammograms showing that an ECW of an IL $[\text { Emim }]^{+}\left[\mathrm{BF}_{4}\right]^{-}$decreases with higher water content.

We found that the ECW of the fresh ILs obtained from the manufacturer can be widened by drying under low pressure ( $\sim 7$ mbar $)$ and high temperature $\left(\sim 150^{\circ} \mathrm{C}\right)$ over several hours. The results are shown in Figure 2.2, indicating an effect of water to the ECW of ILs. In this thesis, the ILs are always dried before used in the experiments and working in dry environment is necessary, especially for electrochemical measurements.

\subsection{Atomic force microscopy (AFM)}

In chapter 4-6, the EDLs of various ILs were characterized by the the technique called force-distance spectroscopy. In this technique, the mechanical properties of the confined liquids are measured as a force between two surface boundaries as a function of surface separation. ${ }^{12}$ An AFM was used to perform force-distance spectroscopy in our studies, where the forces were measured between the AFM (or colloidal) probe and the substrates such as mica, HOPG, or silicon dioxide across the ILs.

The working principle of the AFM can be studied from the drawing in Figure 2.3, which shows a simplified diagram of an experimental setup for 


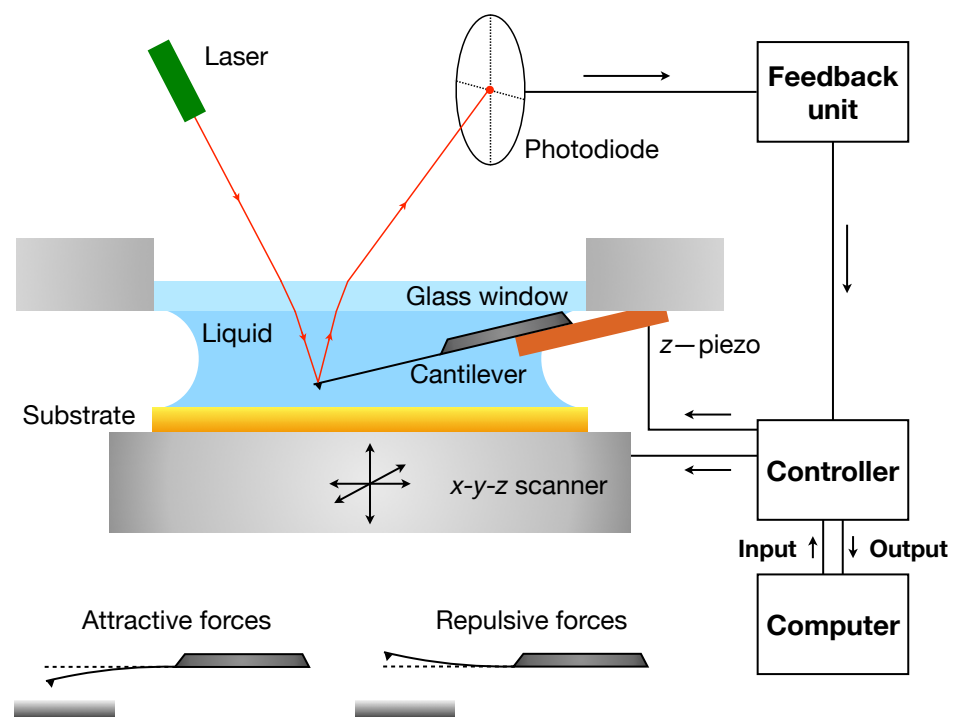

Figure 2.3: The working principle of an AFM.

measuring in liquid. The substrate is placed on a scanner, which can move in three directions using a piezo. A microcantilever, which acts as a force balance or spring due to its flexibility, is held by the cantilever holder above the substrate. The vertical movement of the cantilever is controlled by the $z$-piezo, whose spatial resolution is less than $0.1 \mathrm{~nm}$. A laser beam is shone on the back of the cantilever and the reflected laser beam is detected by a 4-quadrant photodiode, which detects normal and lateral deflections (in volts) of the cantilever when the tip is bent by the forces. An electronic feedback loop is connected between the photodiode and the piezo in order to control the expansion and contraction of the piezo to the desired force. The recorded photodiode voltage can be converted to force once the spring constant, $k_{\mathrm{s}}$, of the cantilever and the voltage-to- $z$-distance of the photodiode are known. The force resolution is limited by the resolution of the photodiode and the deflection of the cantilever at thermal noise level $\left(z_{\text {rms }}\right)$, which can be calculated based on equipartition theorem following this equation: ${ }^{13}$

$$
z_{\mathrm{rms}}=\sqrt{\frac{k_{\mathrm{B}} T}{k_{\mathrm{s}}}}
$$


where $k_{\mathrm{B}}$ is the Boltzmann's constant, and $T$ is absolute temperature.

The spring constant of the cantilever can be determined using different methods. For example, the method that calculates the spring constant from the cantilever's geometry and Young's modulus of its material is call Sader's method. ${ }^{14}$ In this thesis, the spring constants were measured alternatively by the thermal method, where the cantilevers are left to be freely oscillated in experimental environments (air or liquids) and the power spectral density (PSD) was recorded. ${ }^{13}$ This results in the PSD plot as a function of frequency, where the resonance peaks of the cantilever are fitted with the simple harmonic model and the spring constant can be determined.

The geometry of the AFM tip on the flat substrate can be regarded as a sphere on flat surface as shown in Figure 2.4a. This geometry has the same force law compared with the crossed-cylinder geometry shown in Figure 2.4b (with same radius of curvatures) usually used in the surface force apparatus (SFA), as calculated using the Derjaguin approximation. ${ }^{12}$ As a result, experimental data from these two techniques are often compared. However, the absolute force cannot be directly compared because the AFM measures the force on a microscopic scale while the SFA performs the measurements between macroscopic surfaces, which have an ability to measure forces in different range. The comparable quantity is the force normalized by the radius of curvature of the tip or the surfaces, $F / R$. The tip radius of the AFM is typically in the order of $10^{-9} \mathrm{~m}$ while the surface radius of curvature in case of the SFA is usually in the range of $10^{-3}$ to $10^{-2} \mathrm{~m}$. This leads to the difference in the force resolution, where the SFA can measure the same force at longer distance range compared with the AFM. ${ }^{12}$ However, the resolution of the AFM can be increased by enlarging a tip radius, usually by replacing the atomic scale tip with the micron size colloid particle, and the technique is called colloidal probe microscopy $(\mathrm{CPM}) .{ }^{15,16}$ We used this technique to measure the long-range force in the liquid in chapter 6 .

Force-distance spectroscopy can be carried out in both static or dynamic modes with the AFM. In static mode, the tip is just simply moved toward and away from the surface and the forces are measured as a function of distance. Dynamic mode work in similar way, with additional small oscillation imposed on the cantilever with the driven frequency close to the 
(a)

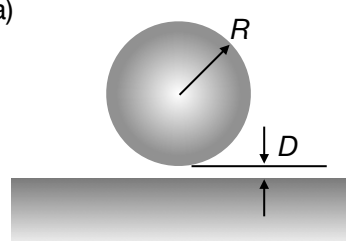

$F=2 \pi R W_{\text {flat }}$ (b)

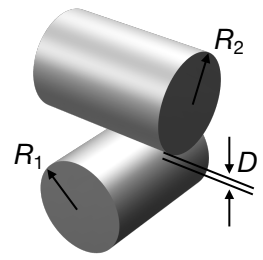

$F=2 \pi \sqrt{R_{1} R_{2}} W_{\text {flat }}$

Figure 2.4: Geometries of bodies with surfaces $D$ apart $(D \ll R)$. A sphere on flat surface geometry is applied for an AFM tip, which is mathematically equivalent to a crossed-cylinder geometry of the SFA when $R_{1}=R_{2}$. Equations show force laws between two surfaces calculated from Derjaguin approximation, where $W_{\text {flat }}$ represents an interaction potential between two flat surfaces.

resonance frequency of the cantilever. This allows more information of the amplitude and phase to be measured to uncouple the conservative and dissipative interactions between tip and sample. ${ }^{17-20}$ More detailed analysis of the dynamic mode force-distance spectroscopy are presented in chapter 4.

Measuring forces in liquids is challenging because the liquid viscosity leads to hydrodynamic resistance. It can have a huge effect on resisting the cantilever's motion and, of course, the measured force curves, especially in highly viscous liquids like ILs (ILs are typically 20 to 80 times more viscous than water). ${ }^{21-25}$ The effects appear on the force-distance curves when recorded at different tip approach speeds. From our experience with the ILs studied in this thesis, an appropriate approach speed between about 1 to $5 \mathrm{~nm} / \mathrm{s}$ is suggested in typical ILs. We note that it is not necessary that the lower approach speed will give more reproducible force-distance curves since the reproducibility also depends on the stiffness of the cantilever and the physical strength of near-wall layers. A relatively soft cantilever can result in lower reproducibility in some cases. This observation is supported by Figure $2.5 \mathrm{a}$ and $2.5 \mathrm{~b}$, where the force curves measured at $5 \mathrm{~nm} / \mathrm{s}$ seem to have slightly better spatial resolution than those measured at $1 \mathrm{~nm} / \mathrm{s}$. We observed in ILs that too fast an approach speed can affect spatial resolution 

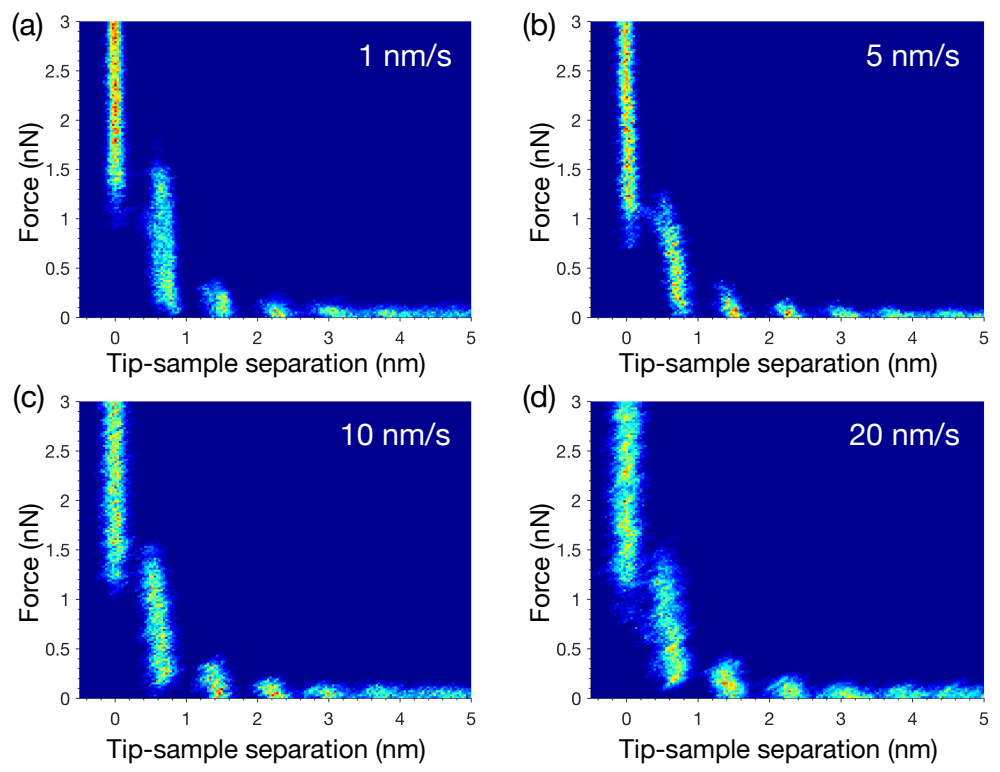

Figure 2.5: (a-d) Force-distance curves recorded at different tip approach speeds from $1-20 \mathrm{~nm} / \mathrm{s}$ in an IL $[\mathrm{Emim}]^{+}\left[\mathrm{NTf}_{2}\right]^{-}$at room temperature. There is no clear effect at the speed lower than $10 \mathrm{~nm} / \mathrm{s}$ but the measurement starts to lose the resolution at $10 \mathrm{~nm} / \mathrm{s}$. The force curves severely loose their resolution at $20 \mathrm{~nm} / \mathrm{s}$.

as can be seen in Figure 2.5c and 2.5d.

A more serious issue appears in the dynamic mode, where the resonance frequency is a key parameter to be determined and tuned. When sample liquids are added to the setup, all parts of the experimental cell including the cantilever and piezo, are immersed in the liquids. As a result, all flexible components are coupled when oscillated, causing the effect call forest of peaks on the PSD plot such that determining the resonance peaks becomes tricky. ${ }^{26,27}$ Instead of using a piezo to drive the cantilever, we used a pulse-laser to drive the oscillations. In this technology, a high energy laser is shone on the back of cantilever, causing local thermal expansion, that can result in the bending of the cantilever. This prevents the surrounding liquid environment to be coupled with the cantilever's oscillation, resulting in very clean resonance peaks in the liquid.

The resonance frequency of a cantilever is typically reduced to about 0.2 

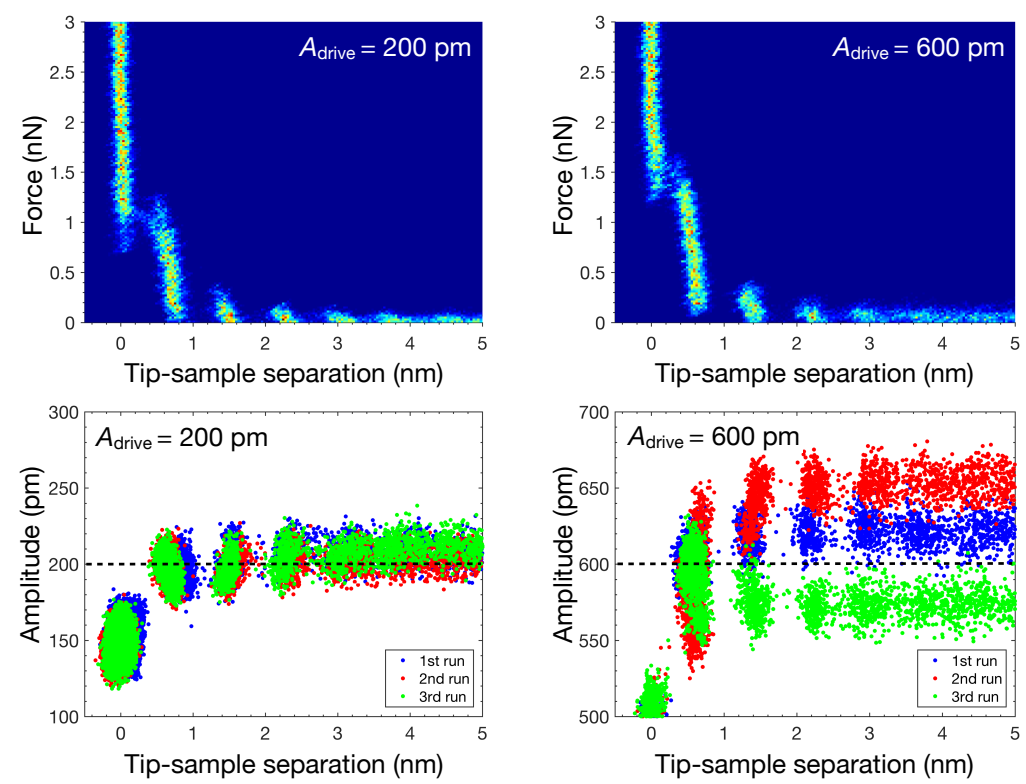

Figure 2.6: Force and cantilever amplitude plotted as a function of tip-sample separation. The results were measured as different drive amplitudes of $200 \mathrm{pm}$ (left) and $600 \mathrm{pm}$ (right). The drive amplitude does not have clear effect on the force-distance curves (top) but have a significant consistency impact on the recorded cantilever amplitude (bottom). Different colors on amplitude plots show different data sets from three consecutive measurements. It is clearly seen that a drive amplitude of $600 \mathrm{pm}$ can lead to inconsistent far field amplitude.

to 0.3 of the resonance frequency in air due to the hydrodynamic resistance of the liquids. ${ }^{21-25}$ This effect depends on both the density and the viscosity of the liquid. The consequence is the merging of the resonance peaks at low mode numbers with the background noise as the peaks shift to lower frequencies. As a result, the spring constant, in some cases, has to be determined in air prior to adding liquids to the cell. Using a higher vibrational mode is possible but has more risk of inaccurate information, especially in measuring the normal component of the forces, as the cantilever will oscillate with a more complicated shape. The effect of the mode number to the measured force is shown in chapter 4.

We also observed the effect of the driving amplitude on the consistency of the acquired data. It is shown clearly in Figure 2.6 (bottom) that us- 
ing large driving amplitude has a significant effect on the measured farfield background amplitude. One may expect a larger driving amplitude to disrupt the near-wall layers of the ILs and affect the measured forcedistance curves. However, we do not observe a clear difference on the force-distance curves recored with different driving amplitudes between $200 \mathrm{pm}$ and $600 \mathrm{pm}$ (Figure 2.6 (top)). Using smaller driving amplitude than $200 \mathrm{pm}$ will result in unmeasurable amplitude and phase responses resulting from too small a perturbation, which is limited by the thermal noise background. Therefore, we always apply driving amplitude of $200 \mathrm{pm}$ in typical ILs for our measurements. 


\section{References}

[1] Bard, A. J. and Faulkner, L. R. (2001) Electrochemical Methods: Fundamentals and Applications, John Wiley \& Son, 2 edition.

[2] Ohno, H. (2005) Electrochemical Aspects of Ionic Liquids, John Wiley \& Sons, .

[3] Barrosse-Antle, L., Bond, A., Compton, R., O’Mahony, A., Rogers, E., and Silvester, D. (2010) Voltammetry in Room Temperature Ionic Liquids: Comparisons and Contrasts with Conventional Electrochemical Solvents. Chem. Asian J., 5(2), 202-230.

[4] Islam, M. M., Alam, M. T., and Ohsaka, T. (2008) Electrical Double-layer Structure in Ionic Liquids: A Corroboration of the Theoretical Model by Experimental Results. J. Phys. Chem. C, 112(42), 16568-16574.

[5] Islam, M. M., Alam, M. T., Okajima, T., and Ohsaka, T. (2009) Electrical Double Layer Structure in Ionic Liquids: An Understanding of the Unusual Capacitance-potential Curve at a Nonmetallic Electrode. J. Phys. Chem. C, 113(9), 3386-3389.

[6] Roling, B., Drüschler, M., and Huber, B. (2012) Slow and Fast Capacitive Process Taking Place at the Ionic Liquid/Electrode Interface. Faraday Discuss., 154, 303-311.

[7] Atkin, R., Borisenko, N., Drüschler, M., El Abedin, S. Z., Endres, F., Hayes, R., Huber, B., and Roling, B. (2011) An in situ STM/AFM and Impedance Spectroscopy Study of the Extremely Pure 1-butyl-1-methylpyrrolidinium tris (pentafluoroethyl) trifluorophosphate/Au (111) Interface: Potential Dependent Solvation Layers and the Herringbone Reconstruction. Phys. Chem. Chem. Phys., 13(15), 6849-6857.

[8] Atkin, R., Borisenko, N., Drüschler, M., Endres, F., Hayes, R., Huber, B., and Roling, B. (2014) Structure and Dynamics of the Interfacial Layer between Ionic Liquids and Electrode Materials. J. Mol. Liq., 192, 44-54.

[9] Drüschler, M., Huber, B., and Roling, B. (2011) On Capacitive Processes at the Interface between 1-Ethyl-3-methylimidazolium tris (pentafluoroethyl) trifluorophosphate and Au (111). J. Phys. Chem. C, 115(14), 6802-6808.

[10] Fedorov, M. V. and Kornyshev, A. A. (2014) Ionic Liquids at Electrified Interfaces. Chem. Rev., 114(5), 2978-3036.

[11] O'Mahony, A. M., Silvester, D. S., Aldous, L., Hardacre, C., and Compton, R. G. (2008) Effect of Water on the Electrochemical Window and Potential Limits of Room-temperature Ionic Liquids. J. Chem. Eng. Data, 53(12), $2884-2891$.

[12] Israelachvili, J. N. (2011) Intermolecular and Surface Forces, Academic press, 
[13] Butt, H.-J. and Jaschke, M. (1995) Calculation of Thermal Noise in Atomic Force Microscopy. Nanotechnology, 6(1), 1.

[14] Sader, J. E., Chon, J. W., and Mulvaney, P. (1999) Calibration of Rectangular Atomic Force Microscope Cantilevers. Rev. Sci. Instrum., 70(10), 3967-3969.

[15] Ducker, W. A., Senden, T. J., and Pashley, R. M. (1991) Direct Measurement of Colloidal Forces Using an Atomic Force Microscope. Nature, 353(6341), 239-241.

[16] Ducker, W. A., Senden, T. J., and Pashley, R. M. (1992) Measurement of Forces in Liquids Using a Force Microscope. Langmuir, 8(7), 1831-1836.

[17] de Beer, S., van den Ende, D., and Mugele, F. (2008) Atomic Force Microscopy Cantilever Dynamics in Liquid in the Presence of Tip Sample Interaction. Appl. Phys. Lett., 93(25), 253106.

[18] de Beer, S., Van den Ende, D., and Mugele, F. (2010) Dissipation and Oscillatory Solvation Forces in Confined Liquids Studied by Small-Amplitude Atomic Force Spectroscopy. Nanotechnology, 21(32), 325703.

[19] Seddon, J. R. (2014) Conservative and Dissipative Interactions of Ionic Liquids in Nanoconfinement. J. Phys. Chem. C, 118(38), 22197-22201.

[20] Jitvisate, M. and Seddon, J. R. (2016) Local Structure and Flow Properties of Ionic Liquids on Charged and Inert Substrates. J. Phys. Chem. C, 120(9), 4860-4865.

[21] Sader, J. E. (1998) Frequency Response of Cantilever Beams Immersed in Viscous Fluids with Applications to the Atomic Force Microscope. J. Appl. Phys., 84(1), 64-76.

[22] Green, C. P. and Sader, J. E. (2005) Small Amplitude Oscillations of a Thin Beam Immersed in a Viscous Fluid near a Solid Surface. Phys. Fluids, 17(7), 073102.

[23] Green, C. P. and Sader, J. E. (2005) Frequency Response of Cantilever Beams Immersed in Viscous Fluids near a Solid Surface with Applications to the Atomic Force Microscope. J. Appl. Phys., 98(11), 114913.

[24] Maali, A., Hurth, C., Boisgard, R., Jai, C., Cohen-Bouhacina, T., and Aimé, J.-P. (2005) Hydrodynamics of Oscillating Atomic Force Microscopy Cantilevers in Viscous Fluids. J. Appl. Phys., 97(7), 074907.

[25] Vinogradova, O. I., Butt, H.-J., Yakubov, G. E., and Feuillebois, F. (2001) Dynamic Effects on Force Measurements. I. Viscous Drag on the Atomic Force Microscope Cantilever. Rev. Sci. Instrum., 72(5), 2330-2339.

[26] Schäffer, T., Cleveland, J., Ohnesorge, F., Walters, D., and Hansma, P. (1996) Studies of Vibrating Atomic Force Microscope Cantilevers in Liquid. 
J. Appl. Phys., 80(7), 3622-3627.

[27] Carrasco, C., Ares, P., de Pablo, P., and Gómez-Herrero, J. (2008) Cutting Down the Forest of Peaks in Acoustic Dynamic Atomic Force Microscopy in Liquid. Rev. Sci. Instrum., 79(12), 126106. 



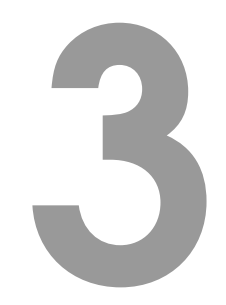

\section{Direct Measurement of the} Differential Capacitance of Solvent-Free and Dilute Ionic Liquids
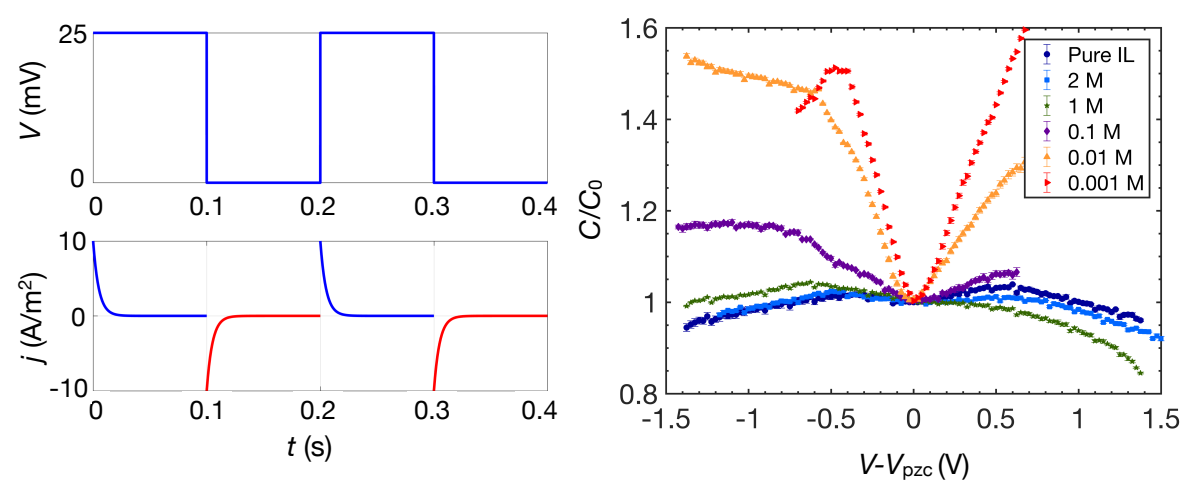

Differential capacitance is a key quantity that bridges the prediction from theoretical EDL model to actual behaviors. Measuring differential capacitance in ILs is of great challenging due to material complexity that breaks the assumptions in conventional measurement techniques. Existing data in literature are highly inconsistent and are not well-fitted with the original mean-field model for ILs. This chapter presents the measurement of the differential capacitance of ILs, in both pure and dilute forms, using chronoamperometric technique. The results are fitted with the extended mean-field model and show good quantitative agreement, which will have implications on the understanding of ILs at electrified electrodes and theoretical model development.

${ }^{*}$ The contents of this chapter have been published as: M. Jitvisate et al., "Direct Measurement of the Differential Capacitance of Solvent-Free and Dilute Ionic Liquids," J. Phys. Chem. Lett., 9, 126-131 (2018) 


\subsection{Introduction}

Room-temperature ionic liquids (ILs) have drawn huge attention recently due to their significant promise for many applications, such as electrochemical energy-storage devices, electrically tunable lubrication, hightemperature/vacuum material synthesis, and novel self-assembly media. ${ }^{1-4}$ The reason for excitement stems from their material properties, which are of technological interest. For example, ILs have wide electrochemical window (ECW), high ionic strength, high temperature stability, and low vapor pressure. ${ }^{2,5,6}$ The development of ionic-liquid-based energy devices, such as supercapacitors, requires an insightful understanding of the electrical double-layer (EDL) charging mechanism, for which the traditional (GouyChapman) model appears inappropriate. ${ }^{6-14}$ An important quantity related to EDL charging is the differential capacitance, which represents the variation of the surface charge with respect to the change of surface potential. It is one of the key properties intensively studied in the field of ILs, from theoretical, numerical, and experimental aspects. ${ }^{6-32}$ However, experimentally measuring the differential capacitance of ILs has proven to be a great challenge. ${ }^{6,8-12,19-26}$

Previous studies have focused on two techniques - cyclic voltammetry (CV) and electrochemical impedance spectroscopy (EIS) - showing that the liquids tend to exhibit complex responses due to their large, bulky molecular dimensions. However, the data from these experiments are inconsistent and often irreproducible. ${ }^{6,8-12,19-26,30-32}$ In both cases, the techniques themselves are most likely the causes of discrepancies, for example, the assumption of negligible time dependence of capacitances in $\mathrm{CV}$ and the validity of the equivalent circuit model and relevant time scale in EIS. ${ }^{10,11,28,29,33-37}$ Many EIS works have even adopted a single-frequency method, even though it is known that a full-frequency spectrum should be recorded. . $^{8,19-21,23-25}$ In short, neither of these techniques provides a direct measurement of the differential capacitance of the ILs, and this disagreement has resulted in inconsistent and confusing messages about the true nature of ILs at electrified electrodes, holding back theoretical advancement.

In this study, we measure the differential capacitance of ILs using the 
chronoamperometry (CA) technique, which allows direct charge measurement and direct calculation of differential capacitance. To the best of our knowledge, this is the first application to ILs. This technique thus gives us experimental access to the differential capacitance without the need for unsupported or questionable assumptions. We find good agreement with the mean-field model of Goodwin-Kornyshev, ${ }^{13,14}$ which is based on that of Kornyshev ${ }^{7}$ extended by adding short-range ion correlations. Our results include a transition of capacitance curves from camel shape to U-like shape as the liquid is diluted, which is important for understanding the nature of ILs and developing real applications, where the capacitance and other quantities, such as, electrode potential, viscosity, liquid volume, and so on, need to be optimized.

\subsection{Experimental methods}

The ILs 1-ethyl-3-methylimidazolium tetrafluoroborate $\left([\mathrm{Emim}]^{+}\left[\mathrm{BF}_{4}\right]^{-}\right)$ (Sigma-Aldrich), 1-ethyl-3-methylimidazolium bis(trifluoromethylsulfonyl) imide $\quad\left([\mathrm{Emim}]^{+}\left[\mathrm{NTf}_{2}\right]^{-}\right)$1-ethyl-3-methylimidazolium dicyanamide $\left([\text { Emim }]^{+}[\mathrm{DCA}]^{-}\right), \quad$ and 1-buthyl-1-methylpyrrolidinium bis (trifluoromethylsulfonyl)imide $\left(\left[\mathrm{C}_{4} \mathrm{mpyr}\right]^{+}\left[\mathrm{NTf}_{2}\right]^{-}\right)$(Merck Millipore) as well as the solvent dimethyl sulfoxide (Sigma- Aldrich) were purchased with purity of $>99 \%$. They were further purified at $150{ }^{\circ} \mathrm{C}$ under vacuum for $>12 \mathrm{~h}$. In this study, the measurements were done using a standard three-electrode system. A $2 \mathrm{~mm}$ diameter polycrystalline platinum working electrode (BASi) was cleaned by polishing on a polishing cloth (BUEHLER micro cloth) with $0.3 \mu \mathrm{m}$ alumina paste (BUEHLER Alpha micropolish II), rinsed with Milli-Q water for several minutes, and dried with nitrogen gas. The coiled platinum pseudoreference electrode and counter electrode (>99.99\%, Sigma-Aldrich), with surface areas greater than the working electrode, were cleaned by flaming in a hot butane flame until glowing red and were immediately placed in cool Milli-Q water, followed by drying with nitrogen gas. All electrodes and glass containers were cleaned before each single measurement. The volume of the test liquid in each measurement was $500 \mu \mathrm{L}$. 
$\mathrm{CV}$ and $\mathrm{CA}$ were performed using a computer-controlled potentiostat (CH-Instrument, CHI832B). Cyclic voltammograms were recorded separately before the $\mathrm{CA}$ measurements for electrochemical window evaluation (Figure A3.1). The open-circuit potential (OCP) was measured and found to have values close to $0 \mathrm{~V}$ for all pure ILs but shifted when solvent was added. These OCPs were chosen to be the initial potentials for CA measurements, as suggested in the literature for high reproducibility. ${ }^{8}$ The initial potential can lead to a hysteresis effect and irreproducible results, as shown in Figure A3.2.

We applied a step-function potential of $25 \mathrm{mV} / \mathrm{step}\left(\sim k_{\mathrm{B}} T\right)$ to a polycrystalline platinum electrode and measured the current density as a function of time. For each potential step, the voltage was stepped back and forth 10 times between lower and higher potentials to minimize hysteresis effects. $^{38}$ The time duration for each step was $100 \mathrm{~ms}$, which was found to be long enough for the current to reach its steady state (Figure A3.3). The potential scan was terminated when it reached the ECW limits. Then, all of the electrodes and the container were cleaned and fresh liquid was replaced for the new measurement in the opposite scan direction. The current was measured with the sampling rate of $0.05 \mathrm{~ms}$ and the sensitivity of $10^{-5} \mathrm{~A} / \mathrm{V}$. All chemical preparation and measurements were carried out at $25^{\circ} \mathrm{C}$ in an MBruan LABmaster glove box filled with a nitrogen atmosphere (water and oxygen $<0.1 \mathrm{ppm}$ ). In total, more than 1000 data set were recorded for the present work.

\subsection{Results and discussion}

We first present the measurement of differential capacitance in pure ILs $[\text { Emim }]^{+}\left[\mathrm{BF}_{4}\right]^{-}, \quad[\mathrm{Emim}]^{+}[\mathrm{DCA}]^{-}, \quad[\text { Emim }]^{+}\left[\mathrm{NTf}_{2}\right]^{-}$, and $\left[\mathrm{C}_{4} \mathrm{mpyr}\right]^{+}\left[\mathrm{NTf}_{2}\right]^{-}$, which will allow comparison between our results and those reported in the literature and the validation of our method and data with the theoretical model of Goodwin-Kornyshev. ${ }^{13,14}$ An example of the potential waveform and the corresponding measured current is shown in Figure 3.1a. The current shows excellent agreement when fitted with the exponential equation, $j=a \exp (-t / \tau)$, where $j$ is the current density and 
(a)
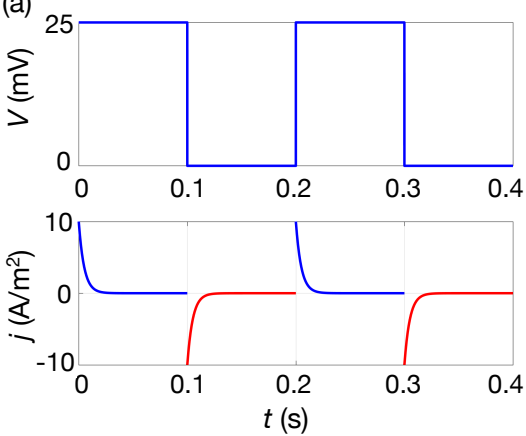

(b)

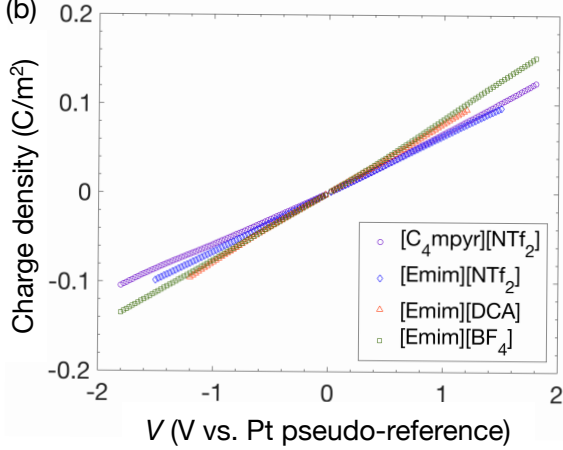

Figure 3.1: (a) Example of step-function potential and corresponding measured charging current. (b) Potential-dependent charge density of pure ILs $\left[\mathrm{C}_{4} \mathrm{mpyr}\right]^{+}\left[\mathrm{NTf}_{2}\right]^{-}, \quad[\mathrm{Emim}]^{+}\left[\mathrm{NTf}_{2}\right]^{-}, \quad[\mathrm{Emim}]^{+}\left[\mathrm{BF}_{4}\right]^{-}$, and $[\text { Emim }]^{+}[\mathrm{DCA}]^{-}$determined from the charging current.

$t$ is time (Figure A3.3). The fitting parameters $a$ and $\tau$ are used for the calculation of the charge density. It is clear that the current reaches its equilibrium within the measured time duration, with the exponential fit indicating that the charging mechanism obeys a normal diffusive charging process. $^{39}$ In principle, $\tau$ represents the characteristic charging time constant, which is defined as $\tau=R C$, where $R$ is the resistance of the bulk liquid and $C$ is the double-layer capacitance. We find in our study that $\tau$ has an average value between 0.1 and $0.5 \mathrm{~ms}$ (Table A3.1), which is in the same range of the fast time scale measured with EIS, representing the diffusive charging mechanism. ${ }^{12}$ The measured time scales have a trend corresponding to the conductivity of the ILs; the higher conductivity liquids have a shorter time constant, as expected. ${ }^{40}$ We do not observe the slow time scale $(\mathcal{O}$ (seconds) ) of the EIS experiments, which is likely caused by the roughness of our (polycrystalline) electrode surface. This slow process is interpreted as originating from ion reorientation, which occurs at the level of the compact ion layers on the electrode rather than the diffuse layer; therefore, it is more pronounced on smooth/crystalline electrodes and is most likely suppressed on polycrystalline platinum. ${ }^{12,31}$

The potential-dependent surface charge densities, $\sigma$, of the studied ILs on platinum (Figure 3.1b) are the results of the cumulative summation of the charge density at each potential step, that is, $\sigma=\sum_{i} a_{i} \tau_{i}(1-$ 
$\left.\exp \left(-t^{\prime} / \tau_{i}\right)\right) \approx \sum_{i} a_{i} \tau_{i}$, where $a_{i}$ and $\tau_{i}$ are obtained from $\int_{0}^{t^{\prime}} j \mathrm{~d} t\left(t^{\prime}=\right.$ $100 \mathrm{~ms}$ ) of the $i$ th potential step. The differential capacitance per unit area, $C$, then can be calculated directly by differentiating the surface charge density with respect to the electrode potential, following the definition ${ }^{39}$

$$
C=\left(\frac{\partial \sigma}{\partial V}\right)_{T, \mu}
$$

where $V$ is the electrode potential, $T$ is the temperature, and $\mu$ is the chemical potential.

The resulting capacitance curves are then fitted with the mean-field model of Goodwin-Kornyshev, where the short-range ion correlations are taken into account, which can be written as

$$
C=\tilde{C}_{0} \frac{\cosh \left(\alpha u_{0} / 2\right)}{1+2 \gamma \sinh ^{2}\left(\alpha u_{0} / 2\right)} \sqrt{\frac{2 \gamma \sinh ^{2}\left(\alpha u_{0} / 2\right)}{\ln \left[1+2 \gamma \sinh ^{2}\left(\alpha u_{0} / 2\right)\right]}}
$$

where $\tilde{C}_{0}$ is a rescaled Debye capacitance, $\alpha$ is a rescaled parameter accounting for ion correlations, having values $<1$ ( $\alpha=1$ recovers the case of zero short-range ion correlations), $u_{0}=e V / k_{\mathrm{B}} T$, and $\gamma$ is an ion fraction defined as the ratio of the total number of ions to the total number of sites available for them. The reader can find the detailed derivation of the model in the original paper of Goodwin et al. ${ }^{13,14}$ In the asymmetric case where the cation and anion are not of equivalent geometry, $\gamma$ is defined as follows ${ }^{7,13}$

$$
\gamma=\gamma_{-}+\frac{\gamma_{+}-\gamma_{-}}{1+\exp \left(\alpha u_{0} / 2\right)}
$$

where $\gamma_{+}$and $\gamma_{-}$are the ion fraction for cations and anions, respectively.

The capacitances of the ILs $\left[\mathrm{C}_{4} \mathrm{mpyr}\right]^{+}\left[\mathrm{NTf}_{2}\right]^{-}, \quad[\mathrm{Emim}]^{+}\left[\mathrm{NTf}_{2}\right]^{-}$, $[\text { Emim }]^{+}\left[\mathrm{BF}_{4}\right]^{-}$, and $[\text {Emim }]^{+}[\mathrm{DCA}]^{-}$are plotted in Figure 3.2 , together with the fits obtained from eq 3.2. Clearly, we see the capacitance curves reveal the predicted camel-shape behavior and the model fits our experimental data well.

The rescaled parameter, $\alpha$, in pure ILs is found to have the value of $\sim 0.06$, which is far from 1 expected for the case of no ion-ion correlation, indicating that ion-ion repulsion dominates ion-pairing in ILs. However, we 

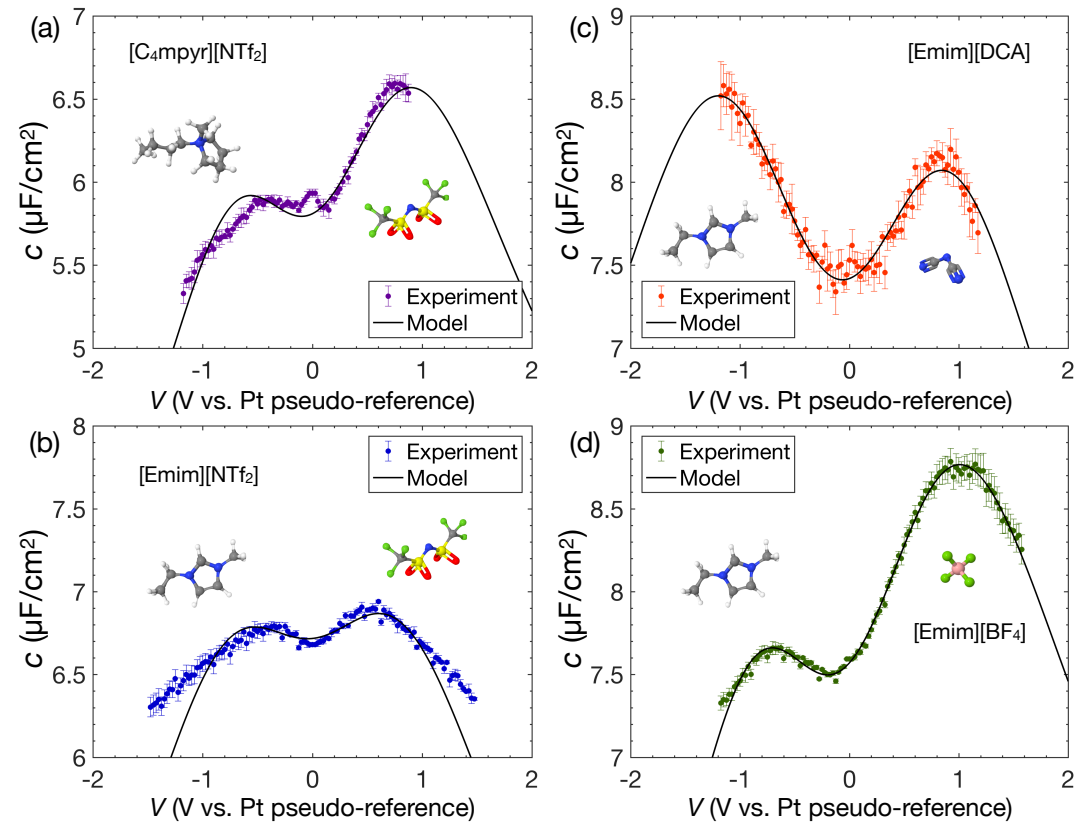

Figure 3.2: (a-d) Differential capacitance of pure ILs $\left[\mathrm{C}_{4} \mathrm{mpyr}\right]^{+}\left[\mathrm{NTf}_{2}\right]^{-}$, $[\text { Emim }]^{+}\left[\mathrm{NTf}_{2}\right]^{-},[\mathrm{Emim}]^{+}[\mathrm{DCA}]^{-}$, and $[\mathrm{Emim}]^{+}\left[\mathrm{BF}_{4}\right]^{-}$, respectively, with the solid lines representing the fits from the extended mean-field model.

cannot compare this result with other measurements because, to the best of our knowledge, this is the first attempt to extract this model parameter from experimental data. The ion fractions $\left(\gamma_{+}, \gamma_{-}\right)$for an asymmetric ILs have been obtained from the fit, with values in the typically predicted range of 0.4 to 0.1 (Table A3.2). These double-humped capacitance curves, which are different from the classical Gouy-Chapman theory, have been previously measured in the literature with the EIS technique but are often hidden in a "forest of peaks" and rarely fit the theory well.9,12,16,25,31 The qualitative agreement of our experimental data with the theoretical model and the quantitative agreement with many experimental observations from the EIS technique, supports the validity of our approach.

We note that the model shows better agreement in the liquids with molecules of smaller size and more simple shape (Figure 3.2c,d) than in the liquids having larger and more complex molecular geometries (Figure $3.2 \mathrm{a}, \mathrm{b})$. In the particular case of $[\mathrm{Emim}]^{+}\left[\mathrm{BF}_{4}\right]^{-}$, which has simplest molecular shapes among the liquids studied, the anions are spherical and 
substantially smaller than the cations, leading to a higher and steeper capacitance peak at positive polarization than at negative polarization. This behavior is described as a higher local ion concentration in the anion-rich region due to smaller anion sizes. ${ }^{7,16,18}$ However, this semiempirical explanation fails for the other liquids whose molecules are much less spherical (an assumption of the model)..$^{13,14}$ It is clear that the mean-field theory is limited here insofar as it does not take into account specific molecular geometries. ${ }^{7,13,14}$

The Debye capacitance $\left(C_{0}\right)$, as described by the mean-field model, is related to the electrostatic screening length, a characteristic length scale defined in the classical theory as the Debye length, $\lambda_{\mathrm{D}}$, by the relation $C_{0}=\epsilon \epsilon_{0} / \lambda_{\mathrm{D}}$, where $\epsilon$ is the dielectric constant of the medium and $\epsilon_{0}$ is the permittivity of free space. By using the lowfrequency bulk dielectric constant of the ILs (Table A3.1) and the capacitance values at the PZC $\left(C_{\mathrm{PZC}}\right)$ from our measurements of 5.8, 6.6, 7.5 , and $7.5 \mu \mathrm{F} / \mathrm{cm}^{2}$, we find screening lengths of about $1.9,1.6,1.3$, and $1.5 \mathrm{~nm}$ for $\left[\mathrm{C}_{4} \mathrm{mpyr}\right]^{+}\left[\mathrm{NTf}_{2}\right]^{-},[\mathrm{Emim}]^{+}\left[\mathrm{NTf}_{2}\right]^{-},[\mathrm{Emim}]^{+}[\mathrm{DCA}]^{-}$and $[\text { Emim }]^{+}\left[\mathrm{BF}_{4}\right]^{-}$, respectively. These screening lengths are $\sim 30$ times larger than those calculated using classical definition of the Debye length, and are about 10 times larger than the rescaled screening length, $\tilde{\lambda}_{\mathrm{D}}=\lambda_{\mathrm{D}} / \sqrt{\alpha}$, calculated using the rescaled factor $(\alpha)$ obtained from the experimental data (Table A3.2, A3.3). Long screening lengths in pure ILs have been observed in force measurements and are explained as being caused by a low concentration of effective free ions in the liquids. ${ }^{41-44}$ However, the extent of ion pairing and dissociation is currently still a highly debated topic, and the final conclusion is not yet clear. This, in turn, affects physical interpretation of the fitting parameter, $\alpha$, whose value is directly related to ion correlations. ${ }^{13,14}$ Therefore, this interpretation may not be the case for our findings.

It must also be emphasized here that the measured capacitance is technically the total capacitance, that is, the combination of the Stern/compact layer and diffuse layer capacitances. As a result, the values of the measured capacitance at the PZC, $C_{\mathrm{PZC}}$, cannot be compared directly to the Debye capacitance, $C_{0}$, of the mean-field model without the knowledge of 

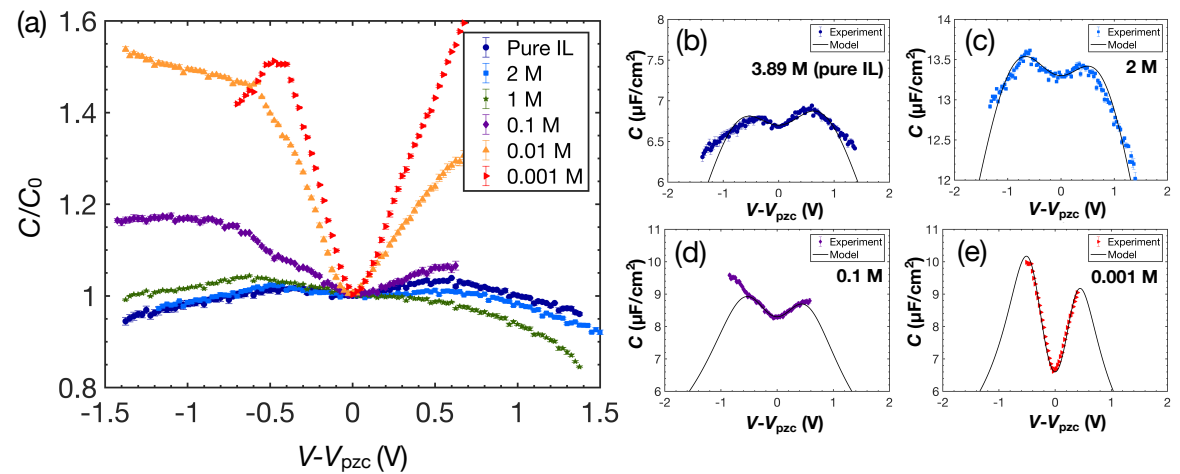

Figure 3.3: (a) Differential capacitance of $[\text { Emim }]^{+}\left[\mathrm{NTf}_{2}\right]^{-} / \mathrm{DMSO}$ mixtures at different concentrations showing a crossover from camel-shape curves in dense concentrations to U-like curves in dilute regime. (b-e) Differential capacitance plotted together with the fits from the mean-field model at varied concentrations.

the compact layer capacitance. It could be that the capacitance measured in pure ILs has a more significant contribution from the Stern capacitance rather than the Debye capacitance. The formation of liquid layers next to the charged surfaces is supported by X-ray reflectivity, ${ }^{45}$ atomic force microscopy (AFM) ${ }^{46}$ and surface force apparatus (SFA) experiments,${ }^{47}$ but the layer-by-layer co/counterion densities are unknown.

Now that we have validated our experimental approach, we move on to study the differential capacitance in dilute IL by adding the solvent dimethyl sulfoxide (DMSO) to the IL $[\text { Emim }]^{+}\left[\mathrm{NTf}_{2}\right]^{-}$, which forms miscible mixtures in a full range of the studied concentrations. The same CA procedure is applied for measuring the differential capacitance, and the results are shown in Figure 3.3. By varying the composition of the mixtures, we observe a clear transition from the pure to dilute regimes, as can be seen by a crossover of the capacitance curves from a camel shape to a Ulike shape (Figure 3.3a), as predicted by the mean-field models. ${ }^{7,13,14}$ This crossover occurs between the concentration of 1 and $0.01 \mathrm{M}$, where the slope of the capacitance is steeper in the lower concentration mixtures, indicating a classical dilute electrolyte character. The mean-field model fitted to the experimental data shows good agreement (Figure 3.3b-e), especially within $\pm(0.5$ to 1$) \mathrm{V}$ potential window from the PZC (Figure A3.4), indicating the validity of the model and the importance of the short-range interaction ef- 
fect added to it. The trend of the ion fraction $(\gamma)$ values is found to decrease (from $\sim 0.4$ to $\sim 0.1$ ) when more solvent is added to the IL (Table A3.4), resulting from the decrease in ion concentration. The parameter $\alpha$ is found to increase as the ion concentration decreases, as expected when the ion correlations are diminished by dilution.

The capacitance at the PZC $\left(C_{\mathrm{PZC}}\right)$ is found to change non-monotonically with concentration (Figure A3.5a). However, calculating $\lambda_{\mathrm{D}}$ from $C_{\mathrm{PZC}}$ without knowledge of the compact layer capacitance leads to discrepancies between $\lambda_{\mathrm{D}}$ measured here and the screening length from surface force measurement (Figure A3.5b).

\subsection{Conclusions}

In conclusion, we measured the differential capacitance of solvent-free and dilute ILs using the CA technique and we find quantitative agreement between our direct capacitance measurement and the extended mean-field model of Goodwin-Kornyshev and qualitative agreement with several of the EIS experiments. Our measurements are a good indication of the validity of the model. The capacitances measured in the pure ILs in our study show camel-shape curves, as predicted by the models for moderate-packing ILs, and the capacitances at the PZC are likely to relate to the compact layer capacitance rather than the diffuse layer capacitance.

Furthermore, crossover from camel to U-like capacitance curves is observed when solvent is added to the ILs. A nonmonotonic dependence of the capacitance at the PZC with the concentration is found, similar to another independent study. ${ }^{48}$ However, quantitative conclusion cannot be made based only on the mean-field model due to lack of knowledge of the compact layer capacitance, which requires further theoretical studies or simulations.

Our observations provide important information for a wide range of uses, from theoretical model improvement to practical/technical implementation. In particular, we see relevance in the development of energy-storage device applications, where the energy density and power density have to be optimized. 
The situation is expected to be more complicated in the case of nonmetallic electrodes, such as glassy carbon, graphite, or graphene, where the density of states (DOF) of the electrode material is limited and the electrode capacitance can have a dramatic effect on the measured capacitance, ${ }^{48-51}$ but for metal electrodes, direct application of the Goodwin-Kornyshev analytical model is satisfactory. 


\subsection{Appendix}

\subsubsection{Data analysis}

- The resolution limit of the potentiostat is $1 \mathrm{pA}$.

- The current data were fitted above the resolution using non-linear least square method with an R-square more than 0.98 .

- For each potential, 5 current-time curves were analysed, leading to 5 surface charge-potential and capacitance-potential curves.

- The average capacitances were calculated and plotted as shown in Figure 3.2 and Figure 3.3 in the main text. The errorbars represent the standard deviation.

- The capacitance curves were then fitted with the model eq 3.2 of the main text using non-linear least square method with the R-square more than 0.95 . The fit range varied between $\pm(0.5$ to 1$) \mathrm{V}$ from the PZC depending on each case, e.g., the fit range for $0.001 \mathrm{M}$ liquid was $\pm 0.5 \mathrm{~V}$ while in pure IL was $\pm 1 \mathrm{~V}$

- The fitting parameters are shown in the tables below.

\subsubsection{Supporting tables and figures}

\begin{tabular}{|c|c|c|c|c|}
\hline $\mathrm{ILs}$ & $\epsilon$ & $\sigma(\mathrm{S} / \mathrm{m})$ & $\tau_{\mathrm{p}}(\mathrm{ms})$ & $\tau_{\mathrm{n}}(\mathrm{ms})$ \\
\hline$[\mathrm{Emim}]^{+}[\mathrm{DCA}]^{-}$ & 11 & 2.93 & 0.07 & 0.08 \\
$\left.[\text { Emim }]^{+}[\mathrm{BF}]_{4}\right]^{-}$ & 12.9 & 1.57 & 0.13 & 0.12 \\
{$[\text { Emim }]^{+}\left[\mathrm{NTf}_{2}\right]^{-}$} & 12 & 0.92 & 0.15 & 0.12 \\
{$\left[\mathrm{C}_{4} \mathrm{mpyr}\right]^{+}\left[\mathrm{NTf}_{2}\right]^{-}$} & 12.5 & 0.28 & 0.20 & 0.45 \\
\hline
\end{tabular}

Table A3.1: List of the dielectric constants, conductivities and measured characteristic time constants for all studied ILs. The dielectric constant and conductivity values are measured at $25^{\circ} \mathrm{C}$ and are obtained from literature. ${ }^{44,52-55}$ Note that $\tau_{\mathrm{p}}$ and $\tau_{\mathrm{n}}$ are the characteristic time constants obtained from charging of cations (negative electrode potential) and anions (positive electrode potential), respectively. 


\begin{tabular}{|c|c|c|c|c|c|}
\hline ILs & {$[\mathrm{IL}](\mathrm{M})$} & $\alpha$ & $\gamma_{+}$ & $\gamma_{-}$ & $\gamma\left(u_{0}=0\right)$ \\
\hline$[\mathrm{Emim}]^{+}[\mathrm{DCA}]^{-}$ & 6.25 & 0.0591 & 0.176 & 0.239 & 0.208 \\
$\left.[\mathrm{Emim}]^{+}[\mathrm{BF}]_{4}\right]^{-}$ & 6.49 & 0.0662 & 0.347 & 0.139 & 0.243 \\
{$[\mathrm{Emim}]^{+}\left[\mathrm{NTf}_{2}\right]^{-}$} & 3.96 & 0.0665 & 0.290 & 0.258 & 0.278 \\
{$\left[\mathrm{C}_{4} \mathrm{mpyr}\right]^{+}\left[\mathrm{NTf}_{2}\right]^{-}$} & 3.30 & 0.0650 & 0.411 & 0.146 & 0.279 \\
\hline
\end{tabular}

Table A3.2: List of the fitting parameters obtained from the mean-field model for pure ILs.

\begin{tabular}{|c|c|c|c|c|}
\hline $\mathrm{ILs}$ & $\begin{array}{c}C_{\mathrm{PZC}} \\
\left(\mu \mathrm{F} / \mathrm{cm}^{2}\right)\end{array}$ & $\begin{array}{c}\lambda_{\mathrm{D}} \\
(\mathrm{nm})\end{array}$ & $\begin{array}{c}\lambda_{\mathrm{D}} / \sqrt{\alpha} \\
(\mathrm{nm})\end{array}$ & $\begin{array}{c}\lambda_{\mathrm{D}}^{\exp } \\
(\mathrm{nm})\end{array}$ \\
\hline$[\mathrm{Emim}]^{+}[\mathrm{DCA}]^{-}$ & 7.5 & 0.046 & 0.188 & 1.3 \\
{$[\mathrm{Emim}]^{+}[\mathrm{BF}]^{-}$} & 7.5 & 0.048 & 0.188 & 1.5 \\
{$[\mathrm{Emim}]^{+}\left[\mathrm{NTf}_{2}\right]^{-}$} & 6.6 & 0.060 & 0.232 & 1.6 \\
{$\left[\mathrm{C}_{4} \mathrm{mpyr}\right]^{+}\left[\mathrm{NTf}_{2}\right]^{-}$} & 5.8 & 0.067 & 0.262 & 1.9 \\
\hline
\end{tabular}

Table A3.3: Measured capacitance at the PZC with the calculated classical Debye length $\left(\lambda_{\mathrm{D}}\right)$, the renormalized Debye length, and the screening length calculated from the measured capacitance, in pure ILs.

\begin{tabular}{|c|c|c|c|c|c|c|c|}
\hline $\begin{array}{c}{[\mathrm{IL}]} \\
(\mathrm{M})\end{array}$ & $\alpha$ & $\gamma_{ \pm}$ & $\begin{array}{c}C_{\mathrm{PZC}} \\
\left(\mathrm{\mu F} / \mathrm{cm}^{2}\right)\end{array}$ & $\epsilon$ & $\begin{array}{c}\lambda_{\mathrm{D}} \\
(\mathrm{nm})\end{array}$ & $\begin{array}{c}\lambda_{\mathrm{D}} / \sqrt{\alpha} \\
(\mathrm{nm})\end{array}$ & $\begin{array}{c}\lambda_{\mathrm{D}}^{\exp } \\
(\mathrm{nm})\end{array}$ \\
\hline 3.88 & 0.0665 & 0.4105 & 6.7 & 12 & 0.06 & 0.23 & 1.59 \\
2 & 0.0586 & 0.4431 & 13.3 & 23.5 & 0.118 & 0.49 & 1.56 \\
1 & 0.0650 & 0.4413 & 12.5 & 33.26 & 0.198 & 0.78 & 2.36 \\
0.1 & 0.1069 & 0.3449 & 8.3 & 46.19 & 0.739 & 2.26 & 4.93 \\
0.01 & 0.1458 & 0.1780 & 6.8 & 47.81 & 2.377 & 6.22 & 6.23 \\
0.001 & 0.1911 & 0.1586 & 6.6 & 47.98 & 7.529 & 17.22 & 6.44 \\
\hline
\end{tabular}

Table A3.4: List of the fitting parameters obtained from the model, the measured capacitance at the PZC, dielectric constant of the mixtures (calculated using the effective medium theory), ${ }^{56}$ the calculated classical Debye length, the renormalized Debye length, and the screening length calculated from experimental data, in $[\text { Emim }]^{+}\left[\mathrm{NTf}_{2}\right]^{-} /$DMSO mixtures. 


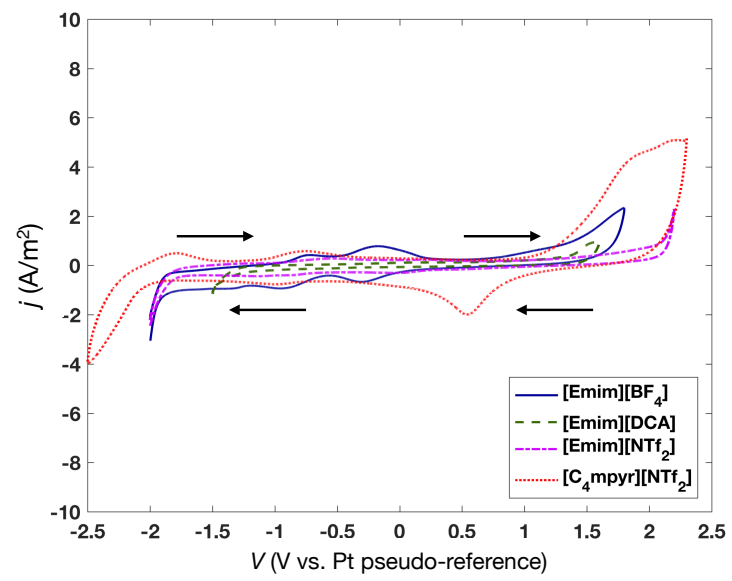

Figure A3.1: Cyclic voltammograms of all ILs used in this study with the arrows representing the scan directions. The ECWs are determined from the rise/fall of the current density at high voltage regime on both polarities. The redox current appears as a result of redox traces created when the electrode potential reached the ECW limits. The cut-off current density for examining the ECW of ILs is accepted to be $10 \mathrm{~A} / \mathrm{m}^{2},{ }^{9}$ which is higher than the current density measured in our CVs.

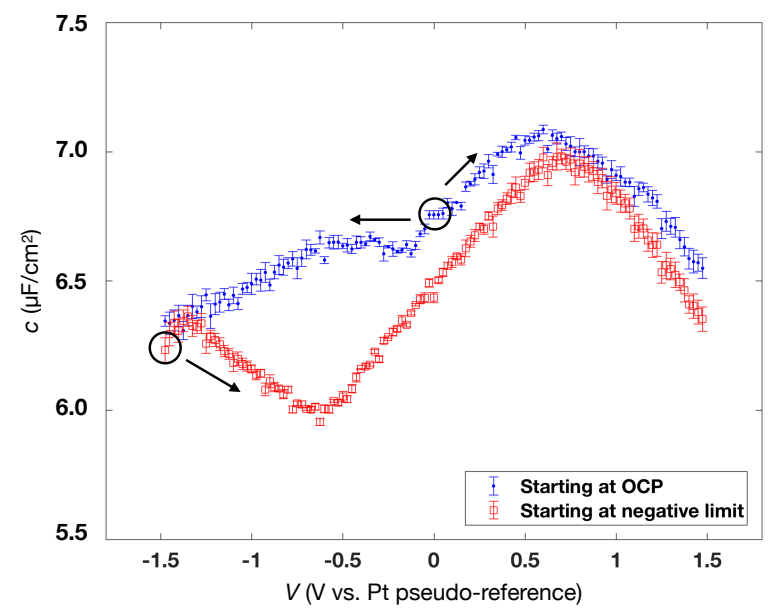

Figure A3.2: Comparison between the capacitance curves in the IL $[\text { Emim }]^{+}\left[\mathrm{NTf}_{2}\right]^{-}$obtained from different starting potential, marked with the circles on the graph. The arrows indicate scan directions. It is clear that different initial voltages result in distinct capacitance curve. Note that starting from the potential close to OCP gives more reproducibility. 

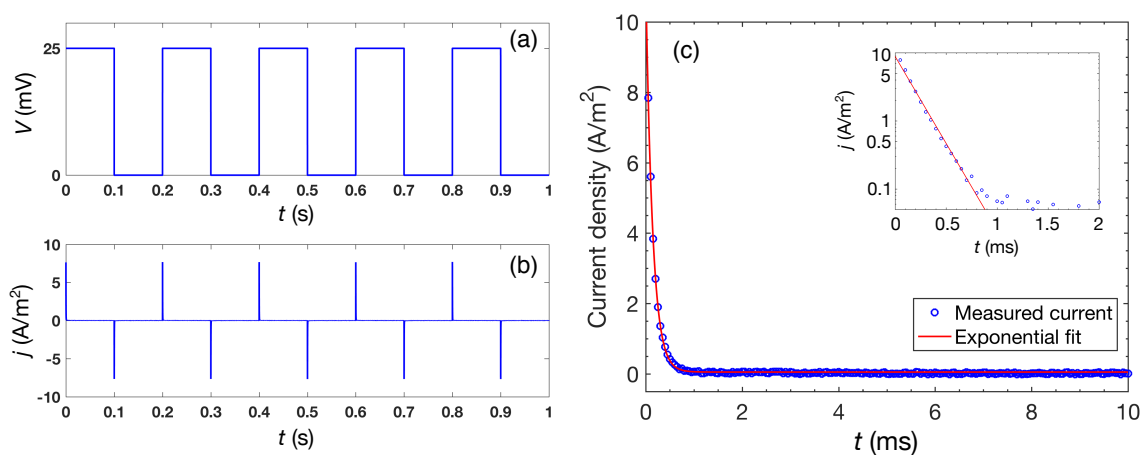

Figure A3.3: (a) An example of potential step on the positive scan dirention from $0 \mathrm{~V}$ to $25 \mathrm{mV}$. (b) The measured current corresponding to the applied potential in (a). (c) An example of the experimental data (circles) with the exponential fit (solid line) with an inset showing the same data on log-linear plot measured in $[\mathrm{Emim}]^{+}\left[\mathrm{NTf}_{2}\right]^{-}$.
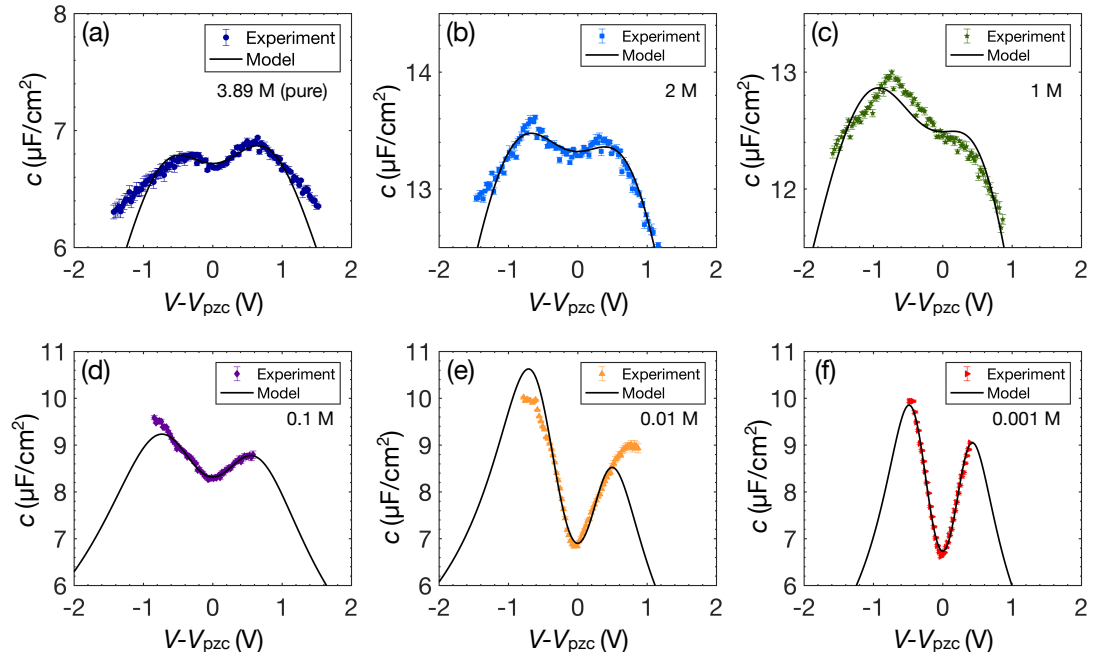

Figure A3.4: (a-f) The differential capacitance of $[\text { Emim }]^{+}\left[\mathrm{NTf}_{2}\right]^{-} / \mathrm{DMSO}$ mixtures at the IL concentration of $3.89 \mathrm{M}$ (pure), $2 \mathrm{M}, 1 \mathrm{M}, 0.1 \mathrm{M}, 0.01 \mathrm{M}$, and $0.001 \mathrm{M}$, respectively. The solid lines represent the fits obtained from the meanfield model. 

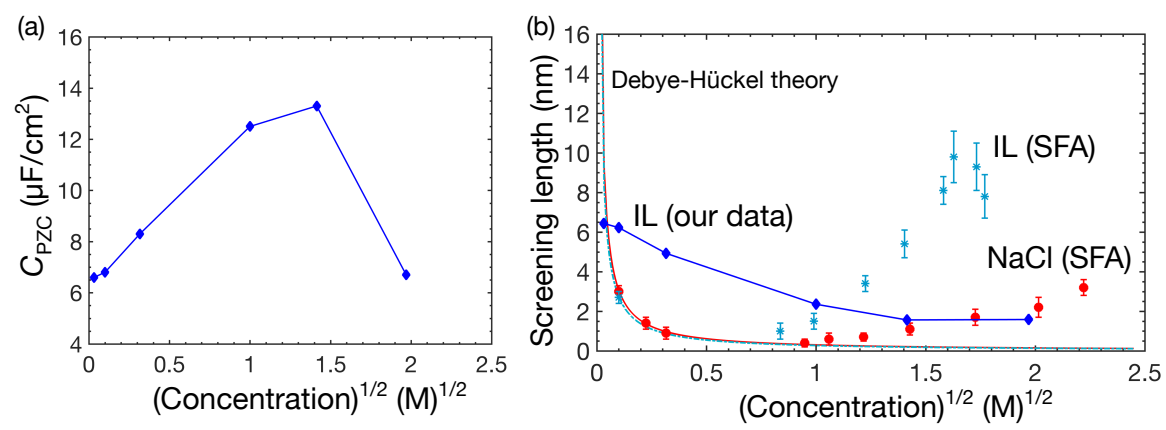

Figure A3.5: (a) A non-monotonic variation of the differential capacitance at PZC as a function of IL concentration $\left([\text { Emim }]^{+}\left[\mathrm{NTf}_{2}\right]^{-} / \mathrm{DMSO}\right)$. (b) The screening lengths calculated from the differential capacitance in (a) compared with the screening lengths measured using surface force apparatus (SFA) in literature. ${ }^{44}$ 


\section{References}

[1] Welton, T. (1999) Room-Temperature Ionic Liquids. Solvents for Synthesis and Catalysis. Chem. Rev., 99(8), 2071-2084.

[2] Ohno, H. (2005) Electrochemical Aspects of Ionic Liquids, John Wiley \& Sons, .

[3] Armand, M., Endres, F., MacFarlane, D. R., Ohno, H., and Scrosati, B. (2009) Ionic-Liquid Materials for the Electrochemical Challenges of the Future. Nat. Mater., 8(8), 621-629.

[4] Kim, T. Y., Lee, H. W., Stoller, M., Dreyer, D. R., Bielawski, C. W., Ruoff, R. S., and Suh, K. S. (2010) High-performance Supercapacitors Based on Poly (Ionic Liquid)-Modified Graphene Electrodes. ACS Nano, 5(1), 436-442.

[5] Barrosse-Antle, L., Bond, A., Compton, R., O'Mahony, A., Rogers, E., and Silvester, D. (2010) Voltammetry in Room Temperature Ionic Liquids: Comparisons and Contrasts with Conventional Electrochemical Solvents. Chem. Asian J., 5(2), 202-230.

[6] Fedorov, M. V. and Kornyshev, A. A. (2014) Ionic Liquids at Electrified Interfaces. Chem. Rev., 114(5), 2978-3036.

[7] Kornyshev, A. A. (2007) Double-Layer in Ionic Liquids: Paradigm Change?. J. Phys. Chem. B, 111, 5545.

[8] Lockett, V., Sedev, R., Ralston, J., Horne, M., and Rodopoulos, T. (2008) Differential Capacitance of the Electrical Double Layer in Imidazolium-based Ionic Liquids: Influence of Potential, Cation size, and Temperature. J. Phys. Chem. C, 112(19), 7486-7495.

[9] Lockett, V., Horne, M., Sedev, R., Rodopoulos, T., and Ralston, J. (2010) Differential Capacitance of the Double Layer at the Electrode/Ionic Liquids Interface. Phys. Chem. Chem. Phys., 12(39), 12499-12512.

[10] Zheng, J., Goonetilleke, P., Pettit, C., and Roy, D. (2010) Probing the Electrochemical Double Layer of an Ionic Liquid using Voltammetry and Impedance Spectroscopy: A Comparative Study of Carbon Nanotube and Glassy Carbon Electrodes in [EMIM]+[EtSO 4]-. Talanta, 81(3), 1045-1055.

[11] Zheng, J., Moganty, S. S., Goonetilleke, P. C., Baltus, R. E., and Roy, D. (2011) A Comparative Study of the Electrochemical Characteristics of $[$ Emim+ $][$ BF4- $]$ and [Bmim+][BF4-] Ionic Liquids at the Surfaces of Carbon Nanotube and Glassy Carbon Electrodes. J. Phys. Chem. C, 115(15), 75277537.

[12] Roling, B., Drüschler, M., and Huber, B. (2012) Slow and Fast Capacitive Process Taking Place at the Ionic Liquid/Electrode Interface. Faraday Discuss., 154, 303-311. 
[13] Goodwin, Z. A., Feng, G., and Kornyshev, A. A. (2017) Mean-Field Theory of Electrical Double Layer In Ionic Liquids with Account of Short-Range Correlations. Electrochim. Acta., 225, 190-197.

[14] Goodwin, Z. A. and Kornyshev, A. A. (2017) Underscreening, Overscreening and Double-Layer Capacitance. Electrochem. Commun., 82, 129-133.

[15] Oldham, K. B. (2008) A Gouy-Chapman-Stern Model of the Double Layer at a (Metal)/(Ionic Liquid) Interface. J. Electroanal. Chem., 613(2), 131-138.

[16] Fedorov, M. V., Georgi, N., and Kornyshev, A. A. (2010) Double Layer in Ionic Liquids: The Nature of the Camel Shape of Capacitance. Electrochem. Commun., 12(2), 296-299.

[17] Trulsson, M., Algotsson, J., Forsman, J., and Woodward, C. E. (2010) Differential Capacitance of Room Temperature Ionic Liquids: The Role of Dispersion Forces. J. Phys. Chem. Lett., 1(8), 1191-1195.

[18] Georgi, N., Kornyshev, A. A., and Fedorov, M. V. (2010) The Anatomy of the Double Layer and Capacitance in Ionic Liquids with Anisotropic Ions: Electrostriction vs. Lattice Saturation. J. Electroanal. Chem., 649(1), 261267.

[19] Alam, M. T., Islam, M. M., Okajima, T., and Ohsaka, T. (2007) Measurements of Differential Capacitance at Mercury/Room-temperature Ionic Liquids Interfaces. J. Phys. Chem. C, 111(49), 18326-18333.

[20] Alam, M. T., Islam, M. M., Okajima, T., and Ohsaka, T. (2007) Measurements of Differential Capacitance in Room Temperature Ionic Liquid at Mercury, Glassy Carbon and Gold Electrode Interfaces. Electrochem. Commun., 9(9), 2370-2374.

[21] Alam, M. T., Islam, M. M., Okajima, T., and Ohsaka, T. (2008) Ionic Liquid Structure Dependent Electrical Double Layer at the Mercury Interface. $J$. Phys. Chem. C, 112(7), 2601-2606.

[22] Alam, M. T., Islam, M. M., Okajima, T., and Ohsaka, T. (2008) Capacitance Measurements in a Series of Room-temperature Ionic Liquids at Glassy Carbon and Gold Electrode Interfaces. J. Phys. Chem. C, 112(42), 16600-16608.

[23] Alam, M. T., Islam, M. M., Okajima, T., and Ohsaka, T. (2009) Electrical Double Layer in Mixtures of Room-temperature Ionic Liquids. J. Phys. Chem. C, 113(16), 6596-6601.

[24] Alam, M. T., Masud, J., Islam, M. M., Okajima, T., and Ohsaka, T. (2011) Differential Capacitance at Au (111) in 1-alkyl-3-methylimidazolium tetrafluoroborate based Room-temperature Ionic Liquids. J. Phys. Chem. C, 115(40), 19797-19804.

[25] Islam, M. M., Alam, M. T., and Ohsaka, T. (2008) Electrical Double-layer 
Structure in Ionic Liquids: A Corroboration of the Theoretical Model by Experimental Results. J. Phys. Chem. C, 112(42), 16568-16574.

[26] Islam, M. M., Alam, M. T., Okajima, T., and Ohsaka, T. (2009) Electrical Double Layer Structure in Ionic Liquids: An Understanding of the Unusual Capacitance-potential Curve at a Nonmetallic Electrode. J. Phys. Chem. C, 113(9), 3386-3389.

[27] Gnahm, M., Pajkossy, T., and Kolb, D. (2010) The Interface between Au (111) and an Ionic Liquid. Electrochim. Acta., 55(21), 6212-6217.

[28] Drüschler, M., Huber, B., and Roling, B. (2011) On Capacitive Processes at the Interface between 1-Ethyl-3-methylimidazolium tris (pentafluoroethyl) trifluorophosphate and Au (111). J. Phys. Chem. C, 115(14), 6802-6808.

[29] Pajkossy, T. and Kolb, D. M. (2011) The Interfacial Capacitance of Au (100) in an Ionic Liquid, 1-butyl-3-methyl-imidazolium hexafluorophosphate. Electrochem. Commun., 13(3), 284-286.

[30] Atkin, R., Borisenko, N., Drüschler, M., El Abedin, S. Z., Endres, F., Hayes, R., Huber, B., and Roling, B. (2011) An in situ STM/AFM and Impedance Spectroscopy Study of the Extremely Pure 1-butyl-1-methylpyrrolidinium tris (pentafluoroethyl) trifluorophosphate/Au (111) Interface: Potential Dependent Solvation Layers and the Herringbone Reconstruction. Phys. Chem. Chem. Phys., 13(15), 6849-6857.

[31] Atkin, R., Borisenko, N., Drüschler, M., Endres, F., Hayes, R., Huber, B., and Roling, B. (2014) Structure and Dynamics of the Interfacial Layer between Ionic Liquids and Electrode Materials. J. Mol. Liq., 192, 44-54.

[32] Li, M.-G., Chen, L., Zhong, Y.-X., Chen, Z.-B., Yan, J.-W., and Mao, B.-W. (2016) The Electrochemical Interface of Ag (111) in 1-ethyl-3methylimidazolium bis (trifluoromethylsulfonyl) imide Ionic Liquid-A Combined in-situ Scanning Probe Microscopy and Impedance Study. Electrochim. Acta., 197, 282-289.

[33] Roling, B. and Drüschler, M. (2012) Comments on "Intrinsic Limitations of Impedance Measurements in Determining Electric Double Layer Capacitances" by H. Wang and L. Pilon [Electrochim. Acta 63 (2012) 55]. Electrochim. Acta., 76, 526-528.

[34] Wang, H. and Pilon, L. (2012) Intrinsic Limitations of Impedance Measurements in Determining Electric Double Layer Capacitances. Electrochim. Acta., 63, 55-63.

[35] Wang, H. and Pilon, L. (2012) Reply to Comments on "Intrinsic Limitations of Impedance Measurements in Determining Electric Double Layer Capacitances" by H. Wang, L. Pilon [Electrochimica Acta 63 (2012) 55]. Electrochim. 
Acta., 76, 529-531.

[36] Drüschler, M. and Roling, B. (2011) Commentary on 'The Interface between $\mathrm{Au}$ (111) and an Ionic Liquid'. Electrochim. Acta., 56(20), 7243-7245.

[37] Pajkossy, T. (2011) Response to the Commentary of Marcel Drüschler and Bernhard Roling on 'The interface between $\mathrm{Au}$ (111) and an ionic liquid'. Electrochim. Acta., 56(20), 7246-7247.

[38] Zhou, W., Inoue, S., Iwahashi, T., Kanai, K., Seki, K., Miyamae, T., Kim, D., Katayama, Y., and Ouchi, Y. (2010) Double Layer Structure and Adsorption/desorption Hysteresis of Neat Ionic Liquid on Pt Electrode Surface An in-situ IR-Visible Sum-Frequency Generation Spectroscopic Study. Electrochem. Commun., 12(5), 672-675.

[39] Bard, A. J. and Faulkner, L. R. (2001) Electrochemical Methods: Fundamentals and Applications, John Wiley \& Son, 2 edition.

[40] Chaban, V. V., Voroshylova, I. V., Kalugin, O. N., and Prezhdo, O. V. (2012) Acetonitrile Boosts Conductivity of Imidazolium Ionic Liquids. J. Phys. Chem. B, 116(26), 7719-7727.

[41] Gebbie, M. A., Valtiner, M., Banquy, X., Fox, E. T., Henderson, W. A., and Israelachvili, J. N. (2013) Ionic Liquids Behave as Dilute Electrolyte Solutions. Proc. Natl. Acad. Sci. U. S. A., 110(24), 9674-9679.

[42] Gebbie, M. A., Dobbs, H. A., Valtiner, M., and Israelachvili, J. N. (2015) Long-range Electrostatic Screening in Ionic Liquids. Proc. Natl. Acad. Sci. U. S. A., 112(24), 7432-7437.

[43] Gebbie, M. A., Smith, A. M., Dobbs, H. A., Warr, G. G., Banquy, X., Valtiner, M., Rutland, M. W., Israelachvili, J. N., Perkin, S., and Atkin, R. (2017) Long Range Electrostatic Forces in Ionic Liquids. Chem. Comm., 53(7), 1214-1224.

[44] Smith, A. M., Lee, A. A., and Perkin, S. (2016) The Electrostatic Screening Length in Concentrated Electrolytes Increases with Concentration. J. Phys. Chem. Lett., 7(12), 2157-2163.

[45] Mezger, M., Ocko, B. M., Reichert, H., and Deutsch, M. (2013) Surface Layering and Melting in an Ionic Liquid Studied by Resonant Soft X-ray Reflectivity. Proc. Natl. Acad. Sci. U. S. A., 110(10), 3733-3737.

[46] Hayes, R., Borisenko, N., Tam, M. K., Howlett, P. C., Endres, F., and Atkin, R. (2011) Double Layer Structure of Ionic Liquids at the Au (111) Electrode Interface: An Atomic Force Microscopy Investigation. J. Phys. Chem. C, 115(14), 6855-6863.

[47] Perkin, S. (2012) Ionic Liquids in Confined Geometries. Phys. Chem. Chem. Phys., 14(15), 5052-5062. 
[48] Bozym, D. J., Uralcan, B., Limmer, D. T., Pope, M. A., Szamreta, N. J., Debenedetti, P. G., and Aksay, I. A. (2015) Anomalous Capacitance Maximum of the Glassy Carbon-Ionic Liquid Interface through Dilution with Organic Solvents. J. Phys. Chem. Lett., 6(13), 2644-2648.

[49] Gerischer, H. (1985) An Interpretation of the Double Layer Capacity of Graphite Electrodes in Relation to the Density of States at the Fermi Level. J. Phys. Chem., 89(20), 4249-4251.

[50] Gerischer, H., McIntyre, R., Scherson, D., and Storck, W. (1987) Density of the Electronic States of Graphite: Derivation from Differential Capacitance Measurements. J. Phys. Chem., 91(7), 1930-1935.

[51] Kornyshev, A., Luque, N., and Schmickler, W. (2014) Differential Capacitance of Ionic Liquid Interface with Graphite: The Story of Two Double Layers. J Solid State Electrochem., 18(5), 1345-1349.

[52] Paluch, M. (2016) Dielectric Properties of Ionic Liquids, Springer, .

[53] Vila, J., Fernández-Castro, B., Rilo, E., Carrete, J., Domínguez-Pérez, M., Rodríguez, J., García, M., Varela, L., and Cabeza, O. (2012) Liquid-SolidLiquid Phase Transition Hysteresis Loops in the Ionic Conductivity of Ten Imidazolium-based Ionic Liquids. Fluid Phase Equilibria, 320, 1-10.

[54] Schreiner, C., Zugmann, S., Hartl, R., and Gores, H. J. (2009) Fractional Walden Rule for Ionic Liquids: Examples from Recent Measurements and a Critique of the So-called Ideal $\mathrm{KCl}$ Line for the Walden Plot. J. Chem. Eng. Data, 55(5), 1784-1788.

[55] Vranes, M., Dozic, S., Djeric, V., and Gadzuric, S. (2012) Physicochemical Characterization of 1-Butyl-3-methylimidazolium and 1-Butyl-1methylpyrrolidinium Bis (trifluoromethylsulfonyl) imide. J. Chem. Eng. Data, 57(4), 1072-1077.

[56] Bergman, D. J. (1978) The Dielectric Constant of a Composite Material-A Problem in Classical Physics. Physics Reports, 43(9), 377-407. 



\section{4}

\section{Local Structure and Flow Properties of Ionic Liquids on Charged and Inert Substrates}

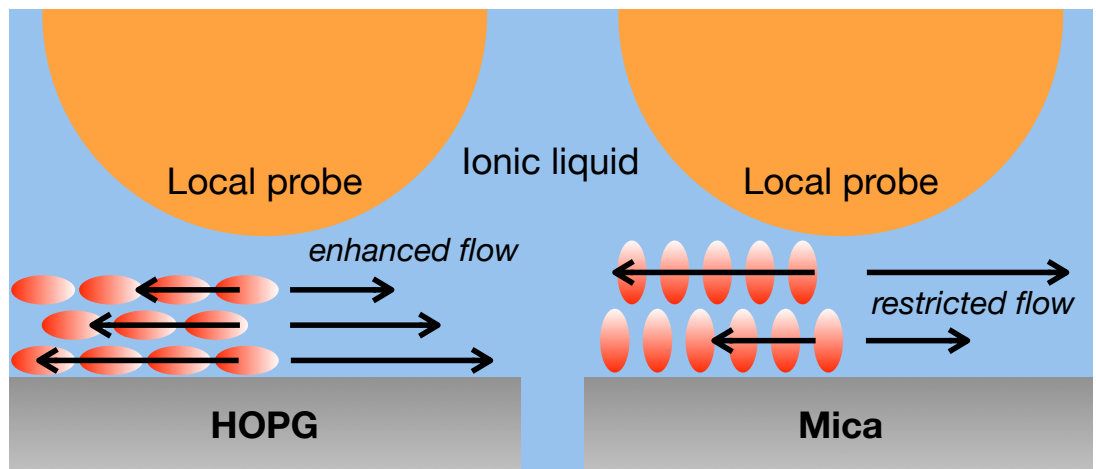

This chapter focuses on the effect of surface charge on the local structure and flow properties of ionic liquids. An atomic force microscope was used to perform force-distance and small-amplitude force-distance spectroscopies to study the ionic liquid's near-wall structure. The comparison was made between charged (mica) and neutral (unbiased HOPG) substrates. As a result, we found stronger near-wall liquid layers on mica than on HOPG, indicating a significant influence electrostatic interaction on the local structure of the ionic liquids. In addition, the flow properties was enhanced on $H O P G$ as compared to the bulk, demonstrating the importance of substrate for controlling near-wall dynamic response.

${ }^{*}$ The contents of this chapter have been published as: M. Jitvisate et al., "Local Structure and Flow Properties of Ionic Liquids on Charged and Inert Substrates," $J$. Phys. Chem. C, 120, 4860-4865 (2016) 


\subsection{Introduction}

Room-temperature ionic liquids (RTILs) are liquid salts with traditional Debye lengths smaller than the atomic scale. This means that they behave as molecular liquids and are expected to display noncontinuum ionic response to electric fields. ${ }^{1}$ A key feature of this behavior is the formation of clear molecular layers on solid substrates, which can form because of both templating and the breakup of the hydrogen-bonded network within the liquid, as well as through maximized ionic packing in response to the application of a surface-electrode potential. ${ }^{2}$

Near-wall layering of RTILs is already well-established from scattering measurements, ${ }^{3-5}$ surface force apparatus (SFA), ${ }^{6-8}$ and atomic force microscopy (AFM).${ }^{9-11}$ Charged surfaces lead both to more layers and stronger layers, as compared to inert surfaces, where "stronger" refers to the increased force required for, e.g., an AFM tip to "pop through" the structure.

If the near-wall structure forms differently in the presence (or lack) of wall charge, great hope lies ahead for applications in electroactuation if, e.g., near-wall ion order leads to modified bulk flow. In the meantime, several studies have highlighted discrete near-wall frictional effects, including layerdependent friction. ${ }^{12,13}$

In ref 17 we extended RTIL-AFM studies by using small-amplitude forcedistance spectroscopy to separate resistance to squeeze into its conservative and dissipative components, equivalent to layer stiffness and viscosity. In that study we used the ionic liquid $[\mathrm{Emim}]^{+}\left[\mathrm{BF}_{4}\right]^{-}$on mica to show a dramatic increase in viscosity from $35 \mathrm{mPa} \cdot \mathrm{s}$ to $550 \mathrm{mPa} \cdot \mathrm{s}$ when moving from the bulk to the first layer adjacent to the wall. However, we were unable to present a comparison to an uncharged surface to see whether the conservative and dissipative components were charge-dependent.

With this in mind, in this paper we examine the near-wall structure of the ionic liquid $[\text { Emim }]^{+}\left[\mathrm{NTf}_{2}\right]^{-}$on both mica and HOPG using smallamplitude force-distance spectroscopy. We consider these two substrates to be prototypical examples for charge-mediated RTIL layering (mica) and template-mediated layering (HOPG). The reason for moving to this differ- 
ent RTIL is because we have been made aware of the difficulty in removing water from the previous one. (In ref 17 we found a substructure within the first ion-pair layer adjacent to the wall, which could have corresponded either to single ions or to water contamination. Despite our extensive efforts to remove water, it would be impossible with current techniques to differentiate these two possibilities.) Our main goal here is to determine to what extent the substrate influences the two components of resistance to squeeze.

\subsection{Experimental methods}

All work took place in an MBraun LABmaster 130 glovebox, operated under prepurified nitrogen with $\mathrm{H}_{2} \mathrm{O}$ and $\mathrm{O}_{2}$ levels both $<0.1 \mathrm{ppm}$.

As substrates we used mica (Bruker) and HOPG (Mikromasch), which were cleaved in the glovebox immediately prior to use.

The room-temperature ionic liquid was 1-ethyl-3-methylimidazolium bis(trifluoromethylsulfonyl)imide $\left([\mathrm{Emim}]^{+}\left[\mathrm{NTf}_{2}\right]^{-}\right)$(Sigma-Aldrich). This was delivered by the manufacturer at $98 \%$ purity, but we further purified it within the glovebox. Specifically, we heat-pump cycled the liquid $\left(150^{\circ} \mathrm{C}\right.$ and $\sim 7$ mbar ) for $>20 \mathrm{~h}$ until we no longer saw Faradaic peaks within the electrochemical window during cyclic voltammetry between Pt electrodes. During this process, the electrochemical window increased from $3.0 \mathrm{~V}$ (immediately upon delivery from manufacturer) to $3.8 \mathrm{~V}$.

Force-distance (FD) and small-amplitude force-distance (SAFD) spectroscopies were carried out on an Asylum Cypher AFM (Santa Barbara, CA) instrument. The AFM instrument was housed within the glovebox, and we switched the glovebox to "eco" mode during the experiments (this turns off the pumps of the glovebox unless the $\mathrm{H}_{2} \mathrm{O}$ or $\mathrm{O}_{2}$ levels rise above safe limits). All SAFD data was recorded with mode $n=2$, unless stated otherwise.

We typically used a $\sim 80 \mu \mathrm{L}$ droplet of RTIL for each experiment. During the SAFD experiments we used different mode numbers, approach speeds, and amplitudes of oscillation, as described in the text of the main body of the article. The driven oscillation was implemented through pulse laser 
drive (BlueDrive), whereby a low-power laser $(\sim 700 \mu \mathrm{W})$ is pulsed at the base of the cantilever, leading to localized thermal expansion and contraction, and thus tip oscillation. This method of oscillation typically heats the bulk liquid by $1-2{ }^{\circ} \mathrm{C}$ but has the advantage that the amplitude and phase are very "clean". (As a comparison, piezo drive excites many parts of the liquid cell (O-rings, seals, bubbles, etc.) because of the relatively large surface area of the piezo compared to the cantilever. The different vibrational modes of these various components can then couple to each other.)

The cantilevers were $\mathrm{Au}$-coated $\mathrm{Si}_{3} \mathrm{~N}_{4}$ (ORC8A, Bruker). Spring constants, $k_{\mathrm{s}}$, and fundamental (air) resonance frequencies were measured to be $0.7 \mathrm{~N} / \mathrm{m}$ and $71 \mathrm{kHz}$, respectively, and the radius of curvature, $R$, was quoted by the manufacturer as $15 \mathrm{~nm}$. Our limiting resolution through thermal noise is thus $\sqrt{k_{\mathrm{S}} k_{\mathrm{B}} T} / R \approx 4 \mathrm{mN} / \mathrm{m}$, where $k_{\mathrm{B}} T$ is the thermal energy. The resonance frequency in the ionic liquid of the $n=2$ mode used here was measured to be $320 \mathrm{kHz}$. Data sets in Figure 4.1 were averaged over 200 bins in both $x$ and $y$. All other processing was as given in the text.

\subsection{Results and discussion}

\subsubsection{Force-distance spectroscopy}

We begin by presenting the force-distance (FD) spectroscopy data of the RTIL on both mica and HOPG in Figure 4.1. For clarity, we show data only up to a maximum force response of $5 \mathrm{nN}$. In fact we recorded data up to a force response of $20 \mathrm{nN}$, but it was clear that we had reached the bare substrate already at forces $\gtrsim 3 \mathrm{nN}$. The $x$ axes represent the separation between the AFM tip and substrate, with the substrate at position $0 \mathrm{~nm}$, to the left of the graphs. The $y$ axes represent the force exerted by the liquid on the AFM tip as it moved toward the wall. To the right of the graphs (separation $\gtrsim 5 \mathrm{~nm}$ ) the force (measured with respect to the response in the bulk of the liquid) is zero, that is, the liquid behaved as bulk. However, as the wall was approached, distinct steps became apparent in the force response, corresponding to discrete layers of RTIL for which the 

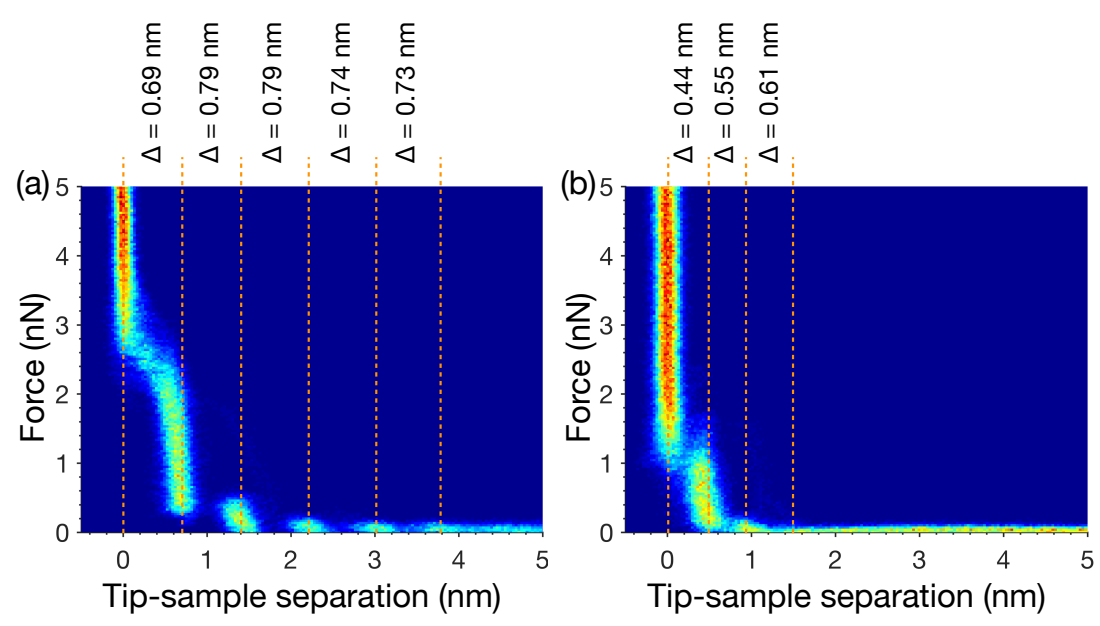

(c)
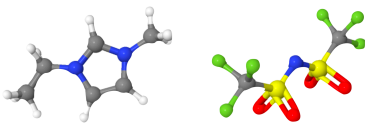

Figure 4.1: Force-distance spectroscopy of the RTIL $[\text { Emim }]^{+}\left[\mathrm{NTf}_{2}\right]^{-}$on mica (a) and HOPG (b). The data are averages of 50 experiments, binned over 200 bins on both axes. The color scales correspond to the probability of finding data in a given bin, with blue indicating a probability of 0 and red indicating a probability of 1. The RTIL forms distinct layers on both substrates, but they are more numerous and stronger on mica as compared to HOPG. (c) Geometry of the RTIL used in the present study. Treating cation and anion as ellipsoids, the cation has principal axes $1.14,0.55$, and $0.28 \mathrm{~nm}$, while the anion has principal axes 1.09, 0.51, and $0.47 \mathrm{~nm}$.

AFM cantilever must store up sufficient energy to "pop" through.

Upon comparison of the liquid's response on the two substrates it is immediately apparent that it forms many more layers on mica ( $\sim 5-6$ layers) as compared to HOPG ( 2-3 layers), within our resolution. This agrees well with literature results using AFM. Intuitively the large wall charge of mica leads to more counterions in the first liquid layer, which increases the layer's density, which in turn templates further layers until the effect is eventually integrated out. ${ }^{7,14}$ We note here that we see only near-wall layers, i.e., we do not see any indication of a continuous electrostatic decay. ${ }^{15,16}$

It is unclear what drives the layering on HOPG. It is probably safe to 
assume that the atomically smooth surface leads to preferential ion-pair orientations in the first liquid layer, i.e., the liquid is templated by the wall. However, it is also possible that specifically adsorbed ionic contaminants attach to the wall and drive the layering in a similar fashion to the mica. As mentioned above, we purified our liquids for a long time and we believe this latter possibility is unlikely.

If we examine the layer step sizes, it becomes clear that they are slightly larger on mica than on HOPG. It is easiest to describe the first layer in terms of the cationic orientation. On mica, the first layer is predominantly cationic for charge screening, and on HOPG, the first layer's thickness is expected to be governed by the larger of the two molecules, i.e., the cation. By inspection of the molecular geometry of the RTIL (see Figure 4.1), on HOPG the first layer's size indicates that the cations are lying flat, whereas on mica they are standing up. We attribute this difference in molecular orientation to good commensurability between the imidazolium ring of the cation and the HOPG's atomic structure, allowing the ions in that system to lie flatter against the wall as shown in the recent simulations. ${ }^{14}$ We attribute the subsequent layers mainly to ion pairs. On HOPG, each layer must maintain electroneutrality, with the preferential adsorption geometries of the first layer quickly integrating out. On mica, it is currently unknown what the excess charge is per layer (for screening purposes), although we believe that maximal ion packing is likely to screen out the mica surface charge within the first 1-2 layers, with these then templating the subsequent layers. We note that our measured layer sizes are consistent with the known literature. ${ }^{14,17-19}$

Finally, we point out the remarkable reproducibility in the data by noting that the FD curves in Figure 4.1a, b correspond to averages of 50 data sets.

At this point, most AFM studies stop. RTILs form layers on surfaces, and the amount of layering depends on surface charge. We could proceed by trying to extract rupture forces from the FD data (as the forces at which the steps are made), or we could try to extract layer stiffnesses (as the gradients of the steps). However, such analyses run into issues regarding the spread of the data. This is a problem regarding AFM FD spectroscopy itself: We measure dynamic response ("dynamic" because we feedback on 
force, not position) and try to extract static information. With AFM, we could approach to a particular layer by careful control of the approach force set point, but even then we expect the separation to vary by as much as the error bar in the position of the layers in Figure 4.1. In this respect, SFA provides much clearer data: The separation can be precisely controlled and the static force measured, but this control comes at the expense of limited substrate availability for the particular technique. We proceed by applying a small-amplitude driven oscillation to the AFM tip, which allows us to extract the static component of the resistance to squeeze.

\subsubsection{Small-amplitude modulation}

In SAFD spectroscopy, a small driven oscillation is imposed on the cantilever during tip-sample approach. ${ }^{20,21}$

The equation of motion is $m \ddot{z}+b_{\mathrm{c}} \dot{z}+k_{\mathrm{c}} z=F_{\mathrm{d}}+F_{\mathrm{ts}}$, where $m$ is the mass of the cantilever (including hydrodynamic loading), ${ }^{2,23} b_{\mathrm{c}}$ the damping, and $k_{\mathrm{c}}$ the spring constant of the cantilever, which is driven with force $F_{\mathrm{d}}$. The additional force, $F_{\mathrm{ts}}$, is the tip-sample interaction which arises because of interaction with the structured interstitial RTIL and can be expanded as $F_{\mathrm{ts}} \approx\left(\partial F_{\mathrm{ts}} / \partial z\right)_{z}+\left(\partial F_{\mathrm{ts}} / \partial \dot{z}\right)_{\dot{z}}$, leading to our final goal: the local interaction stiffness $k_{\mathrm{ts}}=-\left(\partial F_{\mathrm{ts}} / \partial z\right)_{z}$ and the local damping $b_{\mathrm{ts}}=$ $-\left(\partial F_{\mathrm{ts}} / \partial \dot{z}\right) \dot{z}$. The final expressions are given by

$$
k_{\mathrm{ts}}=-k_{\mathrm{c}}+m \omega^{2}+\frac{F_{0}}{A} \cos \phi
$$

and

$$
b_{\mathrm{ts}}=-b_{\mathrm{c}}+\frac{F_{0}}{\omega A} \sin \phi
$$

where $F_{0}=A_{\infty}\left[\left(k_{\mathrm{c}}-m \omega^{2}\right)^{2}+\omega^{2} b_{\mathrm{c}}^{2}\right]^{1 / 2}$ is the driving force and $A_{\infty}$ is the amplitude of oscillation far from the wall; $A$ and $\phi$ are the amplitude and phase, respectively, of the AFM cantilever as the wall is approached. We note that both the mass and bulk damping include hydrodynamic loading. ${ }^{22,23}$

The equation given above is slightly different than the equation given in ref 17 . In that study we used piezo drive to excite the AFM vibration. 
In that case, interpretation of the tip motion requires us to subtract the motion of the cantilever base (i.e., the part of the cantilever clamped to the piezo), because AFMs measure motion with respect to the base and not the zero or average position. In the present study we used pulse laser drive, which does not drive base motion; hence, there is a difference in analysis between the present and past work.

The formalism given above is accurate for high quality factors, $Q$, but it is unclear whether RTILs ever satisfy this. Typically, the quality factor for the fundamental mode of oscillation of a cantilever in RTIL lies in the range of 1-10, which brings into question the validity of using the simple harmonic oscillator equations in the first place, as well as truncation of the Taylor expansion after the first-order terms. ${ }^{22,24,25}$ At low $Q$, the modal responses of oscillation become sufficiently broad that they begin to couple together, rendering the analysis nonquantitative. On the one hand, we could operate at higher mode number, but then the model for hydrodynamic loading quickly becomes invalid. On the other hand we could increase our amplitude of oscillation, but the upper bound for highresolution data is in the order of the molecular length scale. To proceed, we note that Sader showed similarity between the response of a heavily damped oscillator and a simple harmonic oscillator as long as the frequency of oscillation is very close to the resonance frequency, i.e., $\omega \sim \omega_{n}{ }^{22}$ With this in mind, we implement SAFD at $\omega=\omega_{n}$ for $n=2,3,4$ (we define $n=0$ as the fundamental frequency; lower-order modes do not appear distinct on a thermal tune, so we avoid them here).

We now experimentally confirm that we satisfy the above requirements for quantitative analysis. FD resistance and SAFD amplitude and phase of the RTIL on mica are shown in Figure 4.2 for modes 2-4 Already at these low mode numbers it becomes clear that the specific mode of the cantilever affects the measured result. In particular, operating at higher modes smears out resistance to squeeze, demonstrated by shallower slopes for each layer in the FD data. The interpretation of this is that, while our analysis relies on the fact that the tip approaches the substrate normally, as the mode number increases so too does the non-normal component of tip motion. Lower modes predominantly "poke through" the near-wall layers, 

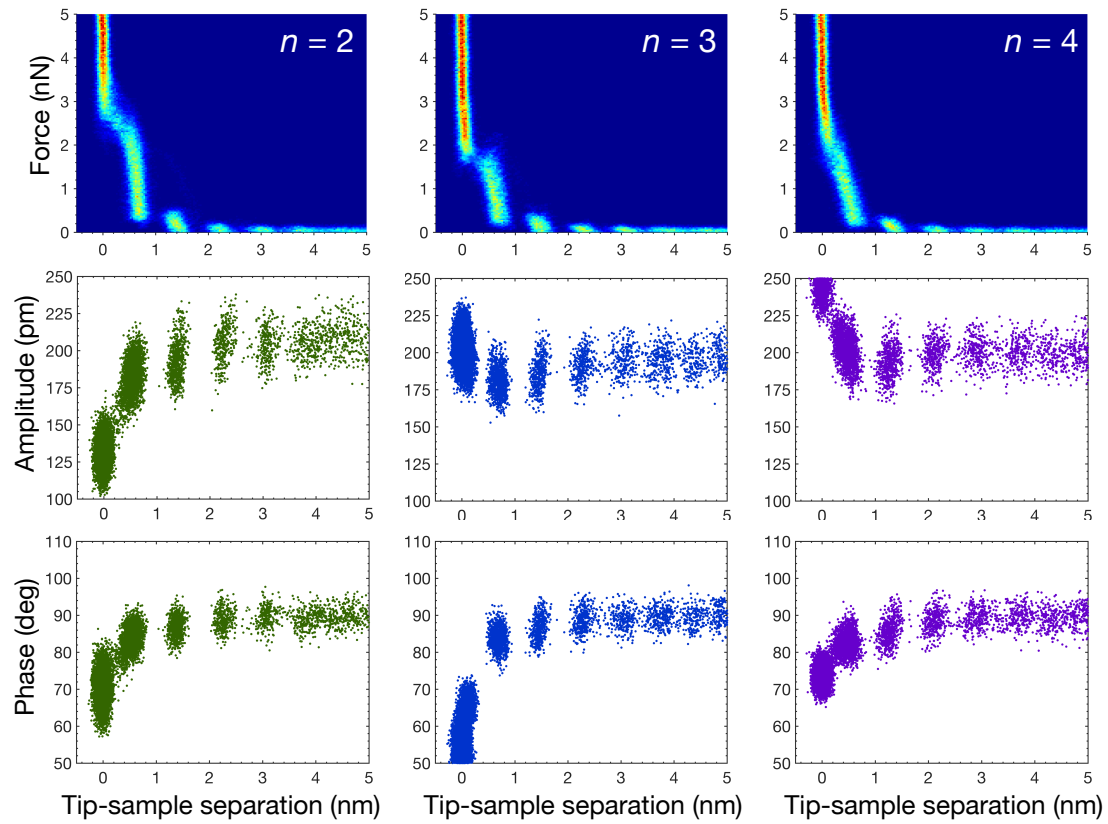

Figure 4.2: (top row) Resistance to squeeze, (middle row) amplitude of oscillation, and (bottom row) phase shift of FD and SAFD data of $[\mathrm{Emim}]^{+}\left[\mathrm{NTf}_{2}\right]^{-}$on mica as a function of mode number of the small-amplitude driven oscillation on the cantilever tip. From the left column to the right column, the data are for the $n=2,3$, and 4 modes (where we define $n=0$ as the fundamental frequency). It is clear that mode number affects the overall motion of the cantilever already for these low harmonics. Fortunately, data for the $n=2$ mode match pure FD spectroscopy data within experimental error, so we proceed with that.

whereas at higher modes there is an increasingly dominant "scraping away" component. The FD response with $n=2$ matches the pure FD data well, so we proceed with that mode for the rest of the present study.

The other important experimental parameters are amplitude of oscillation and tip approach speed. To summarize, varying the amplitude of oscillation from 200-600 pm (close to the maximum length scale of the ions) does not noticeably vary the result, whereas varying the approach speed from 1-20 nm/s already leads to an observable increase in noise. With this in mind, we proceed with amplitude of oscillation of $200 \mathrm{pm}$ and approach speed $1 \mathrm{~nm} / \mathrm{s}$.

Our main results from SAFD are plotted in Figure 4.3, where we show 
both the raw amplitude and phase data, as well as the resulting interaction stiffness, $k_{\mathrm{ts}}$, and local damping, $b_{\mathrm{ts}}$, for both mica and HOPG. The individual layers are easily observable and occur at the same tip-sample separations as we found with FD spectroscopy. For purposes of this discussion, we concentrate on $k_{\mathrm{ts}}$ and $b_{\mathrm{ts}}$.

Interaction stiffness, $k_{\mathrm{ts}}$. As the wall is approached, the stiffness of the liquid is found to gradually increase layer-by-layer. What is most surprising is that, although the liquid forms a different number of layers on both mica and HOPG, the maximum increases in stiffness (i.e., for the first layer adjacent to the wall) as compared to bulk are the same order of magnitude for the two substrates, with $k_{\mathrm{ts}, 1}^{\text {mica }} \sim 0.15 \mathrm{~N} / \mathrm{m}$ and $k_{\mathrm{ts}, 1}^{\mathrm{HOPG}} \sim 0.05 \mathrm{~N} / \mathrm{m}$ (where the subscript 1 indicates the first layer immediately adjacent to the wall). Intuitively, perhaps naïvely, wewould have assumed the strong, charge-driven liquid layering on mica would have been much more robust than the weaker, atomically smooth templated layering on HOPG.

At this stage it is interesting to compare the present data of $[\text { Emim }]^{+}\left[\mathrm{NTf}_{2}\right]^{-}$on mica to the response of $[\mathrm{Emim}]^{+}\left[\mathrm{BF}_{4}\right]^{-}$on mica in our previous work. ${ }^{17}$ In both systems the layers appear at similar tip-sample separations (to within an angstrom), with the present liquid exhibiting typically one additional layer further from the wall. Already this similarity in layer separations raises alarms because of the different anion sizes in the two systems. However, we expect that the layers are made predominantly from cations, in which case the similar sizes can be justified. However, upon inspection of the value of layer stiffness we find $k_{\mathrm{ts}, 1} \sim 0.15 \mathrm{~N} / \mathrm{m}$ for $[\text { Emim }]^{+}\left[\mathrm{NTf}_{2}\right]^{-}$as compared to $k_{\mathrm{ts}, 1} \sim 0.90 \mathrm{~N} / \mathrm{m}$ for $[\mathrm{Emim}]^{+}\left[\mathrm{BF}_{4}\right]^{-}$. How is this possible if in both systems it is the same cation responsible for charge screening and, thus, the layering? Clearly the role of the anion must be accounted for, but without knowing the ratio of cations to anions in each layer it is difficult to give a more quantitative explanation for the different stiffnesses.

We are unable to compare the response of our present RTIL on HOPG to our previous RTIL. This is because we were unable to record data for our previous RTIL on HOPG. It seems that this comes through the implementation of SAFD with piezo drive: Coupled modes throughout the liquid cell 

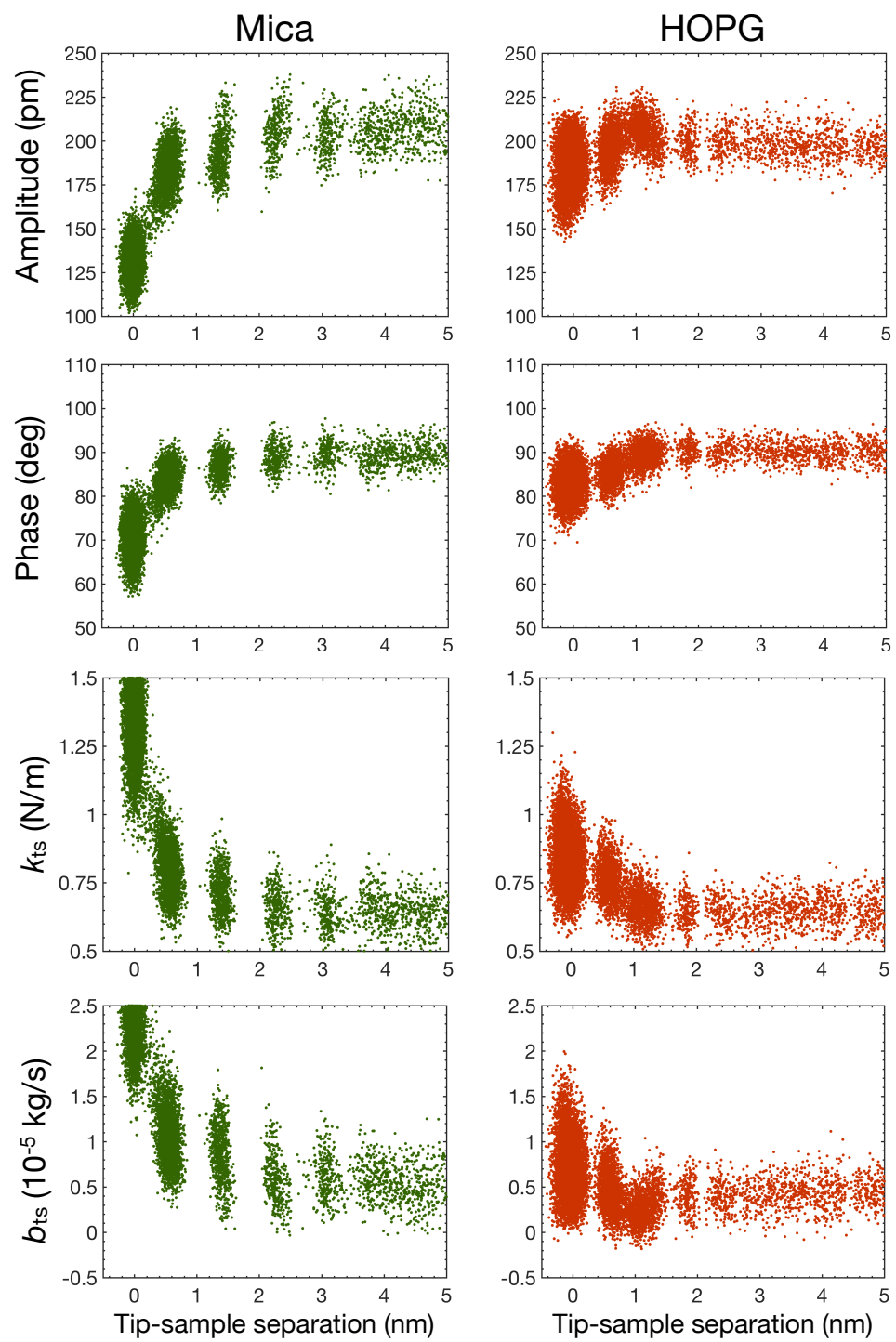

Figure 4.3: (from top to bottom) Amplitude, phase, $k_{\mathrm{ts}}$, and $b_{\mathrm{ts}}$ for the RTIL on mica (left) and HOPG (right). The charge-mediated layers on mica are stronger than the templated layers on HOPG. This leads to an increase in resistance to local flow on mica as the preferentially oriented molecules interlock with each other. On HOPG, the opposite effect is observed, whereby the RTIL has a slight reduction in flow resistance in the presence of the wall. 
increase the noise level above the liquid response. We can confirm with our present liquid that this is indeed the case: Operating with pulse laser drive allows data to be recorded on HOPG, whereas operating with piezo drive does not.

Local damping, $b_{\mathrm{ts}}$. The dissipative component of the force indicates how resistive the liquid is to being squeezed out of the tip-sample interspace. On mica we find an increase in damping of $0.5 \times 10^{-5} \mathrm{~kg} / \mathrm{s}$ for the first layer adjacent to the substrate as compared to the bulk. We compare this first to the RTIL [Emim $]^{+}\left[\mathrm{BF}_{4}\right]^{-}$of our previous study, where we observed an increase in damping of $1.6 \times 10^{-5} \mathrm{~kg} / \mathrm{s}$. The latter RTIL exhibits greater damping, indicating more molecular entanglement between adjacent layers, as we would expect bearing in mind the larger stiffness.

The second comparison is between the present RTIL on mica and HOPG. Whereas we see an increase in damping on mica, on HOPG we observe a slight decrease. (Note that although the damping data on HOPG appears very noisy, this is real, unprocessed (unsmoothed and unfiltered) raw data. The first layer has lower first and second moments as compared to the bulk liquid.) This indicates that, if anything, there is less resistance to squeeze out for the first layer on HOPG as compared to the bulk. The effect is small (a reduction in damping of $0.1 \times 10^{-5} \mathrm{~kg} / \mathrm{s}$ ) but is nevertheless reproducible. On mica there are electrostatic potential wells that help lock the near-wall cations in place (leading to the increase in damping). On HOPG, the near-wall interactions are a lot lower in magnitude. Is it possible for the ions to skate across the surface with greater ease as compared to through the bulk liquid? Enhanced flow properties (in terms of reduced friction) have been shown to exist by the RTIL $\left[\mathrm{Py}_{1,4}\right]^{+}[\mathrm{FAP}]^{-}$on a negatively biased gold electrode, ${ }^{26}$ and it appears that our RTIL naturally achieves the same effect on HOPG. This needs more attention but with higher resolution techniques (or numerical simulations).

As the tip-sample separation is reduced, both the pressure and shear stress in the liquid dramatically increase. The geometry and flow field are known as a squeeze film. The pressure increase drives the flow of liquid out of the gap, whereas the shear stress opposes it. With this in mind, it seems appropriate to define an "effective viscosity". Before doing so it is vital to 
give a warning: Viscosity is a bulk property with no nanoscopic counterpart. However, "effective viscosity" is a useful parameter to quote, because it allows us (at least conceptually) to understand the liquid behavior in terms of macroscopic numbers that we have a better feel for. Conversion is done using Reynolds' lubrication approximation to the Navier-Stokes equations, leading to

$$
\mu_{\mathrm{eff}}=\frac{b_{\mathrm{ts}} d}{6 \pi R_{\mathrm{tip}}{ }^{2}}
$$

where $R_{\text {tip }}$ is the radius of the AFM tip and $d$ is the tip-sample separation. This leads to an increase in effective viscosity on mica of $\mu_{\text {eff }} \sim 810 \mathrm{mPa} \cdot \mathrm{s}$ and a decrease in effective viscosity on $\mathrm{HOPG}$ of $\mu_{\mathrm{eff}} \sim 160 \mathrm{mPa} \cdot \mathrm{s}$. Note that in both these cases the values are measured with respect to the (greatly) hydrodynamically damped cantilever and not the bulk liquid viscosity of $\sim 34 \mathrm{mPa} \cdot \mathrm{s}$. While there is currently no consensus on the correct implementation of hydrodynamic loading in a semi-infinite bath, ${ }^{24,25,27,28}$ we expect that the fractional change in local viscosity with respect to the bulk should remain constant, i.e., the viscosity of our RTIL on mica increases by a factor of $\sim 2.5$ as the wall is approached, while on HOPG it decreases to approximately half its bulk value.

\subsection{Conclusions}

We measured the layered structure of the RTIL $[\text { Emim }]^{+}\left[\mathrm{NTf}_{2}\right]^{-}$on both mica and HOPG using FD and SAFD spectroscopies. Layers on mica are much stronger (and more numerous) than on HOPG, which can be attributed to the stronger driving force (electrostatic versus templating).

Furthermore, we separated the resistance to squeeze into its conservative and dissipative components. This allows the data to be presented universally by removing technique-dependent effects, such as flow, thus allowing direct comparison of layer stiffness to other techniques, such as SFA. Our layer stiffness data (in comparison to our previous work) highlight the importance of the role of the co-ions on the near-wall structure of an RTIL on a charged surface, something that requires more attention in the future.

Finally, the residual component of force (the dissipation) provides in- 
formation on local flow properties. While the charge-mediated layering on mica exhibits greatly enhanced damping, template-mediated layering on HOPG slightly reduces the damping. This suggests the preferentially flat-packed ions can skate across the weak potential landscape of HOPG slightly easier than they can push through bulk liquid, whereas the strong Coulombic potential landscape of mica grips the counterions firmly. Dynamic response can be tuned by careful choice of substrate chemistry. 


\section{References}

[1] Fedorov, M. V. and Kornyshev, A. A. (2014) Ionic Liquids at Electrified Interfaces. Chem. Rev., 114(5), 2978-3036.

[2] Hayes, R., Warr, G. G., and Atkin, R. (2015) Structure and Nanostructure in Ionic Liquids. Chem. Rev., 115(13), 6357-6426.

[3] Pott, T. and Méléard, P. (2009) New Insight into the Nanostructure of Ionic Liquids: A Small Angle X-ray Scattering (SAXS) Study on Liquid tri-alkylmethyl-ammonium bis (trifluoromethanesulfonyl)amides and their Mixtures. Phys. Chem. Chem. Phys., 11(26), 5469-5475.

[4] Morita, T., Ushio, M., Kanoh, K., Tanaka, E., and Nishikawa, K. (2012) Small-Angle X-ray Scattering Measurements of Ionic Liquids Pressurized with Carbon Dioxide Using Titanium Sample Holder: 1-Butyl-3methylimidazolium Bis(trifluoromethylsulfonyl) Amide Mixtures up to 22 MPa. Jpn. J. App. Phys., 51(7R), 076703.

[5] Uysal, A., Zhou, H., Feng, G., Lee, S. S., Li, S., Fenter, P., Cummings, P. T., Fulvio, P. F., Dai, S., and McDonough, J. K. (2013) Structural Origins of Potential Dependent Hysteresis at the Electrified Graphene/Ionic Liquid Interface. J. Phys. Chem. C, 118(1), 569-574.

[6] Perkin, S., Albrecht, T., and Klein, J. (2010) Layering and Shear Properties of an Ionic Liquid, 1-ethyl-3-methylimidazolium Ethylsulfate, Confined to Nano-films between Mica Surfaces. Physical chemistry chemical physics, 12(6), 1243-1247.

[7] Perkin, S., Crowhurst, L., Niedermeyer, H., Welton, T., Smith, A. M., and Gosvami, N. N. (2011) Self-assembly in the Electrical Double Layer of Ionic Liquids. Chem. Commun., 47(23), 6572-6574.

[8] Perkin, S. (2012) Ionic Liquids in Confined Geometries. Phys. Chem. Chem. Phys., 14(15), 5052-5062.

[9] Atkin, R., El Abedin, S. Z., Hayes, R., Gasparotto, L. H., Borisenko, N., and Endres, F. (2009) AFM and STM Studies on the Surface Interaction of [BMP] TFSA and [EMIm] TFSA Ionic Liquids with Au (111). J. Phys. Chem. C, 113(30), 13266-13272.

[10] Hayes, R., Warr, G. G., and Atkin, R. (2010) At the Interface: Solvation and Designing Ionic Liquids. Phys. Chem. Chem. Phys., 12(8), 1709-1723.

[11] Hayes, R., Borisenko, N., Tam, M. K., Howlett, P. C., Endres, F., and Atkin, R. (2011) Double Layer Structure of Ionic Liquids at the Au (111) Electrode Interface: An Atomic Force Microscopy Investigation. J. Phys. Chem. C, $\mathbf{1 1 5}(14), 6855-6863$.

[12] Smith, A. M., Lovelock, K. R., Gosvami, N. N., Welton, T., and Perkin, 
S. (2013) Quantized Friction Across Ionic Liquid Thin Films. Phys. Chem. Chem. Phys., 15(37), 15317-15320.

[13] Li, H., Rutland, M. W., and Atkin, R. (2013) Ionic Liquid Lubrication: Influence of Ion Structure, Surface Potential and Sliding Velocity. Phys. Chem. Chem. Phys., 15(35), 14616-14623.

[14] Black, J. M., Walters, D., Labuda, A., Feng, G., Hillesheim, P. C., Dai, S., Cummings, P. T., Kalinin, S. V., Proksch, R., and Balke, N. (2013) Bias-Dependent Molecular-Level Structure of Electrical Double Layer in Ionic Liquid on Graphite. Nano Lett., 13(12), 5954-5960.

[15] Gebbie, M. A., Valtiner, M., Banquy, X., Fox, E. T., Henderson, W. A., and Israelachvili, J. N. (2013) Ionic Liquids Behave as Dilute Electrolyte Solutions. Proc. Natl. Acad. Sci. U. S. A., 110(24), 9674-9679.

[16] Perkin, S., Salanne, M., Madden, P., and Lynden-Bell, R. (2013) Is a Stern and Diffuse Layer Model Appropriate to Ionic Liquids at Surfaces?. Proc. Natl. Acad. Sci. U. S. A., 110(44), E4121-E4121.

[17] Seddon, J. R. (2014) Conservative and Dissipative Interactions of Ionic Liquids in Nanoconfinement. J. Phys. Chem. C, 118(38), 22197-22201.

[18] Atkin, R. and Warr, G. G. (2007) Structure in Confined Room-Temperature Ionic Liquids. J. Phys. Chem. C, 111(13), 5162-5168.

[19] Hayes, R., El Abedin, S. Z., and Atkin, R. (2009) Pronounced Structure in Confined Aprotic Room-Temperature Ionic Liquids. J. Phys. Chem. B, 113(20), 7049-7052.

[20] de Beer, S., van den Ende, D., and Mugele, F. (2008) Atomic Force Microscopy Cantilever Dynamics in Liquid in the Presence of Tip Sample Interaction. Appl. Phys. Lett., 93(25), 253106.

[21] de Beer, S., Van den Ende, D., and Mugele, F. (2010) Dissipation and Oscillatory Solvation Forces in Confined Liquids Studied by Small-Amplitude Atomic Force Spectroscopy. Nanotechnology, 21(32), 325703.

[22] Sader, J. E. (1998) Frequency Response of Cantilever Beams Immersed in Viscous Fluids with Applications to the Atomic Force Microscope. J. Appl. Phys., 84(1), 64-76.

[23] Maali, A., Hurth, C., Boisgard, R., Jai, C., Cohen-Bouhacina, T., and Aimé, J.-P. (2005) Hydrodynamics of Oscillating Atomic Force Microscopy Cantilevers in Viscous Fluids. J. Appl. Phys., 97(7), 074907.

[24] Green, C. P. and Sader, J. E. (2005) Small Amplitude Oscillations of a Thin Beam Immersed in a Viscous Fluid near a Solid Surface. Phys. Fluids, 17(7), 073102 .

[25] Green, C. P. and Sader, J. E. (2005) Frequency Response of Cantilever Beams 
Immersed in Viscous Fluids near a Solid Surface with Applications to the Atomic Force Microscope. J. Appl. Phys., 98(11), 114913.

[26] Sweeney, J., Hausen, F., Hayes, R., Webber, G. B., Endres, F., Rutland, M. W., Bennewitz, R., and Atkin, R. (2012) Control of Nanoscale Friction on Gold in an Ionic Liquid by a Potential-Dependent Ionic Lubricant Layer. Phys. Rev. Lett., 109(15), 155502.

[27] Vinogradova, O. I., Butt, H.-J., Yakubov, G. E., and Feuillebois, F. (2001) Dynamic Effects on Force Measurements. I. Viscous Drag on the Atomic Force Microscope Cantilever. Rev. Sci. Instrum., 72(5), 2330-2339.

[28] Naik, T., Longmire, E. K., and Mantell, S. C. (2003) Dynamic Response of a Cantilever in Liquid Near a Solid Wall. Sens. Actuators, A, 102(3), 240-254. 



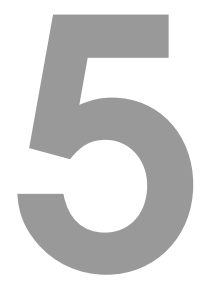

\section{Near-Wall Molecular Ordering of Dilute Ionic Liquids}

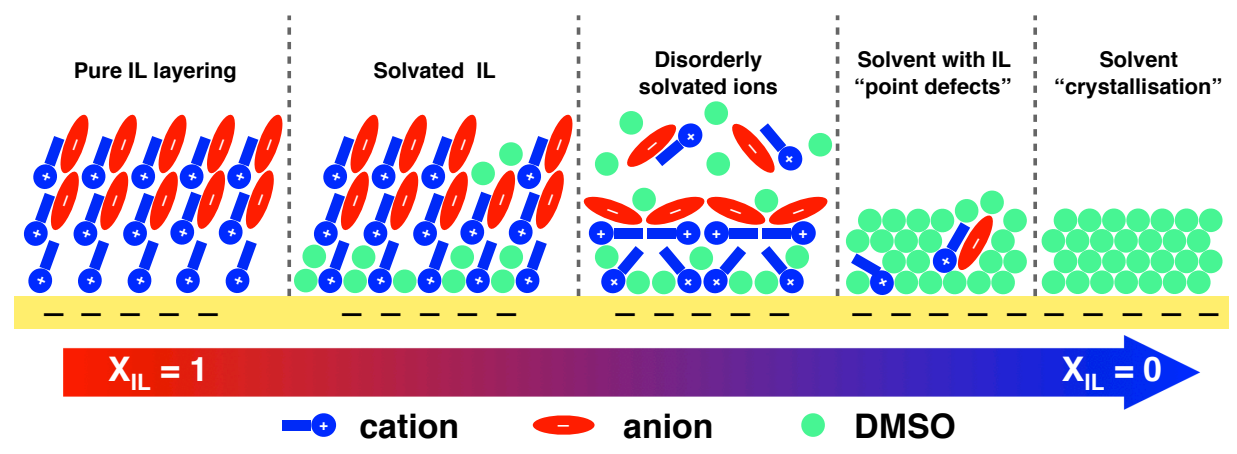

Currently, great interests have been drawn to dilute ionic liquids because their bulks properties, such as electric conductivity, can be optimized for practical uses. The content of this chapter mainly focuses on the near-wall structure of ionic liquid-solvent mixtures. An atomic force microscope was used for the force-distance spectroscopy, revealing nonmonotonic change of the structural force by varying liquid composition. This is of key importance for tunable nanolubrication by controlling the material's bulk properties.

${ }^{*}$ The contents of this chapter have been published as: M. Jitvisate et al., "Near-Wall Molecular Ordering of Dilute Ionic Liquids," J. Phys. Chem. C, 121, 18593-18597 (2017) 


\subsection{Introduction}

Ionic liquids (ILs) are organic salts in the liquid phase at room temperature, with the direct result that they have high ionic strength, low volatility, high temperature stability, and inflammability. ${ }^{1,2}$ This has allowed them to find excellent use in energy harvesting and storage technologies, as well as promising switchable lubrication in nanoconfinement. For these applications, one of the most important properties of ILs is their interfacial behavior: It is well accepted that they form discrete molecular layers at solid/liquid interfaces, formed through the disruption of hydrogen-bonded networks within the liquid, for example. ${ }^{3-14}$ The intricate near-wall behavior of the ions then plays a governing role in interlayer slip, as well as in controlling accessibility to an underlying electrode for electron transfer. $^{2,15-17}$

Despite the vast literature base on IL ordering in the near-wall region, investigations have so far been almost exclusively related to pure ILs. However, in real applications, it is unlikely that ILs would be used in their pure form. The high viscosity counteracts the high ion concentration, so the overall electrical conductivity is relatively low. ${ }^{18}$ Furthermore, pure ILs remain economically unfeasible. This means that the future will depend more heavily on dilute ILs, which are relatively inexpensive and overcome the practical limitations listed above. To date, only a small number of studies in the literature have focused on the interfacial behavior of dilute ILs, but, even then, most use water or acetonitrile (ACN) as the solvent. ${ }^{19,20}$ These solvents are both highly volatile and limited in electrochemical window $(\mathrm{ECW}),{ }^{21}$ which means that they are not desirable because they remove the main reasons for choosing ILs as electrolytes in the first place. A possible way forward is to use dilute ILs but with a solvent that has a low volatility and large ECW. Dimethyl sulfoxide (DMSO) is one such solvent. It is polar and aprotic and overcomes the limitations of both ACN and water in terms of both volatility and ECW. ${ }^{21-23}$ Further, it is miscible with a wide range of ILs, hence offering great practicality for applications.

Here, we use force-distance (FD) spectroscopy with an atomic force microscope (AFM) to study the near-wall structure of 
the ILs 1-ethyl-3-methylimidazolium bis(trifluoromethylsulfonyl)imide $\left([\text { Emim }]^{+}\left[\mathrm{NTf}_{2}\right]^{-}\right)$, 1-buthyl-1-methylpyrrolidinium bis(trifluoromethylsulfonyl $)$ imide $\left(\left[\mathrm{C}_{4} \mathrm{mpyr}\right]^{+}\left[\mathrm{NTf}_{2}\right]^{-}\right)$, and 1-ethyl-3-methylimidazolium dicyanamide $\left([\mathrm{Emim}]^{+}[\mathrm{DCA}]^{-}\right)$, solvated by DMSO, on a mica wall. Mica was chosen as the substrate because it is atomically flat with a well-defined charge per unit area. It has an octahedral crystal structure, with the unit cell parameters $a=0.519 \mathrm{~nm}, b=0.901 \mathrm{~nm}$, and $c=2.00 \mathrm{~nm}$. In its fully dissociated condition, it contains an average area per negative charge site of $0.47 \mathrm{~nm}^{2}$ (approximate surface charge of $2 \mathrm{e} / \mathrm{nm}^{2}$ ). ${ }^{24}$ However, the surface charge of mica in ionic liquids is still not truly known. According to recent electrical double layer potential measurements using surface force apparatus, the calculated surface charges of mica at $22^{\circ} \mathrm{C}$ in the ionic liquids $\left[\mathrm{C}_{2} \mathrm{mim}\right]^{+}\left[\mathrm{NTf}_{2}\right]^{-}$and $\left[\mathrm{C}_{3} \mathrm{mim}\right]^{+}\left[\mathrm{NTf}_{2}\right]^{-}$are $0.28 \mathrm{C} / \mathrm{m}^{2}$ $\left(\sim 1.76 \mathrm{e} / \mathrm{nm}^{2}\right)$ and $0.19 \mathrm{C} / \mathrm{m}^{2}\left(\sim 1.16 \mathrm{e} / \mathrm{nm}^{2}\right)$, respectively. ${ }^{25}$ From these values, it is clear that the mica surface in pure ionic liquids is close to fully dissociated. The three ILs were chosen to allow conclusions to be drawn on the effects of both cations and anions. We found nonlinear near-wall structural changes upon dilution that appear to correlate with solvent molecules initially space-filling and solvating and later disrupting the ionic layers.

\subsection{Experimental methods}

We used mica (Bruker) as the substrate, which we freshly cleaved immediately prior to use. The ILs were $[\text { Emim }]^{+}\left[\mathrm{NTf}_{2}\right]^{-},[\mathrm{Emim}]^{+}[\mathrm{DCA}]^{-}$, and $\left[\mathrm{C}_{4} \mathrm{mpyr}\right]^{+}\left[\mathrm{NTf}_{2}\right]^{-}$(>99\%, Merck Millipore), used as received from the manufacturer. These ILs were mixed with anhydrous dimethyl sulfoxide (DMSO) (>99.9\%, Sigma-Aldrich) to form mixtures with IL mole fractions of $1,0.9,0.75,0.5,0.25$, and 0.1 These mole fractions correspond to number density ratios of IL molecules to total molecules in the mixture. All chemicals were kept and prepared in an MBraun LABmaster glovebox, filled with purified nitrogen, and we performed all experiments at $25^{\circ} \mathrm{C}$.

We measured the near-wall ion ordering with force-distance (FD) spectroscopy using an Asylum Cypher AFM (Santa Barbara, CA). For each IL 


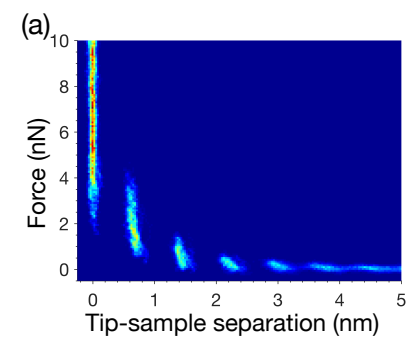

(d)

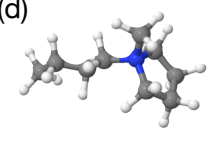

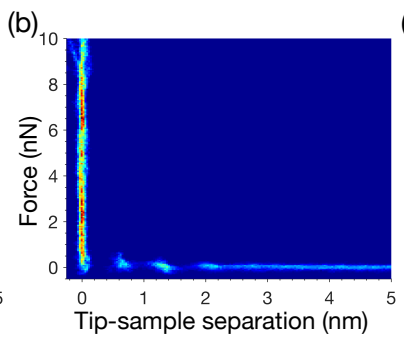

(e)

(f) (g)

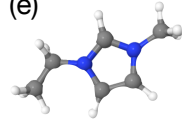

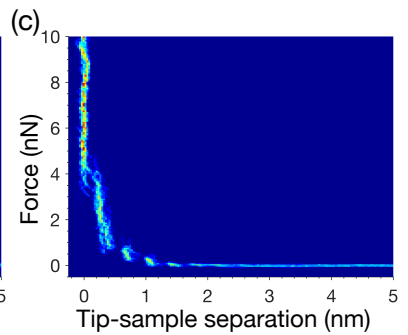

(h)
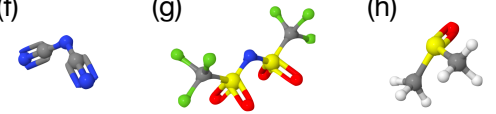

Figure 5.1: (a-c) Force-distance spectroscopy of $[\mathrm{Emim}]^{+}\left[\mathrm{NTf}_{2}\right]^{-} / \mathrm{DMSO}$ mixtures, at IL concentrations of (a) $100 \%$, (b) $50 \%$, and (c) $0 \%$. Discrete molecular layers of the liquids form on the mica wall and extend several nanometers into the bulk. (d-h) The molecules used in this study are $(\mathrm{d})\left[\mathrm{C}_{4} \mathrm{mpyr}\right]^{+}$, (e) $[\text {Emim }]^{+},(\mathrm{f})$ $[\mathrm{DCA}]^{-},(\mathrm{g})\left[\mathrm{NTf}_{2}\right]^{-}$, and (h) DMSO.

dilution, we deposited a droplet of $\sim 80 \mu \mathrm{L}$ on the mica and immediately started measuring. The AFM was placed on a vibration-free bench in the laboratory environment, and each measurement typically took less than $1 \mathrm{~h}$.

The cantilevers were Au-coated $\mathrm{Si}_{3} \mathrm{~N}_{4}$ (ORC8, Bruker). The spring constants, $k_{\mathrm{s}}$, were measured to be between 0.4 and $0.7 \mathrm{~N} / \mathrm{m}$, and the tip radius of curvature, $R$, was quoted to be $15 \mathrm{~nm}$ by the manufacturer. To obtain the force curves, the AFM tip was moved toward the surface using a piezo with the speed of $5 \mathrm{~nm} / \mathrm{s}$ until a predefined trigger point was reached. The voltage of the approach piezo versus deflection of the cantilever measured using a photodiode were converted into tip-wall separation versus force in the usual way. Twenty force curves were collected for each liquid mole fraction in our experiment, and these are plotted as histograms in this article. (As a note, when we discuss the number of layers, this is clearly the number of layers within our resolution, which is approximately $100 \mathrm{pN}$. We imagine that other layers might exist below this measurement resolution). 


\subsection{Results and discussion}

We begin by presenting the FD spectroscopy data for the $100 \%, 50 \%$, and $0 \%$ mixtures of $[\mathrm{Emim}]^{+}\left[\mathrm{NTf}_{2}\right]^{-}$with DMSO in Figure 5.1 (see Figure A5.1 for all dilutions studied for each of the ILs). The $x$ axes represent the separation between the substrate and AFM tip, with the substrate located at $0 \mathrm{~nm}$. The $y$ axes represent the tip-sample interaction due to the squeeze film of IL between tip and wall, that is, the force (sometimes referred to as the structural force) exerted by the liquid on the AFM tip. As the tip approaches the wall, a series of discrete steps occurs, corresponding to ordered layers of liquid molecules on the mica surface. The fact that this near-wall molecular ordering can be seen is because it exhibits quite a large degree of rigidity: To push through each layer, the AFM cantilever must bend to store sufficient (elastic) energy to rupture the layer; then the liquid molecules "pop" out, and the tip jumps to the next layer.

Liquid layering occurs in both ILs and DMSO because the molecules are templated by the underlying atomically smooth crystal structure of mica. ${ }^{26}$ We plot the number of layers observed for each of our IL dilutions in Figure 5.2a. The first data we describe are for the pure systems, namely, the pure ILs at a concentration percentage of $X_{I L}=1$ and the pure solvent at $X_{I L}=0$. In all cases, the pure liquids form several well-ordered layers. However, it is surprising that the different ILs exhibit different numbers of layers. We naïvely expected the first layer to be predominantly filled with cations (due to the dissociation of $\mathrm{K}^{+}$ions from the mica surface) and to template subsequent layers. This would intuitively lead to the two ILs with similar cations $\left([\text { Emim }]^{+}\left[\mathrm{NTf}_{2}\right]^{-}\right.$and $[\text {Emim }]^{+}[\mathrm{DCA}]^{-}$) exhibiting similar near-wall structures. In reality, however, we found that $[\text { Emim }]^{+}\left[\mathrm{NTf}_{2}\right]^{-}$forms six layers whereas $[\text {Emim }]^{+}[\mathrm{DCA}]^{-}$only forms three. This is a strong indication that the co-ion plays a key role in the layer formation, even when charge screening is required, hinting that templating is more important than charge screening as a driving force for the molecular ordering. The third IL $\left(\left[\mathrm{C}_{4} \mathrm{mpyr}\right]^{+}\left[\mathrm{NTf}_{2}\right]^{-}\right)$sits between the other two in terms of the number of layers it creates in its pure form, exhibiting five distinct layers on mica. It could be that the ratio of cation size to anion size 
(a)

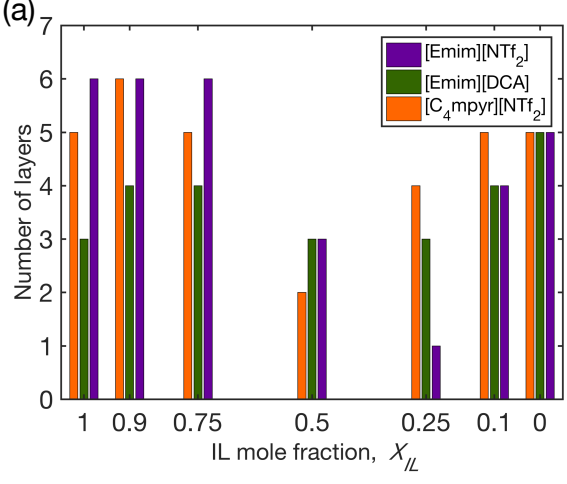

(b)

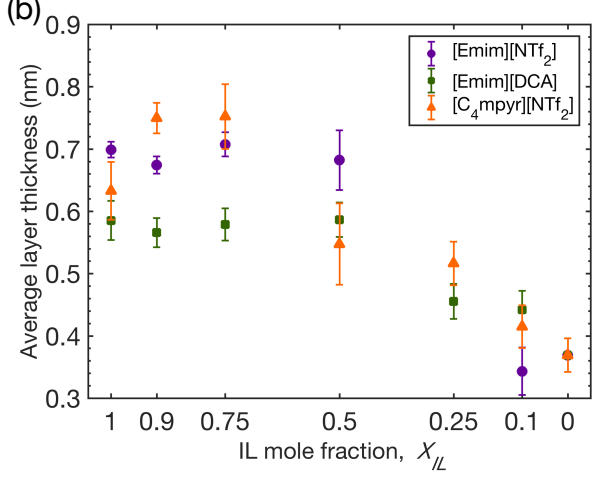

Figure 5.2: (a) Number of layers and (b) average layer thickness as a function of IL mole fraction. The average layer thickness is calculated from the first three layers. The mixtures have fewer of layers at medium dilutions because of structural switching from high to low IL concentration.

governs the number of layers. This is certainly true for our three ILs, with the more equally sized systems exhibiting more layers than the less equally sized systems, but the complex geometries of the different molecules, as well as the position of the valency along the molecule, must also be taken into account for a full description of this observation.

As we began to dilute the ILs, we found the surprising result that the number of ordered liquid layers increases. By comparing the $X_{I L}=1$ data to the $X_{I L}=0.9$ data, one can immediately see that the number of layers of $[\mathrm{Emim}]^{+}[\mathrm{DCA}]^{-}$increases from three to four, whereas the number of layers of $\left[\mathrm{C}_{4} \mathrm{mpyr}\right]^{+}\left[\mathrm{NTf}_{2}\right]^{-}$increases from five to six. This observation was unforeseen: We expected the addition of solvent to disrupt the nearwall molecular ordering of the IL, that is, to reduce the layering effect, not enhance it. We imagine that this is due to solvation of the cations in the first layer by DMSO molecules. Anions would not sit preferentially in the first layer, which should be cation-rich for charge-screening purposes, ${ }^{11,12,27}$ but also the cations would not be immediately adjacent to each other either because of electrostatic repulsion.

Also, working from the pure DMSO case, where one can see five distinct molecular layers form on the mica, adding a small amount of IL disrupts these layers slightly, and the number of layers drops from five to four for the 
two $[\text { Emim }]^{+}$ILs. It is clear that layer enhancement should not occur during the dilution of the pure DMSO: It has only one molecule type, and it can pack very well. Any disruption of this ordering should reduce the overall near-wall preferential ordering. Why do the $[\text { Emim }]^{+}$ILs show a larger effect than $\left[\mathrm{C}_{4} \mathrm{mpyr}\right]^{+}$? We believe that the cation charge location is more accessible to the electronegative oxygen of the DMSO on the $[\text { Emim }]^{+}$ion than on the $\left[\mathrm{C}_{4} \mathrm{mpyr}\right]^{+}$ion, allowing the imidazolium ion to penetrate deeper into the layered structure and thus provide more disruption. ${ }^{28,29}$

In addition to the number of layers, the average layer thickness also provides information on the local packing; see Figure 5.2b. For all pure ILs, the first few layers are slightly thinner than the bulk ion-pair dimensions (see Table A5.1), but it is also clear that the specific orientation of the cation in the first layer changes depending on the type of anion. As we diluted the ILs, the two imidazolium liquids retained their "pure" layer thickness until a mole fraction of $\sim 0.5$. Below this mole fraction, the layer thickness drops linearly until the pure DMSO is reached at $X_{I L}=0$. The near-wall structure of the pyrolidinium liquid actually swells during initial dilution, but then it also drops linearly in the weak dilution limit. This linear drop-off is different from the case of the solvent propylene carbonate (PC). ${ }^{30}$ Mixtures of $\left[\mathrm{C}_{4} \mathrm{mpyr}\right]^{+}\left[\mathrm{NTf}_{2}\right]^{-}$and $\mathrm{PC}$ on mica exhibit a steplike switch in near-wall geometry with concentration, which indicates that the dependence of local ordering on dilution is solvent-specific.

We now understand that DMSO preferentially solvates cations over anions and that this leads to an enhancement of molecular ordering of ILs on mica for highly concentrated solutions, crossing over to full solvent ordering at weak dilutions. This would be confirmed by an increase in the force required to rupture the near-wall ordered layers as solvent is added. The rupture forces of the first three layers are plotted as a function of IL mole fraction in Figure 5.3. Among these layers, we expect the first layer immediately adjacent to the mica to be heavily influenced by the surface charge (Figure 5.3a), that is, electrostatic interaction might be a significant contributory factor for the layer strength of the first layer. In this respect, considering the pure ILs $\left(X_{I L}=1\right)$, it is perhaps unsurprising that the two $[\text { Emim }]^{+}$cations exhibit the same rupture force, within the error, indicating 

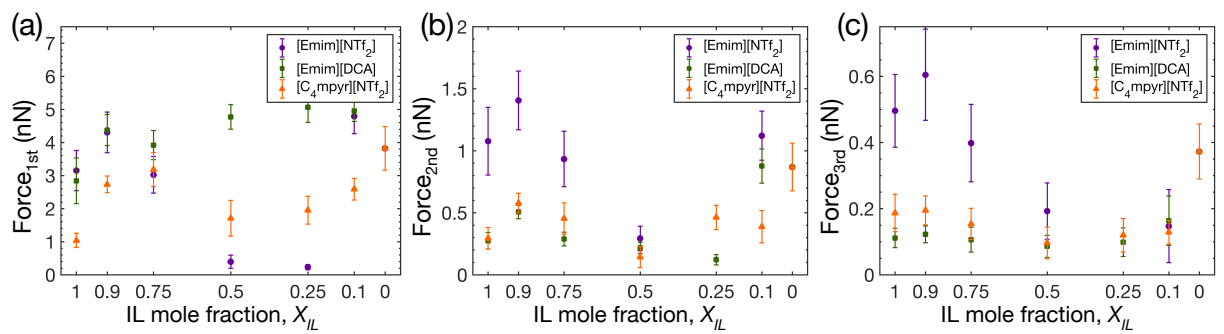

Figure 5.3: Average rupture force required for pushing through (a) the first layer (innermost), (b) the second layer, and (c) the third layer, at corresponding mole fraction. Each data point was averaged over 20 force-distance curves at the highest force of each layer.

that the anion is less important in the packing structure in the first layer. The third pure IL, with the pyrolidinium cation, exhibits a smaller rupture force for the first layer than the two imidazolium ILs, and we interpret this effect as resulting from the bulkiness of the ion disrupting packing with its neighbors in the plane.

Now, we turn to the dilute ILs. The common behavior for the first layer of all three ILs is that the rupture force (i) increases when a small amount of DMSO is added, (ii) decreases at medium concentrations, and (iii) then increases again in the very dilute regime. All of these observations agree with our discussion earlier in the article regarding the solvent sitting in voids between adjacent ions at the wall. For example, the initial increase in rupture force upon a small addition of solvent is fully supported if the solvent molecules do indeed sit in the voids, thus increasing the layer packing through space-filling. At mixtures closer to 50:50 composition, the local packing strength is lost as the liquid become more anisotropic, whereas at weaker dilutions, the strong DMSO packing leads to an increase in strength once more.

The rupture force for the second and third layers exhibits the same overall trend as that for the first layer, with an initial increase in force from a small addition of solvent, then a decrease at intermediate mixture compositions, and then an increase again at almost pure DMSO. The same argument for this behavior in the first layer also holds for these two subsequent layers, but now, $[\mathrm{Emim}]^{+}\left[\mathrm{NTf}_{2}\right]^{-}$is overall stronger than both of 
the other two ILs. This indicates that the packing beyond the first layer is governed primarily by neither the cation (where we would imagine similarity between $[\mathrm{Emim}]^{+}\left[\mathrm{NTf}_{2}\right]^{-}$and $[\mathrm{Emim}]^{+}[\mathrm{DCA}]^{-}$) nor the anion (where we would imagine similarity between $[\text { Emim }]^{+}\left[\mathrm{NTf}_{2}\right]^{-}$and $\left.\left[\mathrm{C}_{4} \mathrm{mpyr}\right]^{+}\left[\mathrm{NTf}_{2}\right]^{-}\right)$. Instead, we believe that ion pairs are the main constituents that give these layers their strength, with or without solvent, and any additional interactions between the dense electron cloud on the oxygen of the DMSO and the $[\text { Emim }]^{+}$cation is now only secondary.

\subsection{Conclusions}

In summary, we measured the layering structure of the ILs $[\text { Emim }]^{+}\left[\mathrm{NTf}_{2}\right]^{-}, \quad[\text { Emim }]^{+}[\mathrm{DCA}]^{-}$, and $\left[\mathrm{C}_{4} \mathrm{mpyr}\right]^{+}\left[\mathrm{NTf}_{2}\right]^{-}$on mica as a function of dilution with DMSO over the full range of concentrations using FD spectroscopy. We found that the number of ordered liquid layers, layer thickness, and rupture force vary with the mole fraction of IL in DMSO. A small amount of DMSO can increase the strength of the layers. Adding more DMSO leads to a structural crossover from a well-ordered IL structure to a well-ordered solvent structure, with the second chemical species acting as point defects disrupting this structure at low concentrations, but this crossover is not switch-like as in the case of the solvent PC. One possible interpretation of our results is that the DMSO solvates the cations and fills the free volume between the IL molecules, with these stronger layers then able to template liquid further into the bulk. This speculative interpretation would explain the observations presented here, but it is clear that extensive (molecular dynamics) computation is required for a full understanding.

We believe that our observations are highly relevant for controllable lubrication in nanoconfinement (e.g., nanofluidics, nanoslits, nanopores) where the interplay of adjacent molecular layers can either enhance or restrict local flow properties. We also see relevance in ionic liquid energy technologies where we expect solvation to prove useful for optimizing electrical conductance, for example, but where "crystallization" of solvent must be avoided. 


\subsection{Appendix}

\subsubsection{Force--distance curves measured in different ionic liq- uids at varied ion compositions}

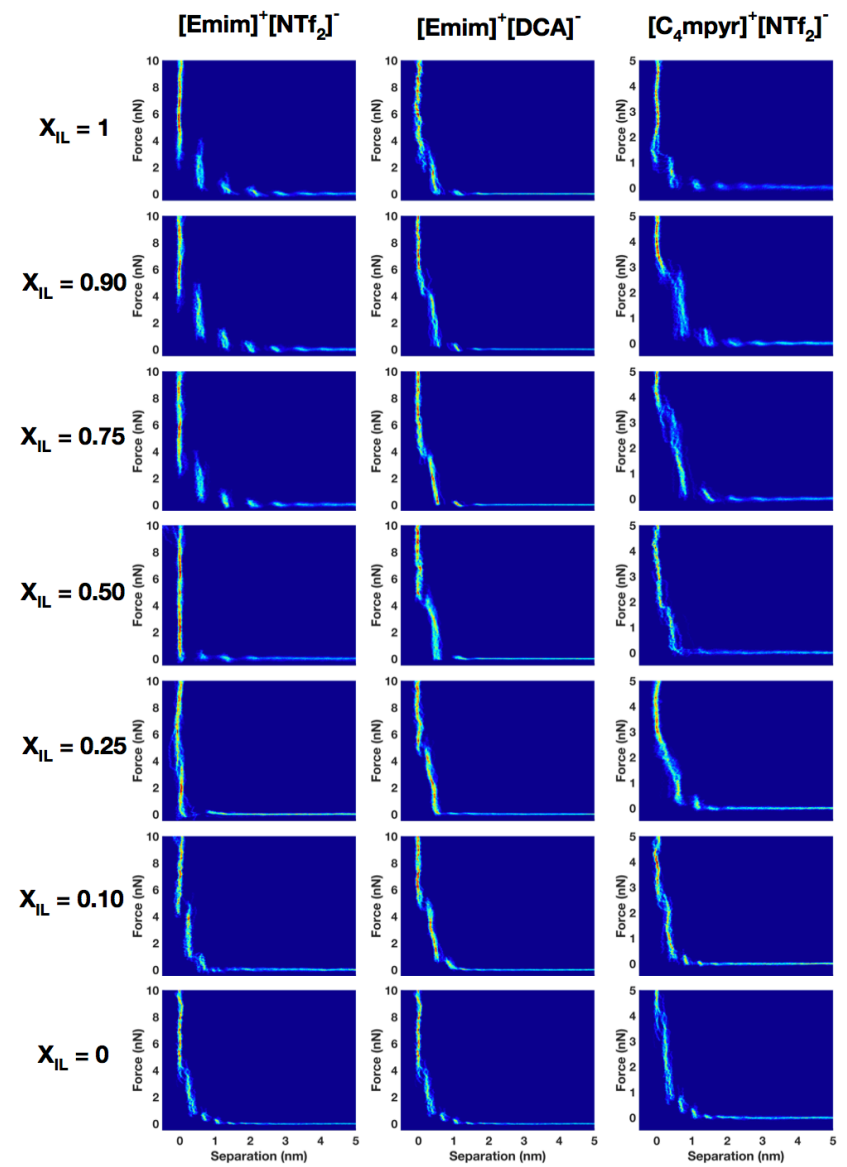

Figure A5.1: Force-distance spectroscopy of the $[\mathrm{Emim}]^{+}\left[\mathrm{NTf}_{2}\right]^{-}$, $[\mathrm{Emim}]^{+}[\mathrm{DCA}]^{-}$, and $\left[\mathrm{C}_{4} \mathrm{mpyr}\right]^{+}\left[\mathrm{NTf}_{2}\right]^{-}$at different dilutions. Note that $X_{\mathrm{IL}}=1$ corresponds to pure ionic liquids and $X_{\mathrm{IL}}=0$ corresponds to pure DMSO. The data are averaged over 20 measurements, binned over 200 bins on both axes. The color scales corresponds to the probability of finding the data in a given bin, with blue indicating 0 probability and red indicating a probability of 1 . 
5.5.2 Molecular dimensions of ionic liquids

\begin{tabular}{|c|c|c|}
\hline Molecules & $\begin{array}{c}\text { Ellipsoidal dimensions } \\
(\mathrm{nm} \times \mathrm{nm} \times \mathrm{nm})\end{array}$ & $\begin{array}{c}\text { Ion pair dimensions } \\
(\mathrm{nm})\end{array}$ \\
\hline$\left[\mathrm{C}_{4} \mathrm{mpyr}\right]^{+}$ & $0.8 \times 0.35 \times 0.3$ & - \\
{$[\mathrm{Emim}]^{+}$} & $0.84 \times 0.6 \times 0.3$ & - \\
{$\left[\mathrm{NTf}_{2}\right]^{-}$} & $1.1 \times 0.5 \times 0.5$ & - \\
{$[\mathrm{DCA}]^{-}$} & $0.49 \times 0.14$ & - \\
{$[\mathrm{BF}]^{-}$} & 0.2 & 0.8 \\
{$\left[\mathrm{C}_{4} \mathrm{mpyr}\right]^{+}\left[\mathrm{NTf}_{2}\right]^{-}$} & - & 0.75 \\
{$[\text { Emim }]^{+}\left[\mathrm{NTf}_{2}\right]^{-}$} & - & 0.64 \\
{$[\mathrm{Emim}]^{+}[\mathrm{DCA}]^{-}$} & - & 0.63 \\
{$[\mathrm{Emim}]^{+}[\mathrm{BF}]_{4}^{-}$} & - & 0.49 \\
$\mathrm{DMSO}$ & $0.42 \times 0.39 \times 0.17$ & - \\
\hline
\end{tabular}

Table A5.1: Molecular dimensions of equivalent ellipsoids for the different molecules used in this study, and the ion pair dimensions calculated from bulk density. 


\section{References}

[1] Pott, T. and Méléard, P. (2009) New Insight into the Nanostructure of Ionic Liquids: A Small Angle X-ray Scattering (SAXS) Study on Liquid tri-alkylmethyl-ammonium bis (trifluoromethanesulfonyl)amides and their Mixtures. Phys. Chem. Chem. Phys., 11(26), 5469-5475.

[2] Fedorov, M. V. and Kornyshev, A. A. (2014) Ionic Liquids at Electrified Interfaces. Chem. Rev., 114(5), 2978-3036.

[3] Morita, T., Ushio, M., Kanoh, K., Tanaka, E., and Nishikawa, K. (2012) Small-Angle X-ray Scattering Measurements of Ionic Liquids Pressurized with Carbon Dioxide Using Titanium Sample Holder: 1-Butyl-3methylimidazolium Bis(trifluoromethylsulfonyl) Amide Mixtures up to 22 MPa. Jpn. J. App. Phys., 51(7R), 076703.

[4] Uysal, A., Zhou, H., Feng, G., Lee, S. S., Li, S., Fenter, P., Cummings, P. T., Fulvio, P. F., Dai, S., and McDonough, J. K. (2013) Structural Origins of Potential Dependent Hysteresis at the Electrified Graphene/Ionic Liquid Interface. J. Phys. Chem. C, 118(1), 569-574.

[5] Mezger, M., Ocko, B. M., Reichert, H., and Deutsch, M. (2013) Surface Layering and Melting in an Ionic Liquid Studied by Resonant Soft X-ray Reflectivity. Proc. Natl. Acad. Sci. U. S. A., 110(10), 3733-3737.

[6] Perkin, S., Crowhurst, L., Niedermeyer, H., Welton, T., Smith, A. M., and Gosvami, N. N. (2011) Self-assembly in the Electrical Double Layer of Ionic Liquids. Chem. Commun., 47(23), 6572-6574.

[7] Perkin, S. (2012) Ionic Liquids in Confined Geometries. Phys. Chem. Chem. Phys., 14(15), 5052-5062.

[8] Smith, A. M., Lovelock, K. R., Gosvami, N. N., Welton, T., and Perkin, S. (2013) Quantized Friction Across Ionic Liquid Thin Films. Phys. Chem. Chem. Phys., 15(37), 15317-15320.

[9] Atkin, R., El Abedin, S. Z., Hayes, R., Gasparotto, L. H., Borisenko, N., and Endres, F. (2009) AFM and STM Studies on the Surface Interaction of [BMP] TFSA and [EMIm] TFSA Ionic Liquids with Au (111). J. Phys. Chem. C, 113(30), 13266-13272.

[10] Hayes, R., Warr, G. G., and Atkin, R. (2010) At the Interface: Solvation and Designing Ionic Liquids. Phys. Chem. Chem. Phys., 12(8), 1709-1723.

[11] Hayes, R., Borisenko, N., Tam, M. K., Howlett, P. C., Endres, F., and Atkin, R. (2011) Double Layer Structure of Ionic Liquids at the Au (111) Electrode Interface: An Atomic Force Microscopy Investigation. J. Phys. Chem. C, 115(14), 6855-6863.

[12] Black, J. M., Walters, D., Labuda, A., Feng, G., Hillesheim, P. C., Dai, 
S., Cummings, P. T., Kalinin, S. V., Proksch, R., and Balke, N. (2013) Bias-Dependent Molecular-Level Structure of Electrical Double Layer in Ionic Liquid on Graphite. Nano Lett., 13(12), 5954-5960.

[13] Seddon, J. R. (2014) Conservative and Dissipative Interactions of Ionic Liquids in Nanoconfinement. J. Phys. Chem. C, 118(38), 22197-22201.

[14] Hayes, R., Warr, G. G., and Atkin, R. (2015) Structure and Nanostructure in Ionic Liquids. Chem. Rev., 115(13), 6357-6426.

[15] Kornyshev, A. A. (2007) Double-Layer in Ionic Liquids: Paradigm Change?. J. Phys. Chem. B, 111, 5545.

[16] Smith, A. M., Lovelock, K. R., and Perkin, S. (2013) Monolayer and Bilayer Structures in Ionic Liquids and their Mixtures Confined to Nano-Films. Faraday Discuss., 167, 279-292.

[17] Jitvisate, M. and Seddon, J. R. (2016) Local Structure and Flow Properties of Ionic Liquids on Charged and Inert Substrates. J. Phys. Chem. C, 120(9), 4860-4865.

[18] Chaban, V. V., Voroshylova, I. V., Kalugin, O. N., and Prezhdo, O. V. (2012) Acetonitrile Boosts Conductivity of Imidazolium Ionic Liquids. J. Phys. Chem. B, 116(26), 7719-7727.

[19] Wu, X., Liu, Z., Huang, S., and Wang, W. (2005) Molecular Dynamics Simulation of Room-Temperature Ionic Liquid Mixture of [bmim][BF4] and Acetonitrile by a Refined Force Field. Phys. Chem. Chem. Phys., 7(14), 27712779 .

[20] Wang, Z., Li, H., Atkin, R., and Priest, C. (2016) Influence of Water on the Interfacial Nanostructure and Wetting of [Rmim][NTf2] Ionic Liquids at Mica Surfaces. Langmuir, 32(35), 8818-8825.

[21] Marcus, Y. (1998) The Properties of Solvents, Vol. 16, Wiley Chichester, .

[22] Laoire, C. O., Mukerjee, S., Abraham, K., Plichta, E. J., and Hendrickson, M. A. (2010) Influence of Nonaqueous Solvents on the Electrochemistry of Oxygen in the Rechargeable Lithium-Air Battery. J. Phys. Chem. C, 114(19), 9178-9186.

[23] Krishnamoorthy, A. N., Zeman, J., Holm, C., and Smiatek, J. (2016) Preferential Solvation and Ion Association Properties in Aqueous Dimethyl Sulfoxide Solutions. Phys. Chem. Chem. Phys., 18(45), 31312-31322.

[24] Christenson, H. K. and Thomson, N. H. (2016) The Nature of the Air-Cleaved Mica Surface. Surf. Sci. Rep., 71(2), 367-390.

[25] Gebbie, M. A., Valtiner, M., Banquy, X., Fox, E. T., Henderson, W. A., and Israelachvili, J. N. (2013) Ionic Liquids Behave as Dilute Electrolyte Solutions. Proc. Natl. Acad. Sci. U. S. A., 110(24), 9674-9679. 
[26] Israelachvili, J. N. (2011) Intermolecular and Surface Forces, Academic press,

[27] Lynden-Bell, R. M., Frolov, A., and Fedorov, M. V. (2012) Electrode Screening by Ionic Liquids. Phys. Chem. Chem. Phys., 14(8), 2693-2701.

[28] Zhao, H. (2016) Protein Stabilization and Enzyme Activation in Ionic Liquids: Specific Ion Effects. J. Chem. Tech. Biotech., 91(1), 25-50.

[29] Schröder, C. (2017) Proteins in Ionic Liquids: Current Status of Experiments and Simulations. Top. Curr. Chem., $\mathbf{3 7 5}(2), 25$.

[30] Smith, A. M., Perkin, S., et al. (2017) Switching the Structural Force in Ionic Liquid-Solvent Mixtures by Varying Composition. Phys. Rev. Lett., 118(9), 096002. 




\section{6 \\ Ion Dissociation in Ionic Liquid Mixtures}

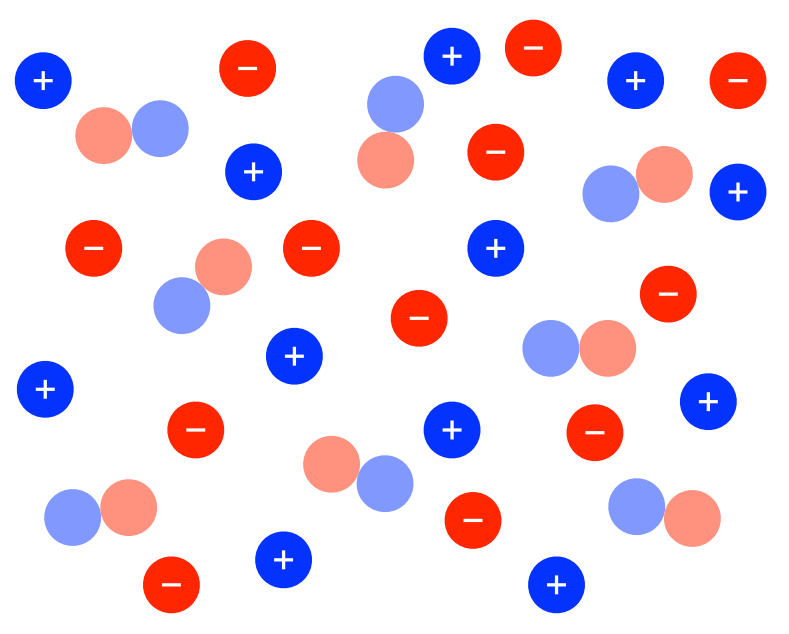

Colloidal probe microscopy is used to measure the electrostatic force between silicon dioxide surfaces across ionic liquid/ethylene glycol mixtures at different temperatures. Ion concentration is extracted from the measured screening length and the free ion fraction is calculated. In this measurement, about $60 \%$ of ions are found to be dissociated. This indicates that ionic liquid in ethylene glycol are not in full dissociation as in the case of traditional salts in water. 


\subsection{Introduction}

Ionic liquids (ILs) are salt in liquid phase at room temperature. They are considered to be a promising material for many applications, resulting from their unique properties such as high thermal/electrochemical stabilities, extremely low vapor pressure, and wide liquidus range. ${ }^{1-4}$ The conceptual picture of ILs has usually been imagined as a very dense electrolyte composed solely of free ions and thus having very short calculated Debye length. There was a recent observation of long-range electrostatic interaction measured with surface force apparatus (SFA) suggesting that an effective free ion concentration in ILs is lower than $0.1 \%$ of the entire bulk concentration, and the ILs should behave as dilute electrolytes. ${ }^{5}$

This surprising result has initiated an intense discussion and also the question about the true nature of free ions and bound ions (ion pairs) in ILs. $^{6,7}$ A following theoretical study contradicted the experimental results as it showed that the fraction of free ions in pure ILs should be approximately $67 \%$, that is, much more than those measured in the force measurements. ${ }^{8}$ However, a follow up experiment still confirmed the existence of a long-range force compatible with low dissociation and showed that the measured screening length decreases with an increasing of temperature, which leads to a conclusion that ILs are mostly composed of neutral aggregations and the population of the free ions can be increased by thermal activation. ${ }^{9}$

More evidences of long-range electrostatic force in ILs as well as in high concentration aqueous solutions have been measured by another research groups. ${ }^{10-14}$ Recent SFA measurements suggested that the screening length measured in electrolytes, including ILs, obeys the Debye-Hückel theory at the low concentration limit but deviates from the classical theory at the high concentration end. ${ }^{10}$ A scaling law for this phenomena was proposed, showing a general trend of the screening length for all electrolytes. ${ }^{15,16}$ However, the physical description of the ILs in the sense of free ions and neutral ion pairs remains a subject of discussion and the interpretations are still controversial.

It must be noted that the number of existing experiments on the longrange interaction in ILs is still very limited and even fewer for dilute ILs. 
In this respect, more independent experimental results are required to strengthen the existing observations and widen the current viewpoint. In this study, we measure the force between silicon dioxide surfaces across a full range of $\mathrm{IL} /$ solvent mixtures at different temperatures, aiming to provide more information about the free ion fraction in IL mixtures. The ion concentration is extracted from the measurement of the screening length and the result can be related to the dissociation nature of ILs in a solvent.

\subsection{Experimental methods}

The IL 1-ethyl-3-methylimidazolium tetrafluoroborate $\left([\mathrm{Emim}]^{+}\left[\mathrm{BF}_{4}\right]^{-}\right)$ and ethylene glycol (EG) were purchased with the purity of more than $99 \%$ (Sigma-Aldrich). The mixtures of $[\mathrm{Emim}]^{+}\left[\mathrm{BF}_{4}\right]^{-}$with EG were prepared to have an IL concentration, $c_{\text {prep }}$, of $0.5 \mathrm{mM}, 1.5 \mathrm{mM}, 5.3 \mathrm{mM}, 11.1 \mathrm{mM}$, $0.1 \mathrm{M}, 0.9 \mathrm{M}, 3.0 \mathrm{M}, 5.0 \mathrm{M}$, and $6.6 \mathrm{M}$ (pure IL). The liquid preparation was done by weighing method, which allows exact concentrations to be calculated from the mass of the liquids.

Force-distance experiments were performed using an Asylum Cypher ES AFM (Oxford Instruments, Santa Barbara, CA), where a sample is located on a temperature controlled stage in a sealed environmental cell. The AFM was placed on a vibration-free bench in the laboratory environment. The substrate was a grown silicon dioxide thin film on a silicon wafer, with the film thickness of a few hundred nanometers. Force probes were CPCONT silicon dioxide colloidal probes (sQube, Germany), with the radius of the colloidal particle quoted to be $\sim 3.3 \mu \mathrm{m}$. The spring constants of the cantilevers were measured to be in the range of $0.15-0.18 \mathrm{~N} / \mathrm{m}$ with the thermal noise method. The resolution of the force per unit radius, $F / R$, was calculated at the thermal limit to be $\pm 0.01 \mathrm{mN} / \mathrm{m}$ at $75^{\circ} \mathrm{C}$. Both the substrates and the colloidal probes were cleaned in oxygen plasma before the measurement. A droplet of examined liquid having a volume of about $50 \mu \mathrm{L}$ was deposited on the substrate. The temperature of the sample was controlled by the active feedback temperature controller of the AFM and the measurement was started immediately after the temperature of the sample was stable. 
Force curves were recorded while the probe was approaching the surface using the piezo with the speed of $\leqslant 8 \mathrm{~nm} / \mathrm{s}$ until the predefined trigger point was reached. The $z$-displacement vs. the deflection of the cantilever measured using a photodiode were converted to an apparent tip-sample separation, $D$, vs. normal force, $F(D)$, in the usual way. The measurement was done first in pure EG and followed by higher concentration mixtures at 25,50 , and $75^{\circ} \mathrm{C}$ for each concentration. More than 5-10 force curves were recorded for each temperature and concentration, and the error bars in this report are calculated from statistical analysis based on these data.

\subsection{Results and discussion}

The forces measured in the IL mixtures were found to be long-range in the liquid mixtures having concentration below $0.1 \mathrm{M}$, including pure EG, and found to be purely oscillatory in the range from $0.1 \mathrm{M}$ to pure IL (Figure A6.1). The near-wall discrete oscillatory force has been intensively studied and reported in literature, ${ }^{17-23}$ and only the long-range monotonic force will be discussed in this study. The representative force curves measured in pure EG and mixtures of $[\mathrm{Emim}]^{+}\left[\mathrm{BF}_{4}\right]^{-}$and EG are shown Figure 6.1, with the line plots corresponding to the exponential fits of eq 6.1

$$
\begin{gathered}
\frac{F(D)}{R}=\frac{8000 \pi N_{\mathrm{A}} e^{2} \lambda_{\mathrm{D}}^{*} c^{*}}{k_{\mathrm{B}} T} \psi^{2} \exp \left(-D / \lambda_{\mathrm{D}}^{*}\right) \\
\lambda_{\mathrm{D}}^{*}=\sqrt{\frac{\epsilon_{0} \epsilon_{\mathrm{r}} k_{\mathrm{B}} T}{2000 N_{\mathrm{A}} e^{2} c^{*}}}
\end{gathered}
$$

where $F(\mathrm{~N})$ is a force measured in the experiment, $R(\mathrm{~m})$ is the radius of the colloid particle, $N_{\mathrm{A}}\left(\mathrm{mol}^{-1}\right)$ is the Avogadro's number, $e(\mathrm{C})$ is an elementary charge, $k_{\mathrm{B}}(\mathrm{J} / \mathrm{K})$ is the Boltzmann's constant, $T(\mathrm{~K})$ is temperature, $\psi(\mathrm{V})$ is an apparent surface potential, $D(\mathrm{~m})$ is an apparent tip-sample separation, $c^{*}(\mathrm{~mol} / \mathrm{L})$ is a measured effective ion concentration, $\lambda_{\mathrm{D}}^{*}(\mathrm{~m})$ is an effective Debye length or an experimental screening length, $\epsilon_{0}(\mathrm{~F} / \mathrm{m})$ is an electric permittivity of free space, and $\epsilon_{\mathrm{r}}$ is a dielectric constant of the mixtures. Eq6.1 is an approximated equation for the constant surface potential solution of the Poisson-Boltzmann equation, 

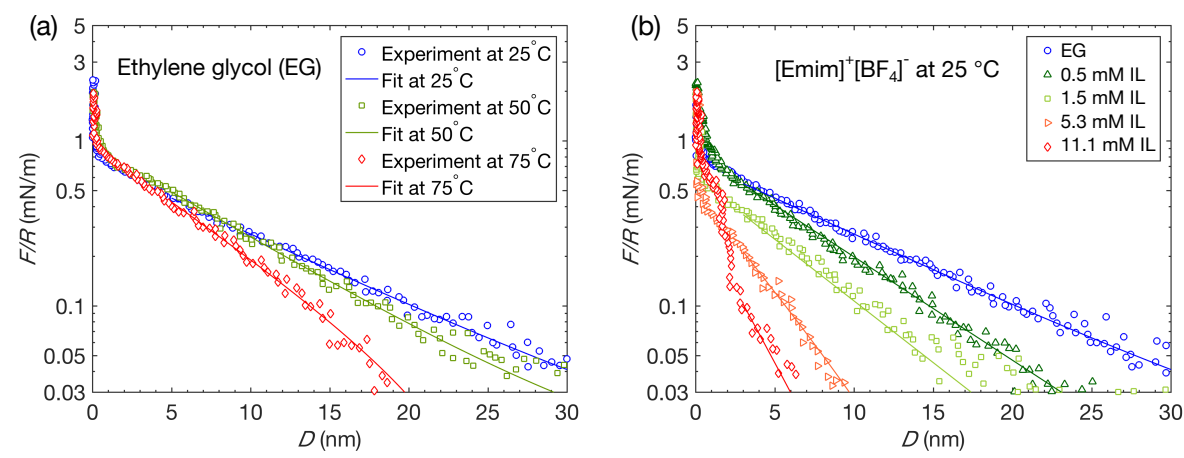

Figure 6.1: (a) Representative force profiles measured in EG at different temperatures showing the decreasing of the screening length as the temperature is elevated. (b) Representative force profiles measured at $25^{\circ} \mathrm{C}$ at varied $[\text { Emim }]^{+}\left[\mathrm{BF}_{4}\right]^{-}$concentration showing the decreasing of the screening length as the IL concentration is increased. The solid lines correspond to the exponential fits of eq 6.1 .

which is a good approximation in the region where $D>\lambda_{\mathrm{D}}^{*} \cdot{ }^{24}$

We first measured the forced in pure EG, where the resultant forcedistance profiles are plotted in Figure 6.1a. It is clear that the measured screening length has finite values that decrease with an increasing temperature. At $25^{\circ} \mathrm{C}$, the screening length is measured to be $9.7 \pm 0.4 \mathrm{~nm}$, corresponding to an effective ion concentration of $0.47 \pm 0.04 \mathrm{mM}$ (calculated from eq 6.2), which is in line with the surface force apparatus (SFA) measurement for EG in literature. ${ }^{25}$ As the temperature increases, the measured screening lengths found to have smaller values, meaning that an effective ion concentration in the solvent increases in its values (see Table 6.1). An increase in ion concentration at higher temperature can be explained by a thermally driven mechanism. This observation in EG could be related to the thermal oxidative reactions of EG, which produce organic acids. The effect is more pronounced at the temperature above $100{ }^{\circ} \mathrm{C}$ as studied in the literature. ${ }^{26}$ Note: The dielectric constant of EG also changes with temperature and this effect is taken into account in the concentration calculation (Figure A6.2). ${ }^{27-29}$ This measurement in pure EG provides information of the background effective ions in the solvent, which 


\begin{tabular}{|c|c|c|c|}
\hline$T\left({ }^{\circ} \mathrm{C}\right)$ & $\lambda_{\mathrm{D}}^{*}(\mathrm{~nm})$ & $c_{\mathrm{EG}}^{*}(\mathrm{mM})$ & $|\psi|(\mathrm{mV})$ \\
\hline 25 & $9.7 \pm 0.4$ & $0.47 \pm 0.04$ & $34 \pm 6$ \\
50 & $7.9 \pm 0.8$ & $0.7 \pm 0.1$ & $31 \pm 5$ \\
75 & $6.5 \pm 0.4$ & $0.9 \pm 0.1$ & $32 \pm 8$ \\
\hline
\end{tabular}

Table 6.1: List of measured screening lengths, corresponding effective ion concentrations, and effective surface potential, of the solvent EG on silicon dioxide.

will be subtracted from the measurements in IL mixtures in the following analysis.

Addition of ILs to EG causes a decrease in the screening lengths as can be seen from Figure 6.1b, as expected from eq 6.2, and the same behavior is observed at all studied temperatures. Eq 6.2 directly gives the total ion concentrations (IL ions plus background ions from EG), represented by $c^{*}$. In order to determine the contribution to the screening length only from IL ions, the effective ion concentrations of pure $\mathrm{EG}\left(c_{\mathrm{EG}}^{*}\right)$ were subtracted from the total effective ion concentrations $\left(c^{*}\right)$, yielding IL free ion concentrations $\left(c_{\mathrm{IL}}^{*}\right)$, which are listed in Table 6.2. These effective ion concentrations of IL can be considered as the concentration of ions in dissociated state or 'free' ions, where the free ion fraction can be written as $X_{\mathrm{d}}=c_{\mathrm{IL}}^{*} / c_{\mathrm{prep}}$. The free ion fractions can be plotted as a function of IL concentration in Figure 6.2. From our measurement, they are found to have a value of 0.6 in most cases. Consequently, we may calculate the activation energy, $E_{\mathrm{a}}$, of the $[\mathrm{Emim}]^{+}\left[\mathrm{BF}_{4}\right]^{-}$in EG following the relation

$$
X_{\mathrm{d}}=\exp \left(-\frac{E_{\mathrm{a}}}{k_{\mathrm{B}} T}\right)
$$

The values in Table 6.2 reveal that for $X_{\mathrm{d}} \sim 0.6$, the activation energy is calculated to be $E_{\mathrm{a}} \sim 0.5 k_{\mathrm{B}} T$. This activation energy is specific for this IL/solvent combination and we expect the value will change if either of them is replaced by another IL or solvent.

The free ion fraction clearly has a constant value over the studied temperature range in most cases. This can be explained as caused by the effect 


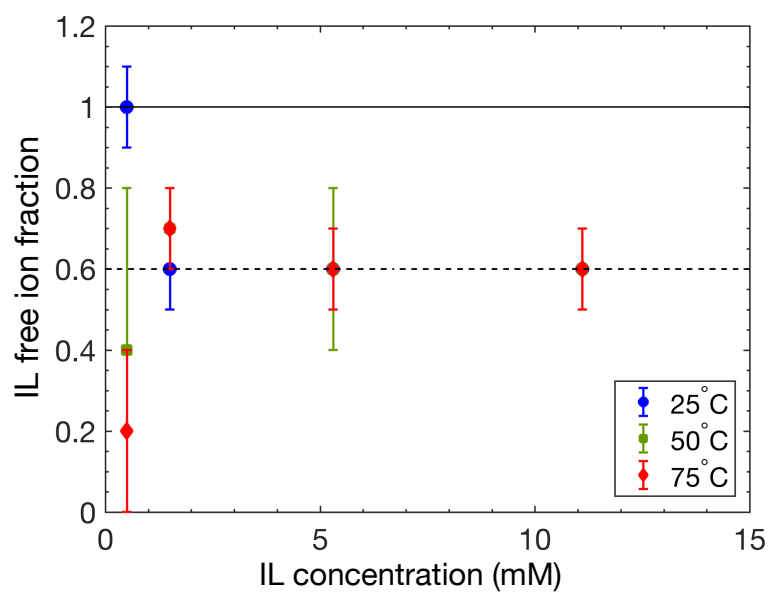

Figure 6.2: The faction of free ions derived from the measured screening lengths at different temperatures and prepared IL concentration.

of temperature on the dielectric constant of EG. It was found in literature that the dielectric constant of EG can change from $\sim 40$ at $25^{\circ} \mathrm{C}$ to $\sim 30$ at $75^{\circ} \mathrm{C}$ (Figure A6.2).$^{27-29}$ Changing of the dielectric constant of the solvent should definitely alter the solubility of salts in a given solvent. ${ }^{24}$ It could be that the decreasing of the dielectric constant of EG at higher temperature would decrease the content of dissociated IL ions in the same amount of the increasing effective ion concentration by thermal activation, and the two effects cancel each other. To support this interpretation, we can rewrite eq 6.3 as

$$
X_{\mathrm{d}} \approx \exp \left(-\frac{\Delta E_{\mathrm{d}}}{\epsilon_{\mathrm{r}} k_{\mathrm{B}} T}\right)
$$

where $\Delta E_{\mathrm{d}}$ represents the dissociation energy of an isolated ion pair in vacuum. ${ }^{9,30}$ From eq 6.4, the free ion fraction of a given ion pair depends on the product of dielectric constant and temperature, $\epsilon_{\mathrm{r}} T$, which in our case differs by only $7 \%$ between $25^{\circ} \mathrm{C}$ and $75^{\circ} \mathrm{C}$.

We are also able to extract the surface potential from the force profiles. The plot of surface potential as a function of IL concentration is shown in Figure 6.3. The surface potential in pure EG shows constant values within the error bars, indicating that the acid products from thermal oxidation of 


\begin{tabular}{|c|c|c|c|c|c|c|c|}
\hline $\begin{array}{c}T \\
\left({ }^{\circ} \mathrm{C}\right)\end{array}$ & $\begin{array}{c}c_{\text {prep }} \\
(\mathrm{mM})\end{array}$ & $\begin{array}{c}\lambda_{\mathrm{D}}^{*} \\
(\mathrm{~nm})\end{array}$ & $\begin{array}{c}c^{*} \\
(\mathrm{mM})\end{array}$ & $\begin{array}{c}c_{\mathrm{IL}}^{*} \\
(\mathrm{mM})\end{array}$ & $X_{\mathrm{d}}$ & $\begin{array}{c}E_{\mathrm{a}} \\
\left(k_{\mathrm{B}} T\right)\end{array}$ & $\begin{array}{c}|\psi| \\
(\mathrm{mV})\end{array}$ \\
\hline \multirow{4}{*}{25} & 0.5 & $6.8 \pm 0.2$ & $0.96 \pm 0.06$ & $0.49 \pm 0.07$ & $1.0 \pm 0.1$ & 0 & $28 \pm 4$ \\
\hline & 1.5 & $5.6 \pm 0.3$ & $1.4 \pm 0.2$ & $0.9 \pm 0.2$ & $0.6 \pm 0.1$ & $0.5 \pm 0.2$ & $19 \pm 6$ \\
\hline & 5.3 & $3.6 \pm 0.2$ & $3.4 \pm 0.4$ & $2.9 \pm 0.4$ & $0.6 \pm 0.1$ & $0.5 \pm 0.2$ & $16 \pm 3$ \\
\hline & 11.1 & $2.4 \pm 0.3$ & $7 \pm 2$ & $7 \pm 2$ & $0.6 \pm 0.1$ & $0.5 \pm 0.2$ & $11 \pm 1$ \\
\hline \multirow{4}{*}{50} & 0.5 & $6.7 \pm 0.6$ & $0.9 \pm 0.2$ & $0.2 \pm 0.2$ & $0.4 \pm 0.4$ & $1 \pm 1$ & $42 \pm 6$ \\
\hline & 1.5 & $4.9 \pm 0.2$ & $1.8 \pm 0.1$ & $1.1 \pm 0.2$ & $0.7 \pm 0.1$ & $0.4 \pm 0.1$ & $23 \pm 7$ \\
\hline & 5.3 & $3.4 \pm 0.4$ & $3.7 \pm 0.9$ & $3.0 \pm 0.9$ & $0.6 \pm 0.2$ & $0.5 \pm 0.3$ & $14 \pm 2$ \\
\hline & 11.1 & $2.3 \pm 0.3$ & $8 \pm 2$ & $7 \pm 2$ & $0.6 \pm 0.1$ & $0.5 \pm 0.3$ & $10 \pm 3$ \\
\hline \multirow{4}{*}{75} & 0.5 & $6.2 \pm 0.3$ & $1.0 \pm 0.1$ & $0.1 \pm 0.1$ & $0.2 \pm 0.2$ & $2 \pm 1$ & $56 \pm 8$ \\
\hline & 1.5 & $4.5 \pm 0.2$ & $2.0 \pm 0.2$ & $1.0 \pm 0.2$ & $0.7 \pm 0.1$ & $0.4 \pm 0.1$ & $32 \pm 4$ \\
\hline & 5.3 & $3.1 \pm 0.2$ & $4.2 \pm 0.5$ & $3.3 \pm 0.5$ & $0.6 \pm 0.1$ & $0.5 \pm 0.2$ & $14 \pm 2$ \\
\hline & 11.1 & $2.2 \pm 0.3$ & $8 \pm 2$ & $7 \pm 2$ & $0.6 \pm 0.1$ & $0.5 \pm 0.2$ & $11 \pm 3$ \\
\hline
\end{tabular}

Table 6.2: List of measured screening lengths, corresponding effective ion concentrations, free ion fraction, activation energy, and effective surface potential, for $[\text { Emim }]^{+}\left[\mathrm{BF}_{4}\right]^{-} / \mathrm{EG}$ mixtures.

EG do not have a significant effect on the surface charge of silicon dioxide over the studied temperature range. Adding IL to EG tends to reduce the surface potential, which is probably caused by ion absorption on the surfaces. This observation is also detected in aqueous solutions on both mica and silica surfaces. ${ }^{31-34}$ This decreasing of the surface potential may, unfortunately, be the cause of an unmeasurable double layer force at high IL concentration, if it drops below the measurement resolution, and only the structural force can be measured in that regime. Again, the temperature does not seem to have significant impact on the surface potential, especially at high concentration. This finding agrees with the AFM study on the effect of temperature on the near-wall ion layers, which shows that temperature only has a small effect on the near-wall structure of ILs. ${ }^{35}$ 


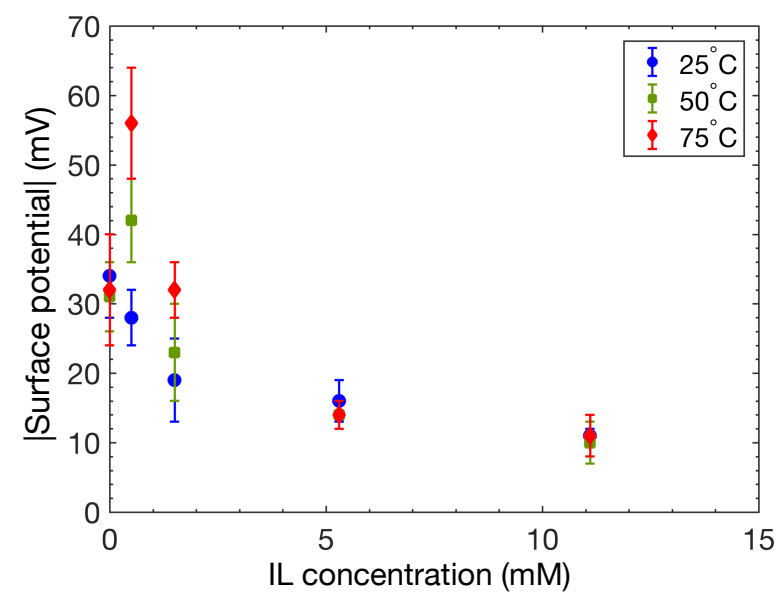

Figure 6.3: The effective surface potential of silicon dioxide in $[\text { Emim }]^{+}\left[\mathrm{BF}_{4}\right]^{-} / \mathrm{EG}$ mixtures at different temperatures and IL concentrations. The values are obtained from the fits of the force-distance profiles. The value for pure EG are shown at zero IL concentration.

\subsection{Conclusions}

The force measured between silicon dioxide surfaces in $[\mathrm{Emim}]^{+}\left[\mathrm{BF}_{4}\right]^{-} / \mathrm{EG}$ shows long-range monotonic behavior in dilute mixtures, as can be expected from the continuum theory. The long-range force vanishes in the mixtures having IL concentration higher than $\sim 10 \mathrm{mM}$, and only the shortrange structural force can be measured. This is likely to be caused by the decreasing of the surface potential at higher IL concentration due to ion adsorption.

In dilute mixtures, the free ion fraction can be extracted from the measured screening length for the IL/solvent combination studied here. It is found to have the value $\sim 0.6$, indicating that more than half of $[\mathrm{Emim}]^{+}\left[\mathrm{BF}_{4}\right]^{-}$are dissociated in EG but full dissociation (as in the case of dilute traditional salts in water) is not achieved. This free ion fraction shows constant values over the studied temperature range, which is attributed to be cause by temperature-dependent dielectric constant of EG. The activation energy was calculated to be about $0.5 k_{\mathrm{B}} T$ in most cases, according to the free ion fractions. 
The effective surface potential of silicon dioxide in pure EG is found to be insensitive to changing of temperature. However, the decreasing of the surface potential is observed when IL is added to EG. This can be explained as caused by IL ion adsorption on the silicon dioxide surface. 


\subsection{Appendix}

\subsubsection{Force-distance curve of $[\mathrm{Emim}]^{+}\left[\mathrm{BF}_{4}\right]^{-}$on silicon dioxide surface}

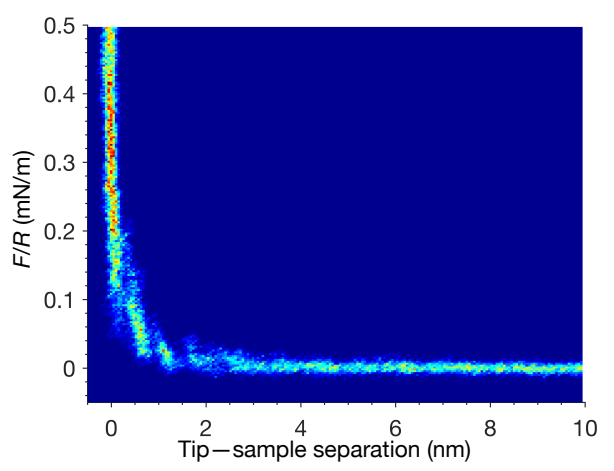

Figure A6.1: Force-distance spectroscopy of pure $[\mathrm{Emim}]^{+}\left[\mathrm{BF}_{4}\right]^{-}$on silicon dioxide substrate measured with silicon dioxide colloidal probe. The data are averaged over 10 measurements, binned over 200 bins on both axes. The color scales corresponds to the probability of finding the data in a given bin, with blue indicating 0 probability and red indicating a probability of 1 .

\subsubsection{Effect of temperature on the dielectric constant of ethylene glycol}

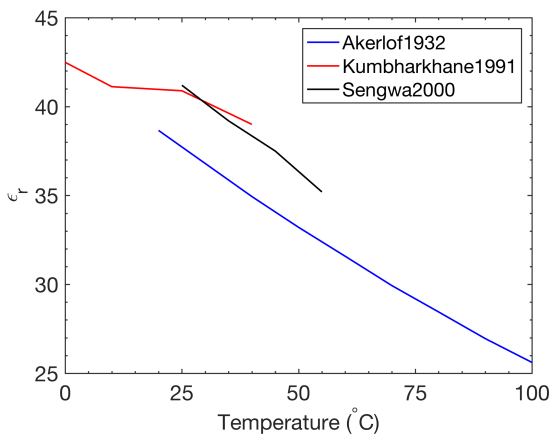

Figure A6.2: Plot of temperature effect on the dielectric constant of EG. The data are replotted from the literature. ${ }^{27-29}$ 


\section{References}

[1] Welton, T. (1999) Room-Temperature Ionic Liquids. Solvents for Synthesis and Catalysis. Chem. Rev., 99(8), 2071-2084.

[2] Ohno, H. (2005) Electrochemical Aspects of Ionic Liquids, John Wiley \& Sons, .

[3] Plechkova, N. V. and Seddon, K. R. (2008) Applications of Ionic Liquids in the Chemical Industry. Chem. Soc. Rev., 37(1), 123-150.

[4] Fedorov, M. V. and Kornyshev, A. A. (2014) Ionic Liquids at Electrified Interfaces. Chem. Rev., 114(5), 2978-3036.

[5] Gebbie, M. A., Valtiner, M., Banquy, X., Fox, E. T., Henderson, W. A., and Israelachvili, J. N. (2013) Ionic Liquids Behave as Dilute Electrolyte Solutions. Proc. Natl. Acad. Sci. U. S. A., 110(24), 9674-9679.

[6] Perkin, S., Salanne, M., Madden, P., and Lynden-Bell, R. (2013) Is a Stern and Diffuse Layer Model Appropriate to Ionic Liquids at Surfaces?. Proc. Natl. Acad. Sci. U. S. A., 110(44), E4121-E4121.

[7] Gebbie, M. A., Valtiner, M., Banquy, X., Henderson, W. A., and Israelachvili, J. N. (2013) Reply to Perkin et al.: Experimental Observations Demonstrate that Ionic Liquids Form Both Bound (Stern) and Diffuse Electric Double Layers. Proc. Natl. Acad. Sci. U. S. A., 110(44), E4122.

[8] Lee, A. A., Vella, D., Perkin, S., and Goriely, A. (2014) Are RoomTemperature Ionic Liquids Dilute Electrolytes?. J. Phys. Chem. Lett., 6(1), 159-163.

[9] Gebbie, M. A., Dobbs, H. A., Valtiner, M., and Israelachvili, J. N. (2015) Long-range Electrostatic Screening in Ionic Liquids. Proc. Natl. Acad. Sci. U. S. A., 112(24), 7432-7437.

[10] Smith, A. M., Lee, A. A., and Perkin, S. (2016) The Electrostatic Screening Length in Concentrated Electrolytes Increases with Concentration. J. Phys. Chem. Lett., 7(12), 2157-2163.

[11] Cheng, H.-W., Stock, P., Moeremans, B., Baimpos, T., Banquy, X., Renner, F. U., and Valtiner, M. (2015) Characterizing the Influence of Water on Charging and Layering at Electrified Ionic-Liquid/Solid Interfaces. Adv. Mater. Interfaces, 2(12).

[12] Espinosa-Marzal, R., Arcifa, A., Rossi, A., and Spencer, N. (2013) Microslips to "Avalanches" in Confined, Molecular Layers of Ionic Liquids. J. Phys. Chem. Lett., 5(1), 179-184.

[13] Hjalmarsson, N., Atkin, R., and Rutland, M. W. (2017) Switchable Longrange Double Layer Force Observed in a Protic Ionic Liquid. Chem. Commun., 53(3), 647-650. 
[14] Gebbie, M. A., Smith, A. M., Dobbs, H. A., Warr, G. G., Banquy, X., Valtiner, M., Rutland, M. W., Israelachvili, J. N., Perkin, S., and Atkin, R. (2017) Long Range Electrostatic Forces in Ionic Liquids. Chem. Comm., 53(7), 1214-1224.

[15] Lee, A. A., Perez-Martinez, C., Smith, A. M., and Perkin, S. (2017) Scaling Analysis of the Screening Length in Concentrated Electrolytes. Phys. Rev. Lett., $\mathbf{1 1 9}(026002)$.

[16] Perez-Martinez, C. S., Smith, A. M., Perkin, S., et al. (2017) Underscreening in Concentrated Electrolytes. Faraday Discuss.,.

[17] Atkin, R. and Warr, G. G. (2007) Structure in Confined Room-Temperature Ionic Liquids. J. Phys. Chem. C, 111(13), 5162-5168.

[18] Atkin, R., El Abedin, S. Z., Hayes, R., Gasparotto, L. H., Borisenko, N., and Endres, F. (2009) AFM and STM Studies on the Surface Interaction of [BMP] TFSA and [EMIm] TFSA Ionic Liquids with Au (111). J. Phys. Chem. C, 113(30), 13266-13272.

[19] Perkin, S., Crowhurst, L., Niedermeyer, H., Welton, T., Smith, A. M., and Gosvami, N. N. (2011) Self-assembly in the Electrical Double Layer of Ionic Liquids. Chem. Commun., 47(23), 6572-6574.

[20] Perkin, S. (2012) Ionic Liquids in Confined Geometries. Phys. Chem. Chem. Phys., 14(15), 5052-5062.

[21] Black, J. M., Walters, D., Labuda, A., Feng, G., Hillesheim, P. C., Dai, S., Cummings, P. T., Kalinin, S. V., Proksch, R., and Balke, N. (2013) Bias-Dependent Molecular-Level Structure of Electrical Double Layer in Ionic Liquid on Graphite. Nano Lett., 13(12), 5954-5960.

[22] Seddon, J. R. (2014) Conservative and Dissipative Interactions of Ionic Liquids in Nanoconfinement. J. Phys. Chem. C, 118(38), 22197-22201.

[23] Jitvisate, M. and Seddon, J. R. (2016) Local Structure and Flow Properties of Ionic Liquids on Charged and Inert Substrates. J. Phys. Chem. C, 120(9), 4860-4865.

[24] Israelachvili, J. N. (2011) Intermolecular and Surface Forces, Academic press,

[25] Christenson, H. K. and Horn, R. G. (1985) Forces Between Mica Surfaces in Ethylene Glycol. J. Colloid Interface Sci., 103(1), 50-55.

[26] Clifton, J. R., Rossiter, W. J., and Brown, P. W. (1985) Degraded Aqueous Glycol Solutions: $\mathrm{pH}$ Values and the Effects of Common Ions on Suppressing pH Decreases. Solar Energy Materials, 12(1), 77-86.

[27] Akerlof, G. (1932) Dielectric Constants of Some Organic Solvent-Water Mixtures at Various Temperatures. J. Am. Chem. Soc., 54(11), 4125-4139. 
[28] Kumbharkhane, A., Puranik, S., and Mehrotra, S. (1992) Temperature Dependent Dielectric Relaxation Study of Ethylene Glycol-Water Mixtures. J. Solution Chem., 21(2), 201-212.

[29] Sengwa, R. J., Kaur, K., and Chaudhary, R. (2000) Dielectric Properties of Low Molecular Weight Poly(ethylene glycol)s. Polym. Int., 49(6), 599-608.

[30] Kirchner, B., Malberg, F., Firaha, D. S., and Hollóczki, O. (2015) Ion Pairing in Ionic Liquids. J. Phys.: Condens. Matter, 27(46), 463002.

[31] Ducker, W. A., Senden, T. J., and Pashley, R. M. (1991) Direct Measurement of Colloidal Forces Using an Atomic Force Microscope. Nature, 353(6341), 239-241.

[32] Ducker, W. A., Senden, T. J., and Pashley, R. M. (1992) Measurement of Forces in Liquids Using a Force Microscope. Langmuir, 8(7), 1831-1836.

[33] Goloub, T. P., Koopal, L. K., Bijsterbosch, B. H., and Sidorova, M. P. (1996) Adsorption of Cationic Surfactants on Silica. Surface Charge Effects. Langmuir, 12(13), 3188-3194.

[34] Pashley, R. (1981) DLVO and Hydration Forces Between Mica Surfaces in $\mathrm{Li}+, \mathrm{Na}+, \mathrm{K}+$, and $\mathrm{Cs}+$ Electrolyte Solutions: A Correlation of Double-layer and Hydration Forces with Surface Cation Exchange Properties. J. Colloid Interface Sci., 83(2), 531-546.

[35] Wakeham, D., Hayes, R., Warr, G. G., and Atkin, R. (2009) Influence of Temperature and Molecular Structure on Ionic Liquid Solvation Layers. $J$. Phys. Chem. B, 113(17), 5961-5966. 




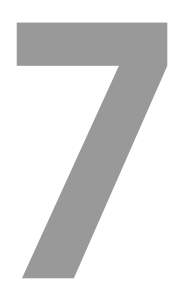

\section{Conclusions and Future Work}

\subsection{Conclusions}

This thesis presents the results obtained during the research project aiming to understand the nature of ionic liquids at interfaces. This can have significant impact on the improvement of many applications such as energy storage devices, micro/nano device lubrication, electrodeposition, nanoparticle synthesis, etc. Ionic liquids usually have huge molecular dimensions and non-symmetric molecular shapes, which make them distinct from traditional salts. An important property is that ionic liquids can exist in liquid state at room temperature, without being dissolved in any solvents. In such a dense ionic system, the underlying physics is governed by complex strong electrostatic interaction between ions.

Interfacial properties are even more complex as the influences from the wall, for example, the surface charge, and the confined geometry, can strongly affect the ions. The interfacial behavior is usually described within the framework of an electrical double layer theory. However, classical theories failed to describe the behaviors of ionic liquids. Theoretical models for ionic liquids at interfaces were developed based on the mean-field theory but only be able to explain existing experimental data qualitatively. Therefore, more studies in all aspects are needed to advance our understanding on this class of material.

To study the interfacial properties of the ionic liquids, we carried out experiments using the techniques that are able to probe the liquids' responses 
at surfaces. An electrochemical technique was applied for measuring the double layer capacitance, where the response of the ionic liquids to an applied electric field was measured. The differential capacitance is a measurable quantity that is used for studying electrical responses of the ionic liquids. In chapter 3, we used the chronoamperometry technique to show that the double layer capacitance of the ionic liquids is different from traditional salts, and can be explained quantitatively by the most recent version of the mean-field model. This measurement also provides comparison between the measurement techniques (cyclic voltammetry and electrochemical impedance spectroscopy) used in the past, where the obtained results from these techniques are often inconsistent and irreproducible.

In order to look into the molecular scale interfacial behavior, we used force-distance spectroscopy technique to directly measure the near-wall structure of both pure and dilute ionic liquids. In this technique, the ionic liquid was confined between the AFM tip and the substrate. The tip was pushed toward the substrate and the force acting on the tip was measured as as function of tip-substrate separation. The measurement done in chapter 4 revealed a semi-crystalline structure of ionic liquids on flat surfaces, which was observed as discrete layers on the wall. The number of layers and their molecular orientations were found to depend on the substrate material as shown by the measurement on mica (charged surface) and bare HOPG (neutral surface). Imposing a small amplitude oscillation on the AFM cantilever allows us to decouple the interaction stiffness and local viscosity of the liquid's layers. We found a decrease in the local viscosity as the AFM tip moved toward the HOPG surface, while it increased in the case of mica. The cause of this observation was attributed to the molecular orientation of the ionic liquids.

Dilute ionic liquids are also very important because most pure ionic liquids have a high viscosity, which is undesirable in many applications. Diluting ionic liquids with molecular solvents can change their viscosity and conductivity. By using force-distance spectroscopy, we observed the structural crossover from pure ionic liquid to pure solvent in chapter 5. This effect is known for binary mixture colloidal systems, where two different sizes 
of colloidal particles are mixed. These changes in the interfacial structure by dilution may have an implication on tuning the friction between surfaces. In addition, we found that the structure of the ionic liquid layers was strengthened by mixing the ionic liquids with dimethyl sulfoxide with the mole fraction of dimethyl sulfoxide of 0.1. It was explained that dimethyl sulfoxide molecules, which are much smaller than ionic liquid molecules, fill in the voids of the near-wall structure, improving its strength. Computational studies will be complementary to support this explanation.

Not only are the discrete layers observed at the ionic liquid/solid interface, but also the recently reported long-range monotonic interaction. This observation has led to an intense debate about the true nature of ionic liquids, whether they are fully dissociated or mostly composed of neutral ion pairs. In chapter 6 , we used colloidal probe microscopy to measure the long-range force in ionic liquids mixed with ethylene glycol at different temperatures. From the measured screening length, the ion contents can be determined. We found that the free ion fraction of the ionic liquid in ethylene glycol is approximately 0.6 , meaning that more than half of the ionic liquid molecules are in free ion state. This value does not change over the studied range of temperature and we described it to be affected by the change of the dielectric constant of ethylene glycol, which will alter the solubility of the ions. We also observed the change of the effective surface potential of silicon dioxide due to the adsorption of the ionic liquids.

\subsection{Future work}

The near-wall structure of ionic liquids has been studied intensively in various aspects using different experimental techniques, and the discrete-layer behavior is well accepted. However, what remains interesting is the specific ion content in each layer, where only the average content per layer has so far been measured. There are only a few published papers about ion imaging using AFM, which needs further confirmation for better understanding of, for example, the local packing of the ions. This includes distinguishment between cations, anions, and neutral pairs in each layers. 
Another important question is about the free ion content in the bulk ionic liquids, which is currently a debated topic in the field. The number of charge carriers is still not truly known and more experimental data from different techniques are needed to strengthen the current understanding. There was a suggestion to measure the charge carrier density of ionic liquids using the Hall effect technique, as is normally used in solids. This is a practical challenge for ionic liquids because their viscosity is high, and so their ion mobility is low. However, if this can be done successfully, it will result in a much more clearer interpretation on the ion interactions and their ionic properties. 




\section{Summary}

Ionic liquids are organic salts that are in liquid phase at room temperature. Their wide liquidus range, particularly at room temperature, results from the liquids' large and asymmetric molecular geometry. This leads to a collection of unique properties, such as, high ionic strength, extremely low vapor pressure, wide electrochemical window, and high thermal and chemical stabilities. These properties make ionic liquids a promising material in many applications, for example, electrochemical energy storage devices, electrically tunable lubrication, high-temperature/vacuum material synthesis, and novel self assembly media. However, ionic liquids do not seem to obey the well established classical electrical double layer models for electrolytes, leading to the necessity of both theoretical and experimental studies.

This thesis is devoted to experimental investigations of the interfacial behavior of ionic liquids, in both pure and dilute forms at various physical and electrical conditions, aiming to reveal their true interfacial nature. Atomic force microscopy (AFM) is used to directly probe the double layer force while electrochemical techniques can be used to measure the response to electric field of the liquids in terms of a double layer capacitance. The observations from these two experimental techniques will lead to a molecular scale picture of the double layer and its charging mechanism, respectively.

As a result, we observed discrete near-wall structure of the ionic liquids formed on flat solid substrates, and their properties vary with the influences of, for example, surface materials and concentration of the liquids. In addition to this near-wall measurement, the long-range electrostatic force is also measurable in dilute ionic liquids by using colloidal probe microscopy, where partial ion dissociation can be inferred from the measured screening length. Double layer capacitance is measured using electrochemical tech- 
niques, showing capacitance curves that well fit with a recently proposed theoretical model for ionic liquids, leading to an understanding of the charging process of the ions. The results explained in this thesis are relevant for many applications ranging from tunable lubrication and electrochemical energy storage devices. 




\section{Samenvatting}

Ionische vloeistoffen zijn zouten die vloeibaar zijn bij omgevingstemperatuur. Het grote bereik waarbij ze vloeibaar zijn, in het bijzonder bij kamertemperatuur, vindt zijn oorsprong in de grote en asymmetrie van de moleculaire structuur. Dit leidt tot een aantal bijzondere eigenschappen zoals hoge ionische sterkte, extreem lage dampdruk, een breed elektrochemisch venster en hoge chemische en thermische stabiliteit. Door deze eigenschappen zijn ionische vloeistoffen een veelbelovend materiaal voor vele toepassingen. Bijvoorbeeld in elektrochemische devices voor energy opslag, elektrisch afstembaar smeren, materiaalsynthese bij hoge temperaturen/vacuüm en unieke self assembly media. Echter, ionische vloeistoffen lijken zich niet aan de aanvaarde modellen te houden voor elektrochemische dubbellagen in elektrolyten. Theoretische en experimentele studies zijn nodig.

Dit proefschrift richt zich op experimenteel onderzoek naar het gedrag van ionische vloeistoffen in het grensvlak tussen vaste stof en vloeistof, in geconcentreerde en verdunde toestand voor verschillende fysische en elektrische condities, met als doel het grensvlak gedrag te onthullen. Atomic force microscopie (AFM) is gebruikt voor het testen van de elektrostatische dubbele laag kracht, terwijl elektrochemische technieken gebruikt worden voor het meten van de elektrische response van de vloeistof op het elektrische veld, uitgedrukt in de dubbellaag capaciteit. Beide experimentele technieken zullen inzicht geven in de moleculaire structuur en het laad mechanisme van de dubbellaag.

Als resultaat van de experimenten nemen we discrete structuren waar in de ionische vloeistoffen die zich gevormd hebben op het oppervlak van

${ }^{*}$ The english-to-dutch translation is provided by Ab Nieuwenhuis. I thank him for his kind help in translating the summary into Dutch. 
de vlakke vaste stof substraten. De eigenschappen van deze structuren worden bijv. beïnvloed door het materiaal van het oppervlak en de concentratie van de vloeistoffen. Naast experimenten op zeer korte afstand van de vaste stof-vloeistof interface kunnen in verdunde ionische vloeistoffen ook elektrostatische krachten op aanzienlijk grotere afstand van de interface gemeten worden met gebruik making van colloidal probe microscopy. Met deze techniek kan d.m.v. de gemeten dubbellaag lengte gedeeltelijk dissociatie van de ionen vastgesteld worden. De met elektrochemisch techniek gemeten dubbellaag capaciteit laat curves zien die zeer goed overeenkomen met recent voorgestelde modellen voor ionische vloeistoffen, wat leidt tot een beter begrip van het laadproces voor deze ionen. De resultaten besproken in dit proefschrift zijn relevant voor diverse toepassingen variërend van afstembare smering tot elektrochemische devices voor energieopslag. 




\section{Acknowledgements}

I would like to express my deep gratitude to Prof. Serge Lemay and Dr. James Seddon, my supervisors, for their guidance, advice, inspiration, and tremendous encouragement during my $\mathrm{PhD}$. Over the past four years, they have trained me effortlessly to develop myself, in many of ways, in order to carry out good scientific research. This will surely influence me in the future regardless of my future career. They showed me their knowledge and enthusiasm in science that motivated me to learn and solve scientific problems. Thank you for all your support that pushed me across many difficulties and barriers. As a Thai scholarship student, I also have to thank you on behalf of all Thais. You are not only my PhD supervisors, but also part of the developments of science and technology of Thailand. I particularly thank James, who worked closely with me as my daily supervisor, for walking me through the research path step-by-step. Thank you for giving me this valuable opportunity to be your student and being patient with me. I am truly proud of this and I would not come this far without you.

It was a fortunate period of life to have worked in a group of nice colleagues. I would like to thank Ingrid for her support related to all the official affairs and documentations. Ab, thank you very much for your lab management. I hope you have a great time finishing your PhD. I would really like to congratulate you when the day comes. I would also like to express my thanks to all of the NI members and alumni: Zinaida, Jin, Minmin, Judith, Stanley, Jos, Chris, Shuo, Cecilia, Sahana, Cyril, Elodie, for making this group a wonderful and unforgettable working place. On a personal note, deep thanks to Minmin for always being a wonderful officemate and friend. I hope we can still contact each other afterwards and do not wait too long for traveling to Thailand.

My gratefulness must also go to generous colleagues in PCF: Frieder, 
Igor, Aram, and Simone, for letting me share their AFM time during my last projects. I also appreciated the discussions with them regarding both research and generic topics.

Teaching was also a big part of my learning experiences during this past four years. It was a challenging task to take care of students and guide them toward the goal, wishing them to learn as much as they can. Conversely, I also learned from the students countless things. I have realised that being a good mentor or teacher is not easy. Therefore, I would like to thank all of my students: Lieselotte, Laura, Jelle, Peter, Daniël, Hidde, Sytze, Johan, Bryan, and all SBM class members, for teaching me how to teach.

The financial support from The Development and Promotion of Science and Technology Talents Project (DPST), Royal Thai governments, is gratefully acknowledged. I wrote on the dedication page, For all Thais, as a remembrance that my study has been funded from the taxes of Thai citizens and I am very grateful for them.

I would also like to thanks all Thai students in Enschede for sharing great moments together in Enschede. I always enjoy chatting and eating with all of you. I wish you success with your study and your work in the future too.

I devoted my entire heart for my beloved mom, who always supports and cheers me up for my whole life. Thank you for always being my tower of strength. I realised that my study has taken me far away from you so I hope my PhD could make you proud of me.

Last but certainly not least, I personally thank Meow, for sharing great times with me. I hope that you smoothly finish your $\mathrm{PhD}$ soon and, once settled in Thailand, I know you will be very happy with everything on the motherland.

Enschede, The Netherlands

January 2018 